\title{
Basin-wide variations in foliar properties of Amazonian forest: phylogeny, soils and climate
}

\author{
N. M. Fyllas ${ }^{1}$, S. Patiño ${ }^{2,3}$, T. R. Baker ${ }^{1}$, G. Bielefeld Nardoto ${ }^{4}$, L. A. Martinelli ${ }^{4}$, C. A. Quesada ${ }^{1,5,10}$, R. Paiva ${ }^{5,6}$, \\ M. Schwarz ${ }^{7}$, V. Horna ${ }^{8}$, L. M. Mercado ${ }^{9}$, A. Santos ${ }^{5,10, \dagger}$, L. Arroyo ${ }^{11}$, E. M. Jiménez ${ }^{12}$, F. J. Luizão ${ }^{5}$, D. A. Neill ${ }^{13}$,

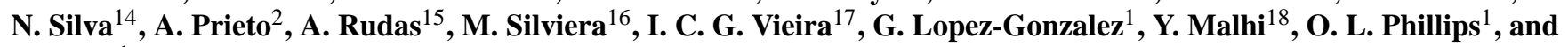 \\ J. Lloyd ${ }^{1}$ \\ ${ }^{1}$ Earth and Biosphere Institute, School of Geography, University of Leeds, LS2 9JT, UK \\ ${ }^{2}$ Instituto de Investigación de Recursos Biológicos, Alexander von Humboldt, Bogotá, Colombia \\ ${ }^{3}$ UMR-ECOFOG, INRA, 97310, Korou, French Guiana \\ ${ }^{4}$ CENA-USP, Av Centenário 303, 13416-000 Piracicaba, SP, Brazil \\ ${ }^{5}$ Instituto National de Pesquisas Amazônicas, Manaus, Brazil \\ ${ }^{6}$ Secretária Municipal de Desenvolvimento e Meio Ammbiente ma Prefeturia Municipal de Maués, Maués, Brazil \\ ${ }^{7}$ Max-Planck-Institut fuer Biogeochemie, Jena, Germany \\ ${ }^{8}$ Abteilung Ökologie und Ökosystemforschung, Albrecht-von-Haller-Institut für Pflanzenwissenschaften, Universität \\ Göttingen, Göttingen, Germany \\ ${ }^{9}$ Centre for Ecology and Hydrology, Wallingford, UK \\ ${ }^{10}$ Departamento de Ecologia, Universidade de Brasília, Brazil \\ ${ }^{11}$ Museo Noel Kempff Mercado, Santa Cruz, Bolivia \\ ${ }^{12}$ Universidad Nacional de Colombia, Leticia, Colombia \\ ${ }^{13}$ Herbario Nacional del Ecuador, Quito, Ecuador \\ ${ }^{14}$ Empera Brasileira de Pesquisas Agropecuária, Belem, Brazil \\ ${ }^{15}$ Instituto de Ciencias Naturales, Universidad Nacional de Colombia, Bogotá, Colombia \\ ${ }^{16}$ Depto de Ciências da Natureza, Universidade Federal do Acre, Rio Branco, Brazil \\ ${ }^{17}$ Museu Paraense Emilio Goeldi Caixa Postal 399 Belém, Pará 66040-170, Brazil \\ ${ }^{18}$ University of Oxford, Oxford, UK \\ ${ }^{\dagger}$ Alexandre Santos died in the Amazon plane crash of 29 September 2006.
}

Received: 16 December 2008 - Published in Biogeosciences Discuss.: 6 April 2009

Revised: 14 October 2009 - Accepted: 5 November 2009 - Published: 27 November 2009

\begin{abstract}
We analysed 1040 individual trees, located in 62 plots across the Amazon Basin for leaf mass per unit area $\left(M_{A}\right)$, foliar carbon isotopic composition $\left(\delta^{13} \mathrm{C}\right)$ and leaf level concentrations of $\mathrm{C}, \mathrm{N}, \mathrm{P}, \mathrm{Ca}, \mathrm{Mg}, \mathrm{K}$ and $\mathrm{Al}$. All trees were identified to the species level with the dataset containing 58 families, 236 genera and 508 species, distributed across a wide range of soil types and precipitation regimes. Some foliar characteristics such as $M_{A},[\mathrm{C}],[\mathrm{N}]$ and $[\mathrm{Mg}]$ emerge as highly constrained by the taxonomic affiliation of tree species, but with others such as $[\mathrm{P}],[\mathrm{K}],[\mathrm{Ca}]$ and $\delta^{13} \mathrm{C}$ also strongly influenced by site growing conditions. By removing the environmental contribution to trait varia-
\end{abstract}

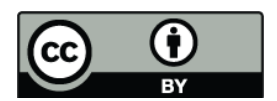

Correspondence to: N. M. Fyllas (n.fyllas@leeds.ac.uk) tion, we find that intrinsic values of most trait pairs coordinate, although different species (characterised by different trait suites) are found at discrete locations along a common axis of coordination. Species that tend to occupy higher fertility soils are characterised by a lower $M_{A}$ and have a higher intrinsic $[\mathrm{N}],[\mathrm{P}],[\mathrm{K}],[\mathrm{Mg}]$ and $\delta^{13} \mathrm{C}$ than their lower fertility counterparts. Despite this consistency, different scaling patterns were observed between low and high fertility sites. Inter-relationships are thus substantially modified by growth environment. Analysing the environmental component of trait variation, we found soil fertility to be the most important predictor, influencing all leaf nutrient concentrations and $\delta^{13} \mathrm{C}$ and reducing $M_{A}$. Mean annual temperature was negatively associated with leaf level $[\mathrm{N}],[\mathrm{P}]$ and $[\mathrm{K}]$ concentrations. Total annual precipitation positively influences $M_{A}$,

Published by Copernicus Publications on behalf of the European Geosciences Union. 
[C] and $\delta^{13} \mathrm{C}$, but with a negative impact on [Mg]. These results provide a first basis for understanding the relationship between the physiological functioning and distribution of tree species across Amazonia.

\section{Introduction}

Plants are the central link in the soil-plant-atmosphere continuum, utilising and cycling a range of atmospherically $(\mathrm{C}$, $\mathrm{H}, \mathrm{O}$, and $\mathrm{N}$ ) or geologically $(\mathrm{P}, \mathrm{Ca}, \mathrm{K})$ derived elements (Jobbagy and Jackson, 2004). Plant growth is usually considered to be either nitrogen- or phosphorus-limited (Aerts and Chapin, 2000), but with less abundant nutrients also being important for discrete ecosystem processes (Hungate et al., 2004; Kaspari et al., 2008). Foliar ratios of leaf level nitrogen, phosphorus, calcium, and potassium concentrations can indicate the nature of nutrient limitation (Koerselman and Meuleman, 1996; Jobbagy and Jackson, 2004). It has been argued, for example, that leaf $\mathrm{N}: \mathrm{P}>12.5$ indicate a limitation on ecosystem processes by $\mathrm{P}$ availability (Tessier and Raynal, 2003). But different hypotheses have been proposed regarding the factors controlling the metabolic tissue concentration of the main nutrients related to plant growth (Reich and Oleksyn, 2004), especially N and P (Niklas, 2006). These hypotheses summarize a physiological, temperature or geochemical driven background of $\mathrm{N}$ and $\mathrm{P}$ cycling and have gained particular interest recently, as foliar C:N:P stoichiometry may be an important factor controlling the growth rate of a wide range of plants (Elser et al., 2000; Kerkhoff et al., 2005; Niklas, 2006). Following on from the now widely accepted suggestion of Vitousek (1984) that tropical forests may generally be $\mathrm{P}$ rather than $\mathrm{N}$ limited, Reich and Oleksyn (2004) showed that tropical trees typically have higher N:P ratios than are observed at higher latitudes. Nevertheless, Townsend et al. (2007) also showed that for trees growing on the more fertile tropical soils, foliar $\mathrm{N}: \mathrm{P}$ ratios are generally similar to those observed in the temperate and boreal zones. Examining a range of potential edaphic and environmental predictors, Quesada et al. (2009a) found total soil phosphorus to be the best predictor of above ground woody biomass growth rates for a wide range of Amazon forest types growing on a wide range of different soil types.

The Amazon Basin is highly diverse in terms of climate (Sombroek, 2001; Malhi and Wright, 2004), soil physical and chemical properties (Sombroek, 2000; Quesada et al., 2009b), and species composition (ter Steege et al., 2006). Such complexity hinders any attempt to accurately estimate significant biogeochemical fluxes (Townsend et al., 2008) or to predict the Amazon carbon balance (Cox et al., 2000). It is also now clear that a large scale gradient in Amazon forest tree dynamics exists, with forests growing on the generally more fertile soils of the western Amazon having lower wood densities (Baker et al., 2004), higher above-ground growth rates (Malhi et al., 2004) and with higher rates of tree turnover (Phillips et al., 2004). But how do key foliar properties vary across evolutionary grouping of trees and relate to these different environmental gradients? This is an important question; both to help us understand the ecology and dynamics of Amazonian rain forests and also to rationally parameterise the next generation of coupled vegetation - climate models.

Recent developments in plant functional ecology have highlighted suites of plant traits such as per area leaf mass $\left(M_{A}\right)$ and leaf nutrient concentrations, that can serve as predictors of individual plant growth and performance (Reich et al., 1991; Garnier et al., 2004; Poorter and Bongers, 2006). Although considerable variability in these characters has been reported, a global spectrum of coordination has also been proposed (Reich et al., 1997; Wright et al., 2004). One of the major axes of ecological variation is thought to be captured by both leaf longevity and $M_{A}$ (or its inverse specific leaf area, SLA), with these two traits well correlated at both a global and a tropical scale (Reich et al., 1991, 1997). Species with low $M_{A}$ tend to have short-lived leaves with high $[\mathrm{N}]$ and $[\mathrm{P}]$ (dry weight basis) and are usually found at the fast payback end of the "economic spectrum" (Wright et al., 2004). This combination of traits is usually found at species with fast growth rates (Poorter and Bongers, 2006). At the other end of the continuum, species characterised by high $M_{A}$, also generally have low leaf [N] and [P] and lower growth rates, thus being considered to represent a more conservative strategy of resource use and turnover (Reich et al., 2003). Wright et al. (2005b) examined the role of potassium within the "leaf economic spectrum", concluding that although associated with $M_{A}, \mathrm{~N}$ and $\mathrm{P},[\mathrm{K}]$ might be more closely associated with other cations such as calcium and magnesium.

All major cations are considered in this study, including [Al], along with an additional major potential component of the leaf physiological spectrum, viz the extent of discrimination against the heavier ${ }^{13} \mathrm{C}$ isotope during photosynthetic $\mathrm{CO}_{2}$ assimilation, $\Delta$. This is indicated by a leaf's carbon isotopic composition, $\delta^{13} \mathrm{C}$, and can provide a measure of a plant's water use efficiency, WUE (Farquhar et al., 1989). It has, for example, been proposed that leaves with a high $M_{A}$ should also have a lower WUE (Lamont et al., 2002).

Here, as well as considering $\delta^{13} \mathrm{C}$ we also examine the integration into the plant physiological spectrum of leaf carbon content. Although often considered to be relatively invariant, differences in $M_{A}$ should nevertheless be accompanied by differences in leaf carbon composition. For example, the greater proportion of dry matter invested in cell walls as expected in high $M_{A}$ plants should also be associated with increased levels of carbon rich structural carbohydrate compounds such as lignin and cellulose (Niinemets, 1997). Although not reporting on the relationships between individual compounds or elements and $M_{A}$, when investigating leaf chemical variations for 45 different French Guiana rain forest 
species, Hättenschwiler et al. (2008) reported considerable variation in foliar carbon contents (from 0.45 to 0.52 of leaf dry weight) with large inter-specific variations in different carbon constituent compounds also noted.

Along with the coordination of leaf functional characters, environmental factors, such as climate and/or soil may affect physiological linkages. Modifications of pair-wise relations (Wright et al., 2001) or systematic trends of a functional trait across environmental gradients should indicate trait plasticity and/or adaptive potential (Sultan, 2000). These may have important consequences for individual and community level processes. Evaluating this plasticity is thus a key issue in developing theoretical and computational schemes of the potential vegetation response to changing environmental conditions.

At a global level, Wright et al. (2005a) have shown how some photosynthetic tissue properties and their relationships also vary across climate, but for the selected traits $\left(M_{A}\right.$, leaf longevity, foliar $[\mathrm{N}]$ and photosynthetic capacity) climate accounted for only 0.18 of the total variation. Nevertheless, such shifts were considered to be of significant importance for the global leaf economic spectrum. At regional scales and along rainfall and soil phosphorus gradients, significant strategic shifts in leaf properties and functioning have also been identified, with species found at drier sites exhibiting a lower photosynthetic capacity for a given foliar $[\mathrm{N}]$ and $[\mathrm{P}]$ and higher $[\mathrm{N}]$ and $[\mathrm{P}]$ concentrations at a given $M_{A}$ (Fonseca et al., 2000; Wright et al., 2001). Niinemets and Kull (2003) suggested that the strength of the correlation between foliar nutrient concentrations and $M_{A}$ were controlled by soil nutrient availability, with the strongest associations between $M_{A}$ and the most limiting nutrient. Similar results were reported for Amazonian species, but with weak $M_{A}$-[N] relationships in what were considered to be $\mathrm{P}$ limited stands (Reich and Walters, 1994). At a pan-tropical scale Townsend et al. (2007) found that leaf N:P ratios vary with soil order, and suggested that species diversity may be an important factor controlling this ratio.

Different tropical tree species may have markedly different foliar nutrient concentrations (Drechsel and Zech, 1991; Townsend et al., 2007) and, at least at the landscape level, different species tend to be associated with soils of different fertility (Phillips et al., 2003; John et al., 2007). Given that even for the same species, natural variations in soil fertility may also serve to modify foliar seedling nutrient concentrations along with other leaf physiological characteristics such as $M_{A}$ (Veenendaal et al., 1996; Kanowski, 2001), we were also interested to ascertain whether differences in foliar nutrient concentrations sampled across Amazonia represented directly different levels of soil fertility and/or intrinsic differences in physiological leaf traits of the different species growing in different plots. Likewise, although there may be large scale changes in physiological traits with rainfall or temperature when a range of species are considered (Santiago et al., 2004a; Wright et al., 2005a) it is important to know if changes in traits observed at the community level arise solely as a consequence of changes in species composition or whether factors such as dry-season length directly influence physiological properties and their inter-relationships.

This plasticity of traits and the potential for tree species population to exhibit different trait combinations according to changing soil and climate conditions may be very important for understanding Amazon forest species distributions. So here we analyse nine key leaf traits of 1040 individuals positioned in sixty-two plots distributed across the Amazon Basin. The traits reported are $M_{A}, \delta^{13} \mathrm{C}$, and leaf level concentrations of $\mathrm{C}, \mathrm{N}, \mathrm{P}, \mathrm{Ca}, \mathrm{Mg}, \mathrm{K}$ and $\mathrm{Al}$ with 508 species sampled across a wide range of Amazon soil types and precipitation regimes. An accompanying paper will investigate structural traits such as maximum tree height, individual leaf area, ratio of supported leaf area to xylem cross sectional area, branch xylem density and seed size, also integrating the dataset presented here with those components, and across the edaphic and precipitation regimes observed (Patiño et al., 2009).

The aims of this paper are first to partition variation in foliar properties into genetic and environmental components. Second to identify the extent to which traits are conservative across evolutionary grouping of tree species, and how these traits differ across taxonomic affinities. Third to explore if there are differences in the trait combinations found under different environmental conditions. Ultimately, we attempt to link environmental components of trait variation with key soil and climate variables. We specifically hypothesised that:

1. Although genetically determined, many of the traits of interest would be modified by the growth environment - as has been demonstrated recently, for example, by Poorter et al. (2009) for $M_{A}$.

2. That species which occur in the faster growing stands on the more fertile soils of the Amazon Basin (Quesada et al., 2009a) would be characterised by leaf traits associated with a faster growth potential - for example a lower $M_{A}$ and intrinsically higher [N] and [P] than species occurring on the less fertile substrates. Although it has long been assumed that this should be the case for plants in general (Lambers and Poorter, 1992), we know of few demonstrations that this is actually the case and none at a spatial scale similar to that of the Amazon Basin.

3. That the strong dependence of Amazon forest growth on soil available phosphorus concentrations (Quesada et al., 2009a) would also be reflected in much higher concentrations of foliar P (as well as possible other elements) for stands growing on more fertile soils - this being above and beyond that expected on the basis of differences in species composition (as in 2. above) alone. 


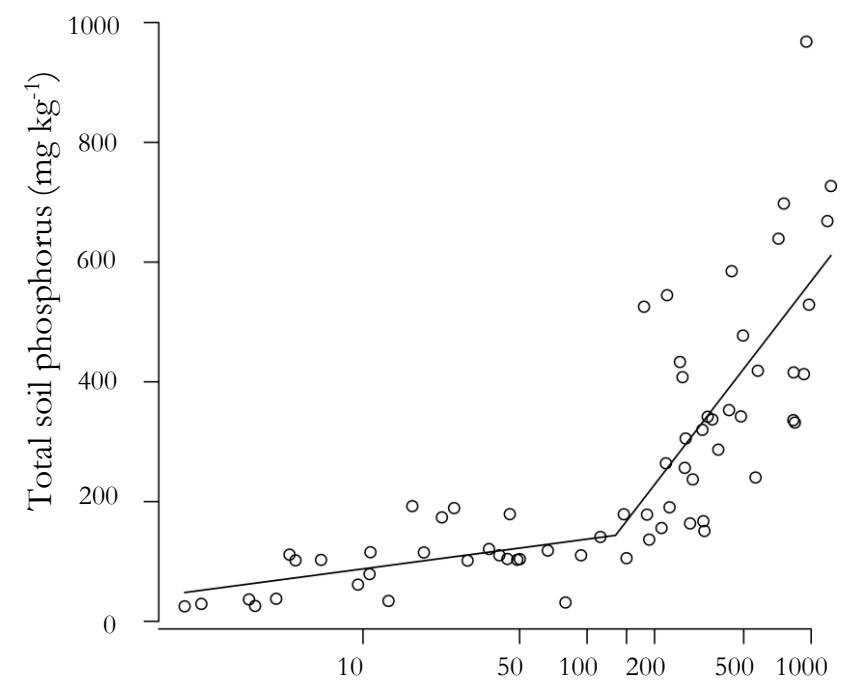

Soil total reserve bases $\left(\mathrm{mmol}_{\mathrm{c}} \mathrm{kg}^{-1}\right)$

Fig. 1. Broken line regression and breakpoint identification in the linear relationship between soil total $\mathrm{P}$ content and $\log _{10^{-}}$ transformed total reserve bases. See also Quesada et al. (2009c).

\section{Methods}

\subsection{Study sites and leaf minerals, xylem density and en- vironmental data}

For 62 of the RAINFOR network plots described in detail in Patiño et al. (2009), we utilised foliar nutrient and $M_{A}$ data from upper canopy sun-exposed leaves from trees reliably identified at the species level, with data collected and analysed as described in detail in Lloyd et al. (2009). The elements of interest were leaf level concentrations of C, N, P, $\mathrm{Ca}, \mathrm{Mg}, \mathrm{K}$, all expressed here in $\mathrm{mg} \mathrm{g}^{-1}$, with leaf mass per unit area, $M_{A}$, expressed in units of $\mathrm{g} \mathrm{m}^{-2}$ and $\delta^{13} \mathrm{C}$ as per mil (\%o). As in Lloyd et al. (2009), [C] as shown and analysed here, has been adjusted for variations in mineral content by subtracting the measured concentrations of the major cations viz $[\mathrm{Ca}]+[\mathrm{Mg}]+[\mathrm{K}]+[\mathrm{Na}]$. This allows variations in $[\mathrm{C}]$ to be better interpreted in terms of variations in foliar carbohydrate chemistry, as opposed to variation in [C] simply reflecting differences in mineral concentrations.

Some sample plots included in Patiño et al. (2009) are not considered in this analysis, due to less than complete species identification (APG II, 2003). These include ALF-01, MAN-03, SIN-01, SUC-04, ZAR01,02,03,04). Data from some plots have been aggregated (ex. TAP-01 \& TAP-02 \& TAP-03 $\rightarrow$ TAP-123, CAX$03 \&$ CAX- 03.1 $\rightarrow$ CAX-03) where they were located in close proximity and having all but identical topography, soils and climatic conditions (see Supplementary information I, Table SI1: http://www.biogeosciences.net/6/2677/ 2009/bg-6-2677-2009-supplement.zip).
Previous work has shown tropical forest soil type to significantly influence foliar trait interactions, for example the slope of the foliar $\mathrm{N}$ versus foliar P relationship (Townsend et al., 2007). Similarly, Kattge et al. (2009) examined photosynthesis versus nitrogen relationships for tropical trees also finding distinctions between fertile ("oxisol") versus infertile ("non-oxisol") soils. To provide some linkage with these studies, soil chemical and physical data for $0-0.3 \mathrm{~m}$ depth, collected and analysed as described in Quesada et al. (2009c) were thus assembled to allow a classification of plots according to soil fertility groups and thus a differentiation of foliar traits and their relationships between low and high fertility sites. Our differentiation into low and high fertility soils was more quantitative, however, being based on the measured "total reserve bases" $\Sigma_{R B}$, from 0.0 to $0.3 \mathrm{~m}$ depth, which provides a quantitative estimate of the extent of soil weathering as described in Quesada et al. (2009c). A "breakpoint" in the linear relationships of different soil variables such as phosphorus content (Fig. 1), $\mathrm{pH}$ and others with $\log _{10}\left(\Sigma_{R B}\right)$, was identified using broken line regression models (Muggeo, 2008), with this breakpoint almost inevitably occurring at a mean $\Sigma_{R B}$ around $130\left(\mathrm{mmol} \mathrm{kg}^{-1}\right)$. Using the World Reference Base for Soil Resources Classification System (IUSS Working Group WRB, 2006), $\Sigma_{R B}<130 \mathrm{mmol} \mathrm{kg}^{-1}$ encompasses nutrient poor soils such as arenosols, podzols and ferralsols along with any dystrophic acrisols, alisols, cambisols gleysols and plinthisols. On the other hand, $\Sigma_{R B}>$ $130 \mathrm{mmol} \mathrm{kg}^{-1}$ defines the usually fertile cambisols, along with the more fertile alisols, nitisols, fluvisols, lixisols and plinthisols. $\Sigma_{R B}$ is an easily measured soil property which is often determined in soil science studies, both in the tropics and elsewhere (e.g. Federer et al., 1998; Barthold et al., 2008; Quesada et al., 2009c).

Climate, temperature and precipitation datasets were obtained from the free access web site at http://www.worldclim. org. This set of global climate layers, "WorldClim", includes annual time series with mean monthly data for precipitation, and mean, minimum and maximum temperatures obtained from over 4000 weather stations between 1950 and 2000 (Hijmans et al., 2005). Solar radiation data is from New et al. (2002).

\subsection{Statistical analysis}

The analysis here focuses on genetic and plot-environmental components of trait variation, as estimated from a multilevel model and discussed below.

Preliminary tests included: analysis of normality (ShapiroWilk), and homogeneity of variances (Fligner-Killeen) for each foliar property. This showed $[\mathrm{C}],[\mathrm{N}],[\mathrm{P}],[\mathrm{Ca}],[\mathrm{Mg}]$ $[\mathrm{K}]$ and $M_{A}$ to all not be normally distributed and these parameters were thus $\log _{10}$-transformed prior to analyses. Foliar $\delta^{13} \mathrm{C}$ was approximately normally distributed, but we $\log _{10}$-transformed the absolute values in order to consistently analyse the full dataset, taking the negative values of the 
transform and then returning the values to the original sign. One way analysis of variance (ANOVA) was used to explore for differences between fertility groups, as well as for differences between families, genera within a family and species within a genus. All analyses were performed with the R statistical platform (R Development Core Team, 2008).

A multilevel model (Snijders and Bosker, 1999; McMahon and Diez, 2007) was first fitted for each foliar trait according to

$T=\mu+p+f / g / s+\varepsilon$,

where $\mu$ is the overall mean value of each trait $(T), p$ is the plot effect, i.e. the effect of the location at which each individual was found (soil and climate), $f / g / s$ represents the genetic structure of the data, i.e. that each individual belongs to a species $(s)$, nested in a genus $(g)$, nested in a family $(f)$, and $\varepsilon$ is the residual term which includes both natural within-species variability as well as any measurement error. All parameters were estimated by the Residual Maximum Likelihood (REML) method with the lme4 library (Bates and Sarkar, 2007). The multilevel model Eq. (1), in a similar way to taxonomically based nested ANOVAs, can be used to partition the variance from species up to the family level. It is particularly useful for not fully resolved plant supertrees (Kerkhoff et al., 2006; Watanabe et al., 2007) and it can be used to estimate group- or individual-level regression coefficients and their variation in unbalanced datasets (Gelman and Hill, 2006; pp. 246) with even one observation per group (Gelman and Hill, 2006; pp. 276). In our case the estimated components of variance can be distinguished into both a ["plot" - "environmental"\} and a "genetic" term. Recognising that our study represents an incomplete and, to a large extent, under-represented sampling of the edaphic and climatic variability of Amazonia, as well as only a selection of the many trees species living there, all terms in the multilevel model were treated as random (as opposed to fixed) effects (McCulloch and Searle, 2001). Random effects were quantified through the best linear unbiased predictor (BLUP) method, providing shrunken estimates of the differences between terms and the overall means (Galwey, 2006). The random genetic and the plot effects were then used for further analysis as described below.

Due to the highly unbalanced nature of our dataset we verified the efficiency of the hierarchical/multilevel model in both partitioning the variance and in providing accurate estimates of the genetic and plot level dependencies of the observed foliar properties through a simulation study (Supplementary Information SII). In these simulations a predefined pattern of variance partitioning as well as species and plot level effects was imposed (along with significant residual effects) with the sampling of individual species undertaken in a highly unbalanced manner similar to that of our actual sample. We then retrieved the genetic and environmental effects for the artificially generated population using the REML approach, also testing the efficacy of the REML procedure in partitioning the trait variation between species and plots in the presence of substantial residual "noise". As is shown in Supplementary Information SII, the hierarchical model was able to adequately extract both the variance structure and the magnitude of the species/plot effects. Most importantly, it also provided unbiased estimates of the slopes of the bivariate relationships existing between the various traits of interest for both the genetic and plot-environmental effects.

In what follows we consider the derived environmental term to represent the combined influences of climate, soil and location. The genetic term (estimated here as the sum of the family, genus and species effects) represents the phylogenetic structure of the dataset. We note that this taxonomically based multilevel model does not have as input values the species means for the one species calculated at single and/or multiple sites as is sometimes the case (e.g. Baker et al., 2004; Wright et al., 2004). But rather, it incorporates the full range of available information, taking into account the observed intra-specific variation in foliage characteristics and allowing for all traits to vary systematically across the different plots sampled, as well as allowing for intra-species variability within any one plot.

Bivariate relationships of foliar properties were first assessed with Pearson's correlation coefficient $(r)$, and with Standardised Major Axis (SMA) line fits (Legendre and Legendre, 1998; Warton et al., 2006) subsequently applied where $r$ was significantly different from zero. SMA regression lines represent the first axis of a principal component analysis (of a correlation matrix) and are often used in plant allometry studies. It is common for variables to be logarithmically transformed with the regression $\log (y)=\log (\beta)+\alpha \log (x)$, this expressing a power law of the form $y=\beta x^{\alpha}$. The slope or scaling exponent $\alpha$, quantifies the rate of increase of $y$ in relation to $x$, indicating an isometric $(\alpha \approx 1)$ or allometric $(\alpha \neq 1)$ scale. The intercept or elevation $\beta$ of the regression line expresses the magnitude of $y$ per unit of $x$ (Kerkhoff and Enquist, 2006). SMA regressions were used for both the genetic $(f / g / s)$ and the plot-environmental $(p)$ component of different trait pairs. For the genetic component we further tested for differences in elevation and shift across the major axis for high and low fertility oriented species using the $\mathrm{R}$ smatr library (Warton et al., 2006).

The plot effect trait estimates were further explored with three different statistical methods; one of them presented here and two of them in Appendix A and Supplementary Information 3 (http://www.biogeosciences.net/6/2677/2009/ bg-6-2677-2009-supplement.zip). Initially multiple linear regressions (OLS) of plot contribution to trait variation against a set of key soil and climate variables were performed. For this, a matrix of soil variables was assembled using data from Quesada et al. (2009c) i.e. total soil C and $\mathrm{N}$ concentration, exchangeable $\mathrm{Ca}, \mathrm{Mg}, \mathrm{K}, \mathrm{Na}$ and $\mathrm{Al}$, total extractable phosphorus, $\Sigma_{R B}$, effective cation exchange capacity, base saturation and the sand and clay fraction. To reduce dimensions and avoid multicollinearity we applied 


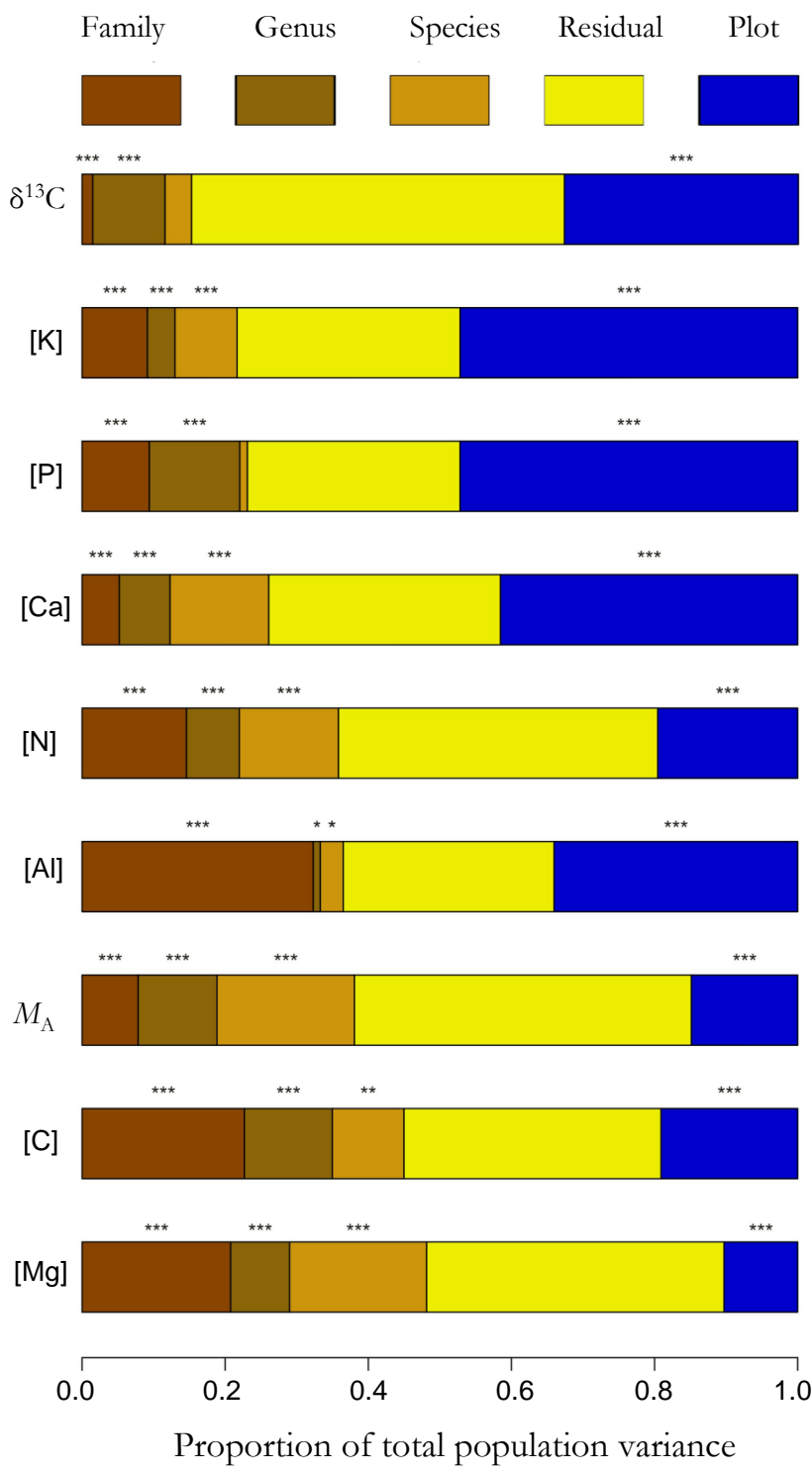

Fig. 2. Partitioning of the total variance for each foliar property into genetic (family/genus/species), environmental (plot) and an error (residual) components. Foliar properties are sorted from less to more phylogenetically constrained. Significance of each variance component was tested with a likelihood ratio test (Faraway, 2004; Galwey, 2006). Significance codes: $* * *<0.001, * *<0.01, *<0.05$. $M_{A}$ denotes leaf mass per unit area, $\delta^{13} \mathrm{C}$ represents the dry matter ${ }^{13} \mathrm{C} /{ }^{12} \mathrm{C}$ composition (per mil) with all other symbols representing the elemental composition of the leaves (dry weight basis). All values had been $\log _{10}$ transformed prior to analysis.

principal components analysis (PCA), using the R ade4 library (Chessel et al., 2004), to the correlation table of the soil matrix with most variables log-transformed (Quesada et al., 2009b) and derived the main axes of variation. Multiple regressions for each trait's "plot effect" were then computed on the first three principal components (Legendre and Legendre, 1998) with four climate variables also included; annual mean temperature, total annual precipitation, precipitation during the three driest months of the year and mean annual radiation (Appendix A). Simplification of the full model was explored following a stepwise elimination of the less significant terms, based on Akaike's Information Criterion (AIC) to derive the minimum adequate model (Crawley, 2007). Additionally, simultaneous autoregressive models (SAR) including a spatial error term at two scales were also fitted (Appendix A). Our spatial analysis was not designed to fully disentangle the scales where different environmental variables control the observed variation of the leaf properties studied. Rather, we have tried to filter the most important environmental predictors and to investigate if the trends identified by the OLS were biased and if the identified important environmental variables from OLS remained significant after accounting for spatial patterns in our models (Lichstein et al., 2002).

Finally as some plot effect versus environmental predictor relationships did not show a simple linear trend and/or normally distributed homoscedatic errors, we used Kendall's $\tau$ as a non-parametric measure of association. Though less common than Spearman's $\rho$, Kendall's $\tau$ has slightly better distributional properties and also has the advantage that it can be interpreted in terms of probabilities of observing concordant and discordant pairs (Conover, 1980). Specifically, $\tau=\pi_{c}-\pi_{d}$, where $\pi_{c}$ is the probability of concordant pairs and $\pi_{d}$ is the probability of discordant. For example, if $\tau=0.5$, then 0.75 of the ranked pairs are concordant and 0.25 are discordant. Kendall's $\tau$ also has the advantage that it can be generalised to a partial correlation coefficient (Legendre and Legendre, 1998; pp. 202). As is discussed in Legendre and Legendre (1998) it is, however, difficult to assess the statistical significance of the partial $\tau$ and so here we assess likely significance levels of our calculated partial $\tau$ by numerical simulation as described in Maghsoodloo and Laszlo Pallos (1981). Although not allowing spatial patterns to be taken implicitly into account, this approach does allow the inter-relationships between environmental predictors to be explicitly included in the analysis of environmental factors influencing the studied plant physiological properties in a non-parametric manner.

\section{Results}

\subsection{Partitioning of the variance}

Through fitting the multilevel model of Eq. (1), a partitioning of the variance to genetic and plot level components was achieved with results presented in Fig. 2. This shows that, not only does the proportion of the variance attributable to the nested taxonomy (genetic) component differ for different traits, but also that the level of genetic variation, particularly at the species level, contrasts greatly between traits. For example, for $M_{A}$ the genetic component accounts for 

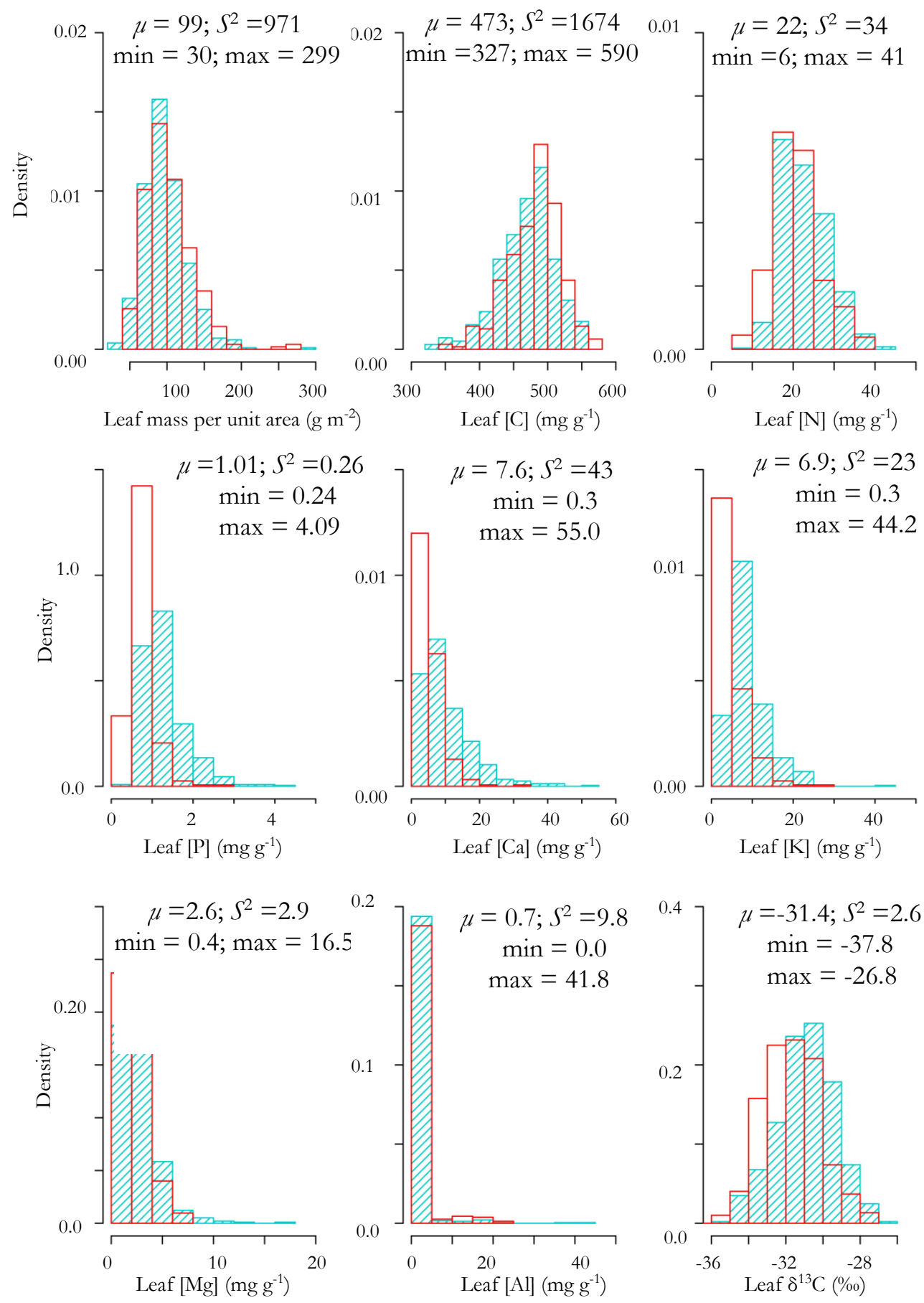

Fig. 3. Probability density histograms of raw data per fertility group. Red bars represent low and blue bars high soil fertility plots, as defined by the quantitative determinations of the level of total reserve bases from $0-30 \mathrm{~cm}$ depth (see Fig. 1 and text). Also given the overall mean, range and variance for each property.

approximately 0.38 of the total variance (with half of this attributable to species effect) and with the variability associated with tree location, the "plot effect", being only 0.15 of the total variance. A little less than half the variance in the dataset is attributable to an error term. As mentioned previously, the "error term" represents the proportion of the variance in the dataset attributable to intra-species variability as well as any measurement error.

In contrast to $M_{A}$, the principle source of variation in [P] was the "plot effect" (accounting for 0.47 of the total variance) with only 0.23 of the observed variance attributable to a genetic component and with the species 
specific component of the variation being less significant. The "plot effect" was similarly very high for [Ca] and [K] ( 0.42 and 0.47 of the total variance respectively), whilst the lowest plot contribution of 0.1 was observed for $[\mathrm{Mg}]$. Along with $M_{A}$, partitioning of the variance to the genetic component was highest for $[\mathrm{Mg}](0.48)$ and $[\mathrm{C}](0.40)$. Also of note is the high proportion of the variance in $[\mathrm{Al}]$ attributable at the family level (0.32), consistent with independent phylogenetic analyses (Jansens et al., 2002). For $\delta^{13} \mathrm{C}$, the attributed genetic variation was less than for any of the elements or $M_{A}$, but still with an appreciable "plot effect", suggesting that geographic variations in either soil or climate exert significant effects on the extent of photosynthetic ${ }^{13} \mathrm{CO}_{2}$ discrimination across Amazonia.

The ability of the REML model to accurately retrieve the correct partitioning of the variance for the various traits is demonstrated in Supplementary Information II (http://www.biogeosciences.net/6/2677/2009/ bg-6-2677-2009-supplement.zip) and, for the interested reader, some aspects of the inferred taxonomic variation of the examined foliar properties is presented and discussed in Appendix B, including a consideration of differences between $\mathrm{N}_{2}$-fixing and non- $\mathrm{N}_{2}$ fixing members of the Fabaceae.

\subsection{Statistical distribution of measured traits}

Trait distributions for the complete dataset divided into the low and high soil-fertility groups are shown in Fig. 3, with the overall arithmetic mean, range and variances also shown. Significant differences across mean plot values were identified for all foliar properties as summarised in the Supplementary Information I, Table SI1. Figure 3 shows that although $M_{A}$ and $[\mathrm{C}]$ had similar statistical distributions for both low and high fertility plots, for the other traits examined the distributions for trees growing on the more fertile soils were shifted to the right, apart from [Al] (shifted to the left). Mean leaf N:P ratio was $30.1 \pm 9.5$ for the low soil fertility plots, this being significantly higher $\left(F_{1,789}=388.6\right.$, $p<0.001$ ) than the $19.6 \pm 5.6$ observed on high fertility soils. Thus, the natural variations in rain forest soil fertility that occur within the Amazon Basin, exert a strong effects on plant nutrient concentrations and $\delta^{13} \mathrm{C}$, but do not strongly influence $M_{A}$ and [C].

\subsection{Bivariate relationships (raw data)}

A preliminary analysis of the raw data foliar properties showed significant correlations between most of the examined trait pairs as shown in Table 1 (left panel), where we also summarise the SMA regression estimates for the whole dataset (no separation into low and high fertility plots). Nevertheless, when low and high fertility sites were considered separately, most of the pairwise associations remained important, but with significant differences in slope or elevation and shift of the SMA axis being identified (see Supplemen- tary Information I, Table SI2: http://www.biogeosciences. net/6/2677/2009/bg-6-2677-2009-supplement.zip). Interestingly, the $[\mathrm{P}]$ vs. $[\mathrm{N}]$ relationship and all bivariate relationships including $[\mathrm{K}]$, showed statistically significant differences in slope between low and high fertility sites (apart from $[\mathrm{K}]$ vs. $[\mathrm{N}])$. In what follows we therefore retained our consideration of the effects of soil fertility on trait variation, probing differences between our fertile and infertile soil classes on the nature of the bivariate relationships for the genetic components of the overall variation observed. Some of the raw data bivariate relationships are presented in Fig. SI1.

\subsection{Bivariate relationships (Genetic component)}

The genetic component of the multilevel model (i.e. the family+genus+species) showed numerous significant correlations (Table 1 - middle panel). By separating species to low and high fertility oriented ones, most relationships identified as significant in the raw dataset, retained their importance (Table 2). As is also shown in Fig. 4a and b, using the convention $y \leftrightarrow x$ to denote bivariate relationships, a strong relationship was identified for $[\mathrm{N}] \leftrightarrow M_{A}(r=-0.403$ and -0.407 on low and high fertility soils respectively) and $[\mathrm{P}] \leftrightarrow M_{A}(r=-0.388$ and -0.433$)$. There was also a reasonably strong relationship between $M_{A}$ and [K] but this was considerably weaker for $[\mathrm{Mg}]$ for both soil types (Table 2, graph not shown). $M_{A}$ showed a weak correlation with [Ca] and was stronger associated with $[\mathrm{C}]$ in species found at low soil fertility sites. The genetic component of $[\mathrm{C}] \leftrightarrow[\mathrm{N}]$ was only marginally significant on low fertility sites, while strong negative associations were found between leaf carbon and cations $(\mathrm{Ca}, \mathrm{K} \& \mathrm{Mg})$ content on both fertile and infertile plots.

Very strong correlations were also observed between some of the individual nutrients, with $[\mathrm{P}] \leftrightarrow[\mathrm{N}](r=0.648$ and 0.698 on low and high fertility soils respectively) being especially well associated (Fig. 4c). The relationships between $[\mathrm{K}]$ and $[\mathrm{P}](r=0.394$ and 0.507 ; Fig. $4 \mathrm{e}),[\mathrm{Mg}]$ and $[\mathrm{Ca}]$ $(r=0.643$ and 0.660 ; Fig. $4 \mathrm{f})$ and between $[\mathrm{K}]$ and $[\mathrm{Ca}]$ $(r=0.447$ and 0.450$)$ are also of note, as is the observation that the relationship between $[\mathrm{K}]$ and $[\mathrm{N}]$ is substantially weaker than for $[\mathrm{K}] \leftrightarrow[\mathrm{P}]$. Though not shown in Fig. 4, of interest were the generally strong correlations between all three base cation pairs and with $P$.

A comparison of SMA slopes for all $M_{A} \leftrightarrow$ [nutrient] relationships showed no difference between low and high fertility sites (Table 2). This was also true for between nutrient pairs such as $[\mathrm{P}] \leftrightarrow[\mathrm{N}],[\mathrm{K}] \leftrightarrow[\mathrm{P}],[\mathrm{Ca}] \leftrightarrow[\mathrm{K}]$ and $[\mathrm{Ca}] \leftrightarrow[\mathrm{Mg}]$. This suggests that the intrinsic (genetically defined) way $M_{A}$ is linked with leaf nutrient concentrations, as well as the way in which different nutrients are related to each other is to a large degree common for species found across the Amazon and independent of the fertility of the soil where they usually grow. 

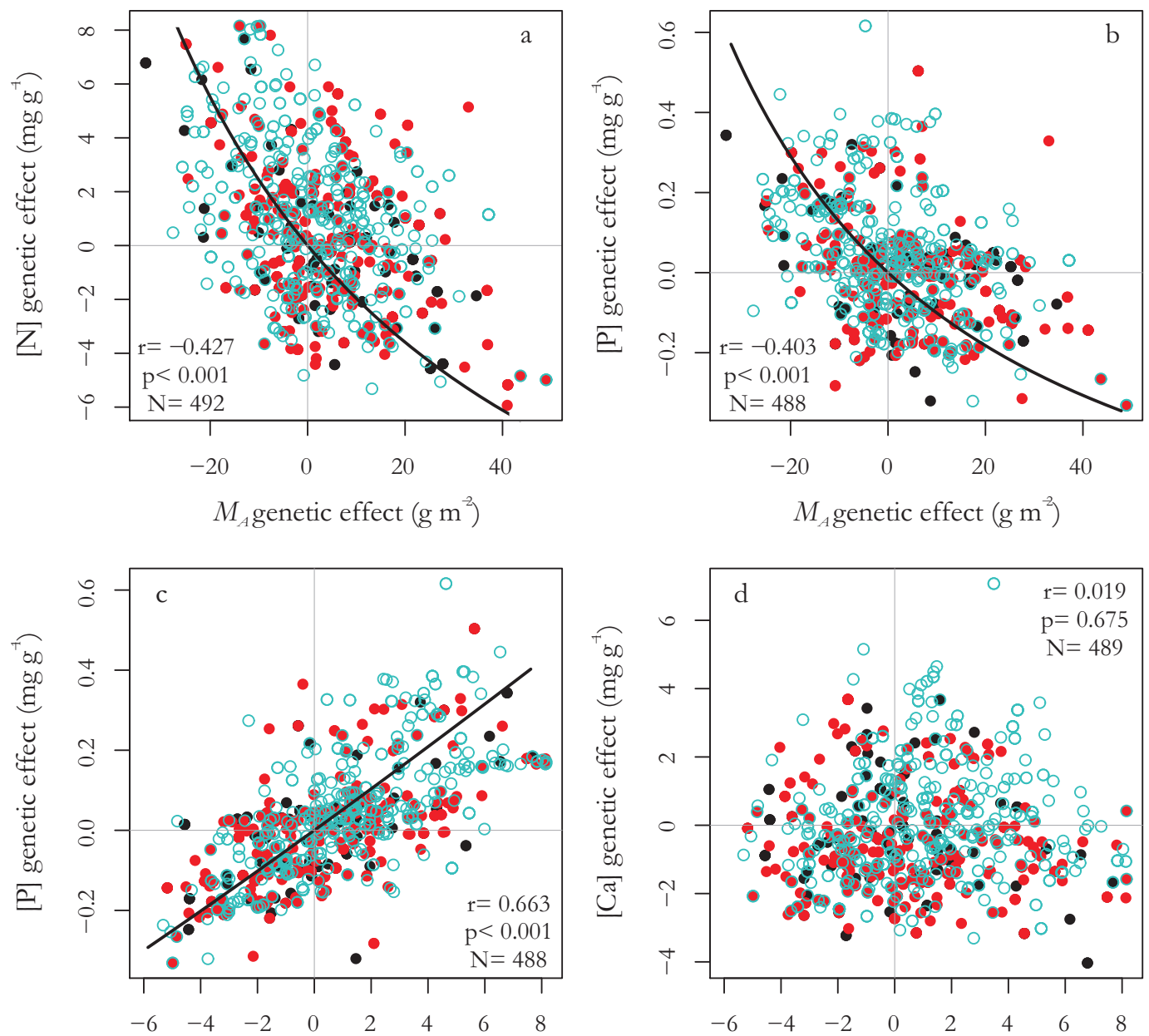

$[\mathrm{N}]$ genetic effect $\left(\mathrm{mg} \mathrm{g}^{-4}\right)$

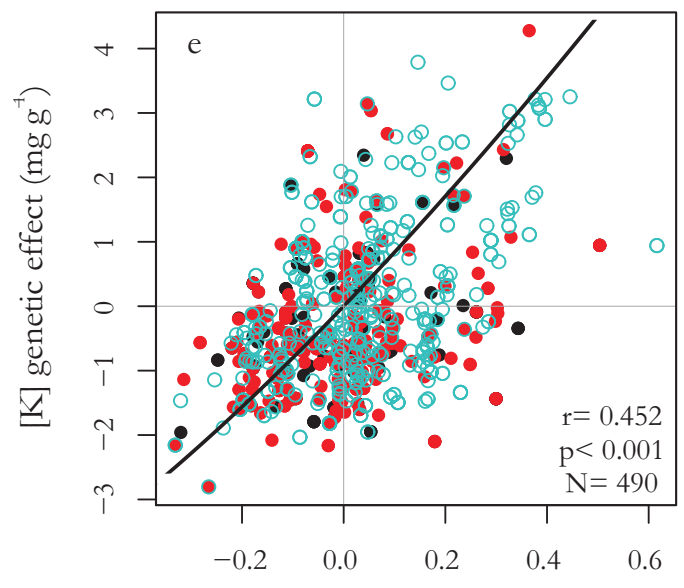

[P] genetic effect $\left(\mathrm{mg} \mathrm{g}^{-4}\right)$

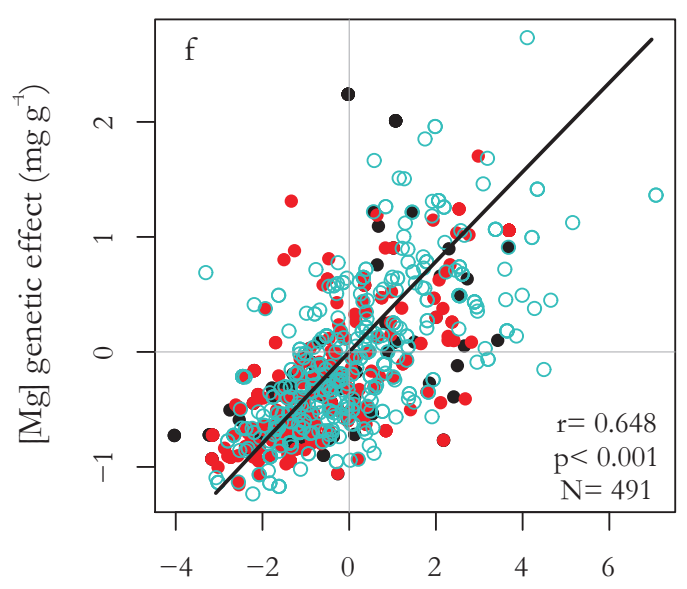

[Ca] genetic effect $\left(\mathrm{mg} \mathrm{g}^{-1}\right)$

Fig. 4. Relationship between genetic effect terms for selected pairs of foliar properties. These curves are reconstructed following the footnote on Table 1 (analysis originally done on $\log _{10}$ transformed variables, but here back transformed to the original scale) and with the overall geometric mean for each foliar property subtracted. Red dots indicate species found on low fertility sites and blue circles indicate species found on high fertility sites. Species found on both soil fertility groups are illustrated with black dots (see text for details). Common slope SMA lines are shown, though shifts along the SMA axis with fertility were also common (Table 2). $M_{A}$ denotes leaf mass per unit area with other symbols representing the elemental composition of the leaves (dry weight basis). 

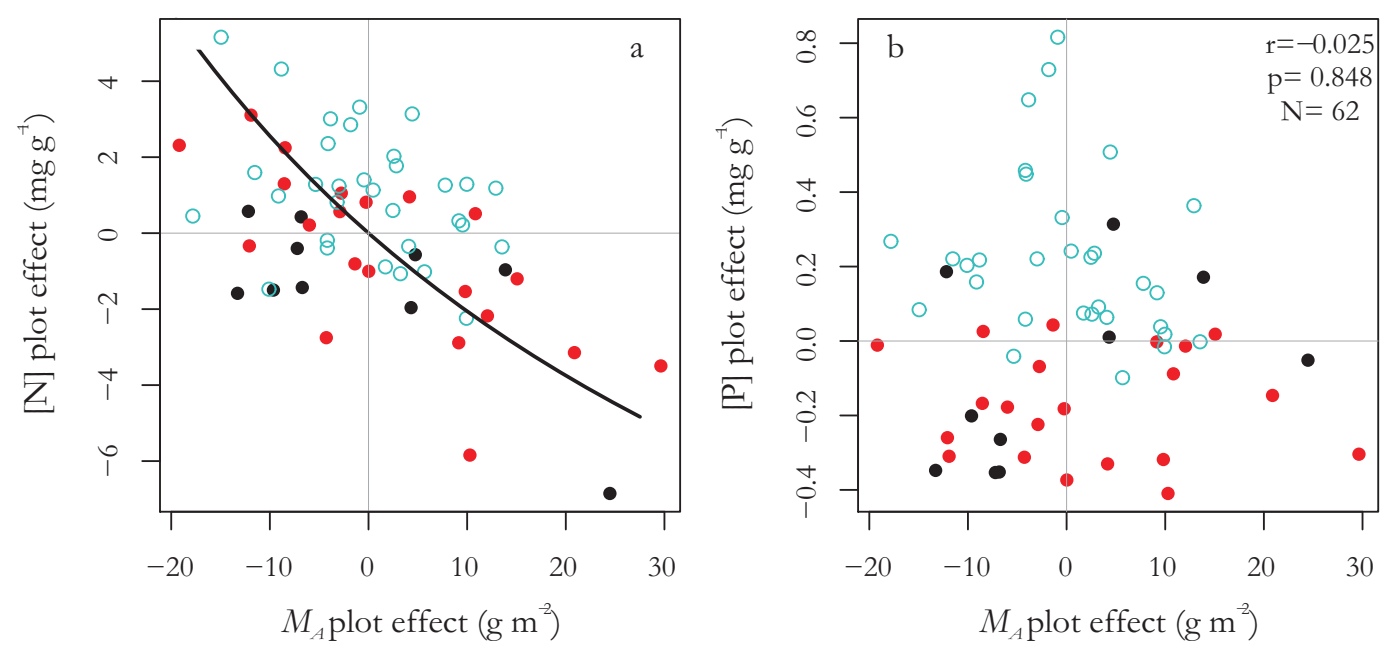

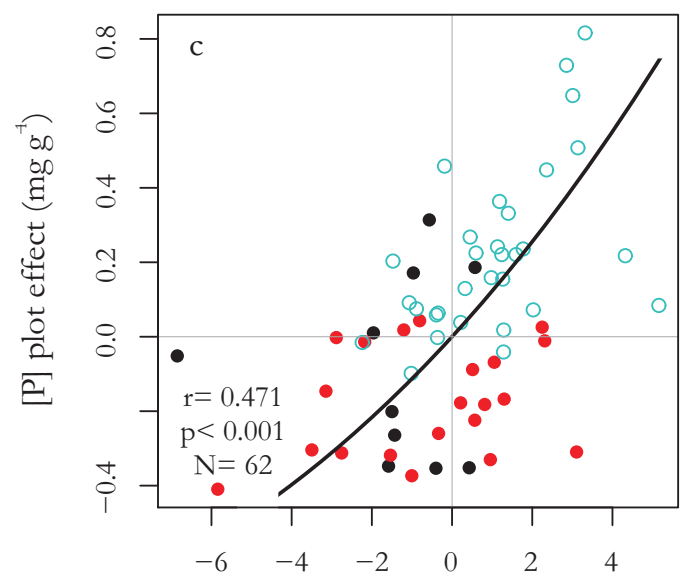

$[\mathrm{N}]$ plot effect $\left(\mathrm{mg} \mathrm{g}^{-4}\right)$

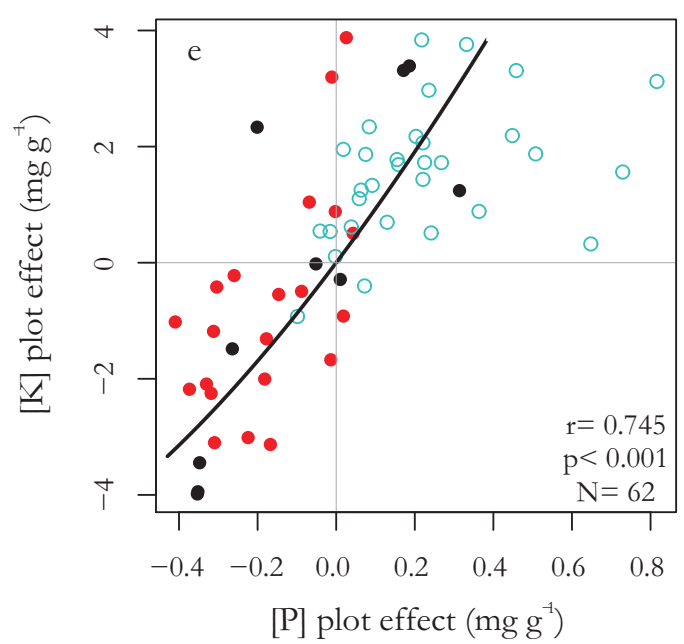

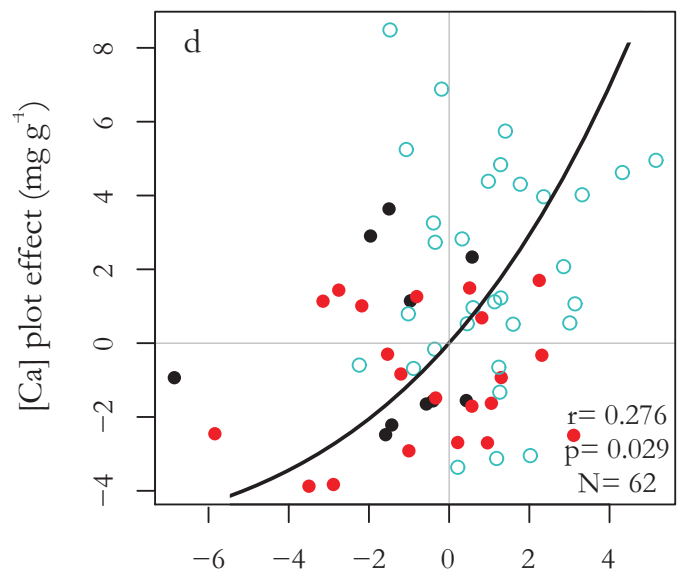

$[\mathrm{N}]$ plot effect $\left(\mathrm{mg} \mathrm{g}^{-4}\right)$

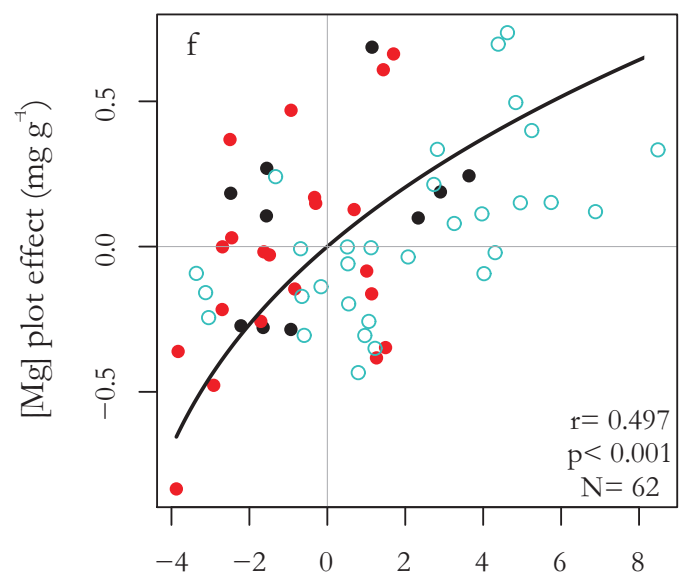

[Ca] plot effect $\left(\mathrm{mg} \mathrm{g}^{-1}\right)$

Fig. 5. Relationship between plot-environmental effects for selected pairs of foliar properties. These curves are reconstructed following the footnote on Table 1 (analysis originally done on $\log _{10}$ transformed variables, but here back transformed to the original scale) with the overall geometric mean for each foliar property subtracted. Red dots indicate low fertility sites, blue circles indicate high fertility ones and black dots illustrate plots with no fertility classification. $M_{A}$ denotes leaf mass per unit area with other symbols representing the elemental composition of the leaves (dry weight basis). 

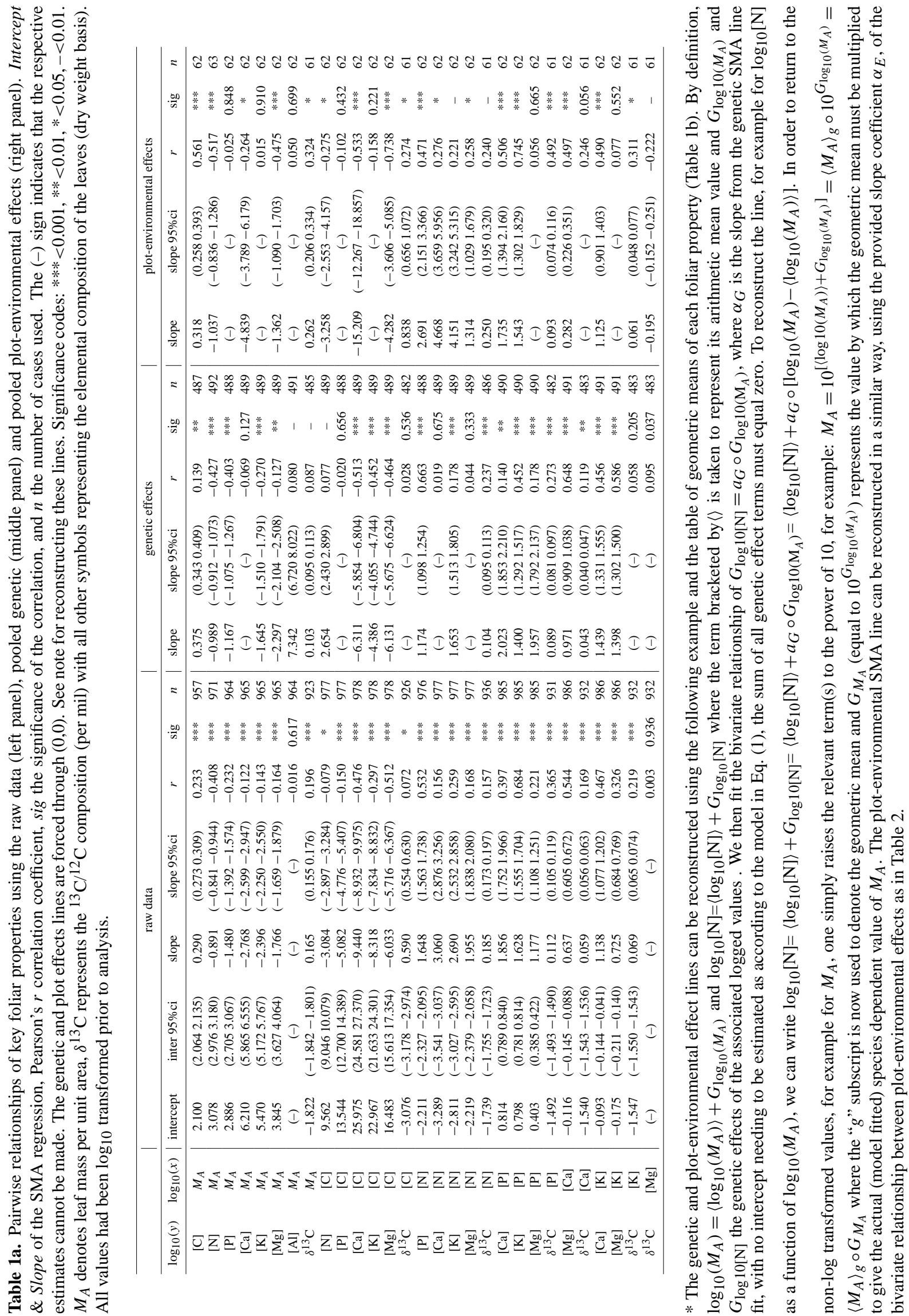
As there was no effect of soil fertility on the SMA slopes, for each bivariate relationship exhibiting a common scaling exponent, further tests for difference in elevation and/or shift were subsequently applied (Warton et al., 2006). Although in no case were significant differences in elevation (intercept) identified between SMA regression lines of low and high fertility oriented species, all of the $M_{A} \leftrightarrow$ [nutrient] and $[\mathrm{P}] \leftrightarrow[\mathrm{N}],[\mathrm{K}] \leftrightarrow[\mathrm{P}],[\mathrm{Ca}] \leftrightarrow[\mathrm{K}]$ pairs presented significant shifts along the $M_{A}$ axis (Table 2). Thus species found on fertile soils are shifted towards the upper end of the $M_{A}$ vs. [nutrient] scaling line, tending to have inherently lower $M_{A}$ and inherently higher leaf nutrient concentrations (Fig. 4a, b). There were 33 species found at both low and high fertility sites, overlapping the two soil groups which were not included in the calculation of the above effects.

Finally for $\delta^{13} \mathrm{C}$ there was a strong positive relationship with both $[\mathrm{N}]$ and $[\mathrm{P}]$ only and with soil fertility affecting the elevation of (rather than a shift in) the SMA regressions (Table 2). This suggests that although there is a general tendency for species with intrinsically higher $[\mathrm{N}]$ and $[\mathrm{P}]$ to also have an intrinsically lower photosynthetic discrimination against ${ }^{13} \mathrm{CO}_{2}(\Delta)$, the magnitude of this effect is offset because species on the more fertile soils also have a higher $\Delta$ than those typically found under less fertile conditions.

\subsection{Bivariate relationships (plot-environmental component)}

The aggregated SMA regressions of the plot (environmental) component are summarised in the right panel of Table 1. Although a substantially smaller sample size was used (number of plots «number of species) many significant linear relationships were identified. However in some cases, relationships identified as important for the genetic component were weak for the plot level effects and vice versa. For example, although the relationships between $[\mathrm{C}] \leftrightarrow M_{A}$ and $[\mathrm{N}] \leftrightarrow M_{A}$ (Fig. 5a) were significant for the plot level effects and with a similar slope to the genetic level effects, this was not the case for the $[\mathrm{P}] \leftrightarrow M_{A}$ (Fig. 5b) and the $[\mathrm{K}] \leftrightarrow M_{A}$ pairs. This suggests that the often observed relationship between $M_{A}$ and [P] does not reflect some sort of fundamental physiological imperative. The correlation between plot level $[\mathrm{N}]$ and $[\mathrm{P}]$ contribution was significant (Fig. 5c) and the same was true for the $[\mathrm{Ca}] \leftrightarrow[\mathrm{N}]$ pair (Fig. $5 \mathrm{~d}$ ), although for the latter no significant association was identified for the genetic component. The strongest association was found between $[\mathrm{K}] \leftrightarrow[\mathrm{P}]$ (Fig. 5e).

Another point of interest was the comparison of the SMA slopes, for the genetic and plot component which describe the functional relationship across and within species respectively (though note that our "residual" component must also contain some aspects of within-species variability). Out of the 17 cases where pairwise relationships were important both for the genetic and the plot component, seven had overlapping slope confidence intervals, i.e. similar slopes, and ten had different slopes. For example the SMA slope for the $[\mathrm{K}] \leftrightarrow[\mathrm{P}]$ relationship was equal to 1.40 , almost identical with the one estimated for the genetic component pair (1.54). On the other hand the slope for the $[\mathrm{P}] \leftrightarrow[\mathrm{N}]$ plot effect relationship was 2.69 as compared to 1.17 when genotype was the source of variation and with no overlapping confidence interval limits (Table 2). Clearly then, although $M_{A},[\mathrm{~N}]$ and $[\mathrm{P}]$ are closely linked in a consistent way when examined across different species, the relationships between $M_{A}$ and $[\mathrm{P}]$ and between $[\mathrm{N}]$ and $[\mathrm{P}]$ for tropical trees can both be substantially modified by the environment in which they are growing.

\subsection{Environmental predictors of the plot effects}

The results from the ordination of the soil variables are illustrated in Table 3 with the first three PCA axes explaining 0.74 of the total variance. The first axis which accounted for 0.45 of the variance was mainly related with variations in exchangeable bases (viz $\mathrm{Ca}, \mathrm{K}$ and $\mathrm{Mg}$ ), total extractable $\mathrm{P}$, total reserve bases $\left(\Sigma_{R B}\right)$ and effective cation exchange capacity, thus reflecting variations in soil fertility (denoted $\varphi_{F}$ ). The second axis, $\varphi_{T}$, explained 0.18 of the variance and was mostly associated with variations in exchangeable $\mathrm{Al}$ and soil texture, with the third, $\varphi_{C}$, (accounting for 0.11 of the variance) mostly associated with variations in total soil $\mathrm{C}$ and $\mathrm{N}$. These principal components were used as non-collinear predictor variables, along with mean annual temperature, annual total precipitation, precipitation during the dry months and incoming solar radiation in a multiple linear regression against the plot level effect as derived from the multilevel model of Eq. (1).

As is outlined in Appendix A, important environmental predictors of trait variation were identified using both ordinary regression and simultaneous autoregressive models (SAR). However, some OLS analyses (especially for [P], $[\mathrm{Ca}],[\mathrm{K}],[\mathrm{Al}]$ and $\delta^{13} \mathrm{C}$ ) suggested that data normality and homoscedacity did not always occur. Thus, we utilised the rank-based Kendall's $\tau$ to evaluate the relationships between plot-level trait effects and environmental predictors (i.e. using the $\varphi_{F}$ axis and the climatic variables) that retained the strongest significance in the OLS-SAR comparative analysis. These relationships are illustrated in Figs. 6 and 7 along with their associated $\tau$ and level of significance.

Bearing in mind that any spatial autocorrelation will lead to an overestimate of the level of significance, Fig. 6a thus suggests that the relationship showing a decline between $M_{A}$ and $\varphi_{F}$, is weak, but that the decrease in [C] plot effect with $\varphi_{F}$ (Fig. 6b) and the increasing [N] effect with $\varphi_{F}$ (Fig. 6c) are both much more likely to be significant, with the very strong relationship between $[\mathrm{P}]$ plot effects and $\varphi_{F}$ (Fig. 6d) even more so. Of the cations, the relationships between $\varphi_{F}$ and both the [Ca] (Fig. 6e) and [K] plot effect (Fig. 6f) were both also quite strong, but as is shown in Fig. $6 \mathrm{~g}$ this was much less the case for the $[\mathrm{Mg}]$, for which, 

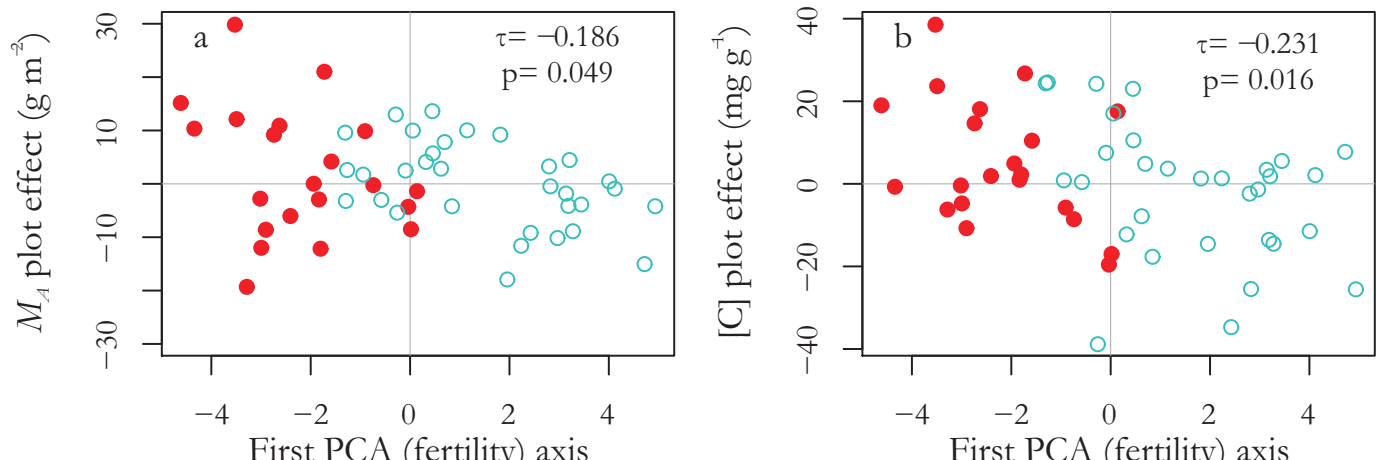

First PCA (fertility) axis
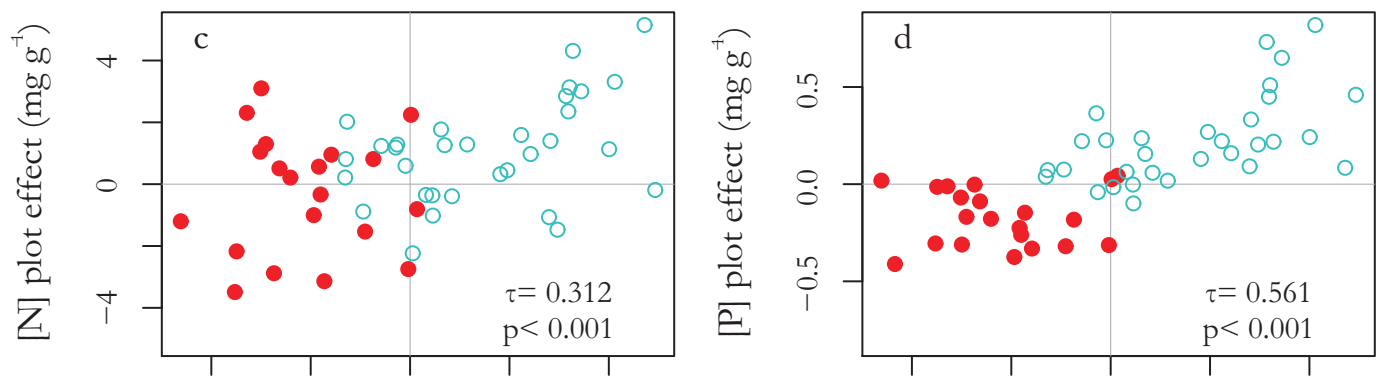

$\begin{array}{lllll}-4 & -2 & 0 & 2 & 4\end{array}$

First PCA (fertility) axis

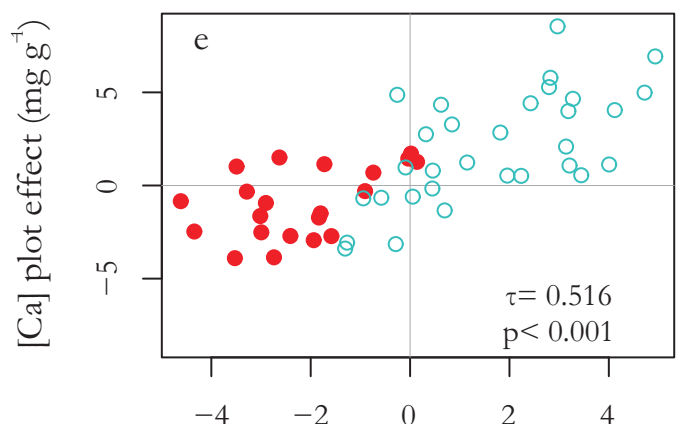

First PCA (fertility) axis

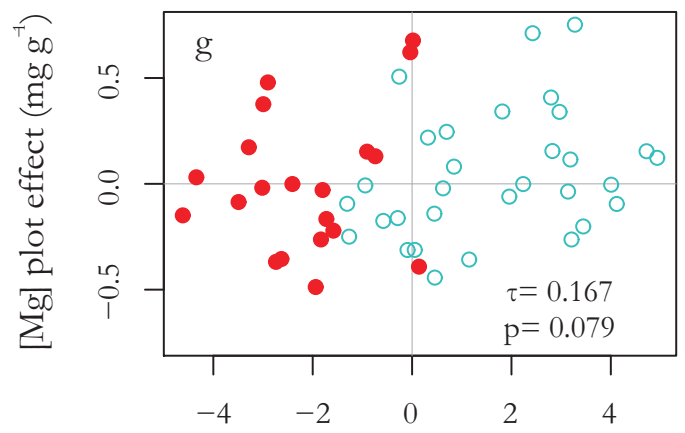

First PCA (fertility) axis

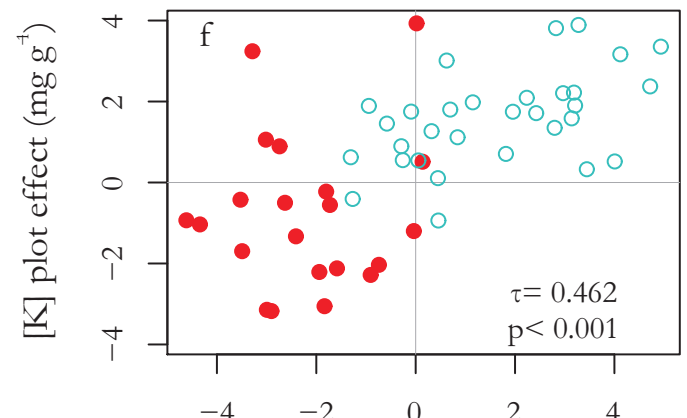

First PCA (fertility) axis

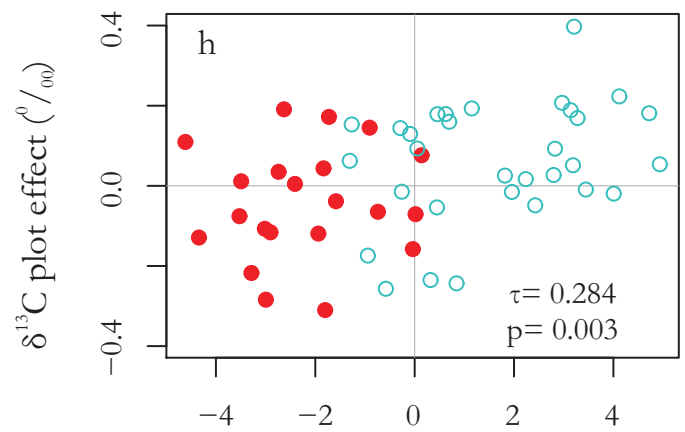

First PCA (fertility) axis

Fig. 6. Relationships between plot-environmental effects and the PCA first PCA (fertility) axis, $\varphi_{F}$ for key foliar properties. Red dots indicate low fertility plots and blue circles indicate high fertility ones. Full Kendall's $\tau$ along with its significance is also given. $M_{A}$ denotes leaf mass per unit area, $\delta^{13} \mathrm{C}$ represents the dry matter ${ }^{13} \mathrm{C} /{ }^{12} \mathrm{C}$ composition (per mil) with all other symbols representing the elemental composition of the leaves (dry weight basis). 

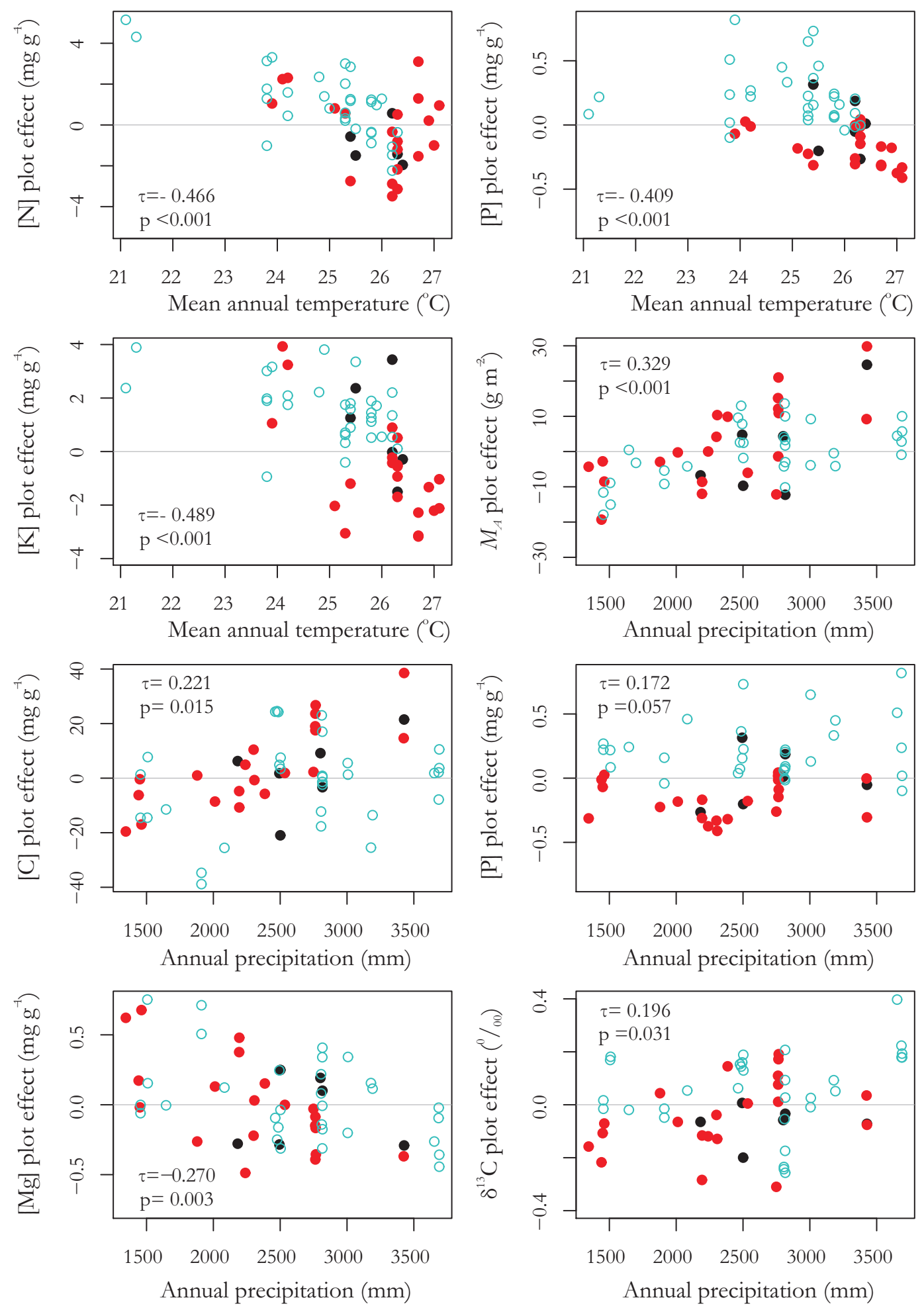

Fig. 7. Relationships between plot-environmental effects and mean annual temperature and precipitation for key foliar properties. Red dots indicate low fertility plots, blue circles indicate high fertility ones and black dots plots with no soil fertility data. Full Kendall's $\tau$ along with its significance is also given. $M_{A}$ denotes leaf mass per unit area, $\delta^{13} \mathrm{C}$ represents the dry matter ${ }^{13} \mathrm{C} /{ }^{12} \mathrm{C}$ composition (per mil) with all other symbols representing the elemental composition of the leaves (dry weight basis). 
Table 1b. Table of geometric means.

\begin{tabular}{|c|c|c|c|c|c|c|c|c|c|}
\hline & $\begin{array}{c}M_{A} \\
\left(\mathrm{~g} \mathrm{~m}^{-2}\right)\end{array}$ & $\begin{array}{c}{[\mathrm{C}]} \\
\left(\mathrm{mg} \mathrm{g}^{-1}\right)\end{array}$ & $\begin{array}{c}{[\mathrm{N}]} \\
\left(\mathrm{mg} \mathrm{g}^{-1}\right)\end{array}$ & $\begin{array}{c}{[\mathrm{P}]} \\
\left(\mathrm{mg} \mathrm{g}^{-1}\right)\end{array}$ & $\begin{array}{c}{[\mathrm{Ca}]} \\
\left(\mathrm{mg} \mathrm{g}^{-1}\right)\end{array}$ & $\begin{array}{c}{[\mathrm{K}]} \\
\left(\mathrm{mg} \mathrm{g}^{-1}\right)\end{array}$ & $\begin{array}{c}{[\mathrm{Mg}]} \\
\left(\mathrm{mg} \mathrm{g}^{-1}\right)\end{array}$ & $\begin{array}{c}{[\mathrm{Al}]} \\
\left(\mathrm{mg} \mathrm{g}^{-1}\right)\end{array}$ & $\begin{array}{c}\left|\delta^{13} \mathrm{C}\right| \\
(\% \circ)\end{array}$ \\
\hline $\begin{array}{l}\text { Overall geometric mean } \\
\text { ( } \log _{10} \text { estimate) }\end{array}$ & $\begin{array}{l}94.85 \\
(1.97)\end{array}$ & $\begin{array}{c}471.53 \\
(2.67)\end{array}$ & $\begin{array}{l}20.69 \\
(1.31)\end{array}$ & $\begin{array}{c}0.91 \\
(-0.04)\end{array}$ & $\begin{array}{l}5.48 \\
(0.74)\end{array}$ & $\begin{array}{c}5.38 \\
(0.73)\end{array}$ & $\begin{array}{c}2.26 \\
(0.35)\end{array}$ & $\begin{array}{c}0.044 \\
(-1.357)\end{array}$ & $\begin{array}{l}31.33 \\
(1.50)\end{array}$ \\
\hline
\end{tabular}

Table 2. Pairwise relationships between the genetic components of key foliar properties of species found in low and high fertility plots. The genetic component is computed by summing the Family+Genus+Species effect as estimated from the multilevel model. Slope of the SMA, Pearson's $r$ correlation coefficient, sig the significance of the correlation, and $n$ the number of cases used. Boldface indicates significant difference $(p<0.05)$ in slope or elevation and/or shift across the SMA axis. The $(-)$ sign indicates that the respective test cannot be applied. sig: $* * *<0.001, * *<0.01, *<0.05,-<0.1 . M_{A}$ denotes leaf mass per unit area, $\delta^{13} \mathrm{C}$ represents the ${ }^{13} \mathrm{C} /{ }^{12} \mathrm{C}$ carbon isotopic composition with all other symbols representing the elemental composition of the leaves(dry weight basis). All values had been $\log _{10}$ transformed prior to analysis.

\begin{tabular}{|c|c|c|c|c|c|c|c|c|c|c|c|c|c|c|}
\hline \multirow[b]{2}{*}{$\log _{10}(y)$} & \multirow[b]{2}{*}{$\log _{10}(x)$} & \multicolumn{5}{|c|}{ low fertility } & \multicolumn{5}{|c|}{ high fertility } & \multicolumn{3}{|c|}{ sig. of difference in } \\
\hline & & slope & slope $95 \%$ ci & $r$ & sig & $n$ & slope & slope $95 \%$ ci & $r$ & sig & $n$ & slope & elevation & shift \\
\hline [C] & $M_{A}$ & 0.353 & (0.307 0.407) & 0.228 & $* *$ & 188 & 0.392 & $(0.3490 .440)$ & 0.099 & - & 289 & 0.267 & 0.623 & $<0.001$ \\
\hline$[\mathrm{N}]$ & $M_{A}$ & -1.045 & $(-0.916-1.192)$ & -0.403 & $* * *$ & 189 & -0.959 & $(-0.863-1.065)$ & -0.407 & $* * *$ & 293 & 0.313 & 0.994 & 0.003 \\
\hline$[\mathrm{P}]$ & $M_{A}$ & -1.202 & $(-1.052-1.373)$ & -0.388 & $* * *$ & 188 & -1.170 & $(-1.054-1.298)$ & -0.433 & $* * *$ & 290 & 0.751 & 0.525 & 0.001 \\
\hline$[\mathrm{Ca}]$ & $M_{A}$ & -2.284 & $(-1.980-2.635)$ & -0.134 & - & 188 & $(-)$ & $(-)$ & -0.083 & 0.157 & 291 & $(-)$ & $(-)$ & $(-)$ \\
\hline$[\mathrm{K}]$ & $M_{A}$ & -1.616 & $(-1.408-1.855)$ & -0.291 & $* * *$ & 188 & -1.703 & $(-1.527-1.900)$ & -0.323 & $* * *$ & 291 & 0.559 & 0.272 & $<0.001$ \\
\hline$[\mathrm{Mg}]$ & $M_{A}$ & -2.082 & $(-1.806-2.399)$ & -0.179 & $*$ & 188 & -2.194 & $(-1.957-2.461)$ & -0.124 & $*$ & 291 & 0.570 & 0.365 & $<0.001$ \\
\hline [Al] & $M_{A}$ & $(-)$ & $(-)$ & 0.087 & 0.232 & 190 & 6.775 & $(6.0427 .596)$ & 0.133 & $*$ & 291 & $(-)$ & $(-)$ & $(-)$ \\
\hline$\delta^{13} \mathrm{C}$ & $M_{A}$ & 0.117 & $(0.1010 .135)$ & 0.126 & - & 184 & $(-)$ & $(-)$ & 0.025 & 0.667 & 293 & $(-)$ & $(-)$ & $(-)$ \\
\hline$[\mathrm{N}]$ & {$[\mathrm{C}]$} & 2.956 & (2.562 3.411) & 0.122 & - & 188 & $(-)$ & $(-)$ & 0.064 & 0.277 & 290 & $(-)$ & $(-)$ & $(-)$ \\
\hline$[\mathrm{P}]$ & {$[\mathrm{C}]$} & $(-)$ & $(-)$ & 0.116 & 0.113 & 188 & $(-)$ & $(-)$ & -0.086 & 0.146 & 289 & $(-)$ & $(-)$ & $(-)$ \\
\hline$[\mathrm{Ca}]$ & [C] & -6.462 & $(-5.658-7.381)$ & -0.387 & $* * *$ & 188 & -5.679 & $(-5.154-6.257)$ & -0.546 & $* * *$ & 290 & 0.123 & 0.182 & $<0.001$ \\
\hline$[\mathrm{K}]$ & [C] & -4.572 & $(-3.998-5.228)$ & -0.368 & $* * *$ & 188 & -4.346 & $(-3.923-4.814)$ & -0.467 & $* * *$ & 290 & 0.555 & 0.536 & $<0.001$ \\
\hline$[\mathrm{Mg}]$ & {$[\mathrm{C}]$} & -5.888 & $(-5.147-6.737)$ & -0.359 & $* * *$ & 188 & -5.608 & $(-5.063-6.212)$ & -0.470 & $* * *$ & 290 & 0.571 & 0.598 & $<0.001$ \\
\hline$\delta^{13} \mathrm{C}$ & {$[\mathrm{C}]$} & 0.330 & $(0.2860 .381)$ & 0.146 & $*$ & 183 & $(-)$ & $(-)$ & -0.059 & 0.315 & 290 & $(-)$ & $(-)$ & $(-)$ \\
\hline$[\mathrm{P}]$ & {$[\mathrm{N}]$} & 1.150 & (1.030 1.284) & 0.648 & $* * *$ & 188 & 1.217 & $(1.1201 .323)$ & 0.698 & $* * *$ & 289 & 0.419 & 0.387 & 0.002 \\
\hline [Ca] & {$[\mathrm{N}]$} & $(-)$ & $(-)$ & -0.015 & 0.838 & 188 & $(-)$ & $(-)$ & 0.090 & 0.127 & 290 & $(-)$ & $(-)$ & $(-)$ \\
\hline$[\mathrm{K}]$ & {$[\mathrm{N}]$} & 1.547 & $(1.3401 .784)$ & 0.127 & - & 188 & 1.767 & (1.579 1.978) & 0.230 & $* * *$ & 290 & 0.151 & 0.318 & $<0.001$ \\
\hline$[\mathrm{Mg}]$ & {$[\mathrm{N}]$} & $(-)$ & $(-)$ & -0.055 & 0.454 & 188 & 2.280 & $(2.0322 .559)$ & 0.103 & - & 290 & $(-)$ & $(-)$ & $(-)$ \\
\hline$\delta^{13} \mathrm{C}$ & {$[\mathrm{N}]$} & 0.111 & $(0.0970 .128)$ & 0.277 & $* * *$ & 184 & 0.101 & $(0.0900 .113)$ & 0.240 & $* * *$ & 293 & 0.263 & 0.008 & 0.221 \\
\hline$[\mathrm{Ca}]$ & {$[\mathrm{P}]$} & $(-)$ & $(-)$ & 0.046 & 0.530 & 188 & 1.896 & $(1.6942 .121)$ & 0.229 & $* * *$ & 291 & $(-)$ & $(-)$ & $(-)$ \\
\hline$[\mathrm{K}]$ & {$[\mathrm{P}]$} & 1.345 & $(1.1781 .535)$ & 0.394 & $* * *$ & 188 & 1.441 & $(1.3051 .592)$ & 0.507 & $* * *$ & 291 & 0.412 & 0.524 & $<0.001$ \\
\hline$[\mathrm{Mg}]$ & {$[\mathrm{P}]$} & $(-)$ & $(-)$ & 0.067 & 0.363 & 188 & 1.858 & (1.661 2.079) & 0.242 & $* * *$ & 291 & $(-)$ & $(-)$ & $(-)$ \\
\hline$\delta^{13} \mathrm{C}$ & {$[\mathrm{P}]$} & -0.099 & $(-0.087-0.114)$ & -0.349 & $* * *$ & 183 & -0.082 & $(-0.073-0.092)$ & -0.242 & $* * *$ & 290 & 0.033 & $(-)$ & $(-)$ \\
\hline$[\mathrm{Mg}]$ & {$[\mathrm{Ca}]$} & 0.911 & $(0.8161 .018)$ & 0.643 & $* * *$ & 188 & 0.987 & (0.905 1.076) & 0.660 & $* * *$ & 292 & 0.266 & 0.311 & $<0.001$ \\
\hline$\delta^{13} \mathrm{C}$ & {$[\mathrm{Ca}]$} & $(-)$ & $(-)$ & 0.095 & 0.201 & 183 & 0.043 & $\left(\begin{array}{lll}0.038 & 0.048)\end{array}\right.$ & 0.223 & $* * *$ & 291 & $(-)$ & $(-)$ & $(-)$ \\
\hline$[\mathrm{Ca}]$ & {$[\mathrm{K}]$} & 1.413 & (1.242 1.608) & 0.447 & $* * *$ & 188 & 1.307 & (1.179 1.449) & 0.450 & $* * *$ & 292 & 0.352 & 0.493 & $<0.001$ \\
\hline$[\mathrm{Mg}]$ & {$[\mathrm{K}]$} & 1.288 & (1.140 1.455) & 0.534 & $* * *$ & 188 & 1.290 & (1.175 1.415) & 0.591 & $* * *$ & 292 & 0.987 & 0.888 & $<0.001$ \\
\hline$\delta^{13} \mathrm{C}$ & {$[\mathrm{K}]$} & $(-)$ & $(-)$ & 0.106 & 0.154 & 183 & $(-)$ & $(-)$ & 0.085 & 0.150 & 291 & $(-)$ & $(-)$ & $(-)$ \\
\hline$\delta^{13} \mathrm{C}$ & {$[\mathrm{Mg}]$} & $(-)$ & $(-)$ & 0.065 & 0.386 & 183 & 0.044 & $\left(\begin{array}{ll}0.039 & 0.049)\end{array}\right.$ & 0.146 & $*$ & 291 & $(-)$ & $(-)$ & $(-)$ \\
\hline
\end{tabular}

after taking into account the likely spatial autocorrelation discussed in Appendix A, is probably not significantly related to $\varphi_{F}$. Likewise for $\delta^{13} \mathrm{C}$ the relationship with $\varphi_{F}$ was relatively weak, though still of interest.

In a similar manner, Fig. 7 illustrates the strongest relationships found between the various plot effects and climate. Three likely significant plot effects related to mean annual temperature $\left(T_{a}\right.$, ) were observed, namely a decline in leaf nitrogen (Fig. 7a), leaf phosphorus (Fig. 7b) and K (Fig. 7c) with increasing temperature. Figure $7 d-h$ shows the most important relationships with mean annual precipi- tation, $P_{a}$, with a strong positive relationship observed with $M_{A}$ (Fig. 7d), [C] (Fig. 7e) and a negative slope for [Mg] (Fig. 7g). Figure $7 \mathrm{f}$ and $\mathrm{h}$ shows less dramatic, though potentially important relationships with precipitation for the [P] and $\delta^{13} \mathrm{C}$ plot effects respectively.

Table 4 lists Kendall's partial rank coefficients $\left(\tau_{P}\right)$ for the various plot effects examined as related to $\varphi_{F}, \varphi_{T}, T_{a}, P_{a}$ and mean annual radiation, $Q_{a}$. In all cases the coefficient given is for the one factor after controlling for the other four. Based on our numerical simulations of the partial $\tau$ sampling distribution quantiles and the issue of spatial autocorrelation 
Table 3. Summary of the Principal Components Analysis for selected soil variables averaged over $0.0-0.3 \mathrm{~m}$ depth. Full details on methods used for soil analysis are provided in Quesada et al. (2009c).

\begin{tabular}{|c|c|c|c|}
\hline Eigenvalue & 6.227 & 2.537 & 1.597 \\
\hline Proportion of total variance & 0.445 & 0.181 & 0.114 \\
\hline $\mathrm{pH}$ & -0.278 & 0.371 & -0.082 \\
\hline $\log _{10}[$ total reserve bases] & -0.328 & -0.072 & 0.050 \\
\hline $\log _{10}[\text { total extractable } \mathrm{P}]^{\mathrm{a}}$ & -0.340 & -0.103 & -0.148 \\
\hline $\log _{10}[$ total N] & -0.290 & -0.095 & -0.514 \\
\hline $\log _{10}[$ total $C]$ & -0.169 & -0.044 & -0.667 \\
\hline $\log _{10}[$ exchangable $\mathrm{Ca}]$ & -0.360 & 0.162 & 0.103 \\
\hline $\log _{10}[$ exchangable $\mathrm{Mg}]$ & -0.367 & 0.083 & 0.202 \\
\hline $\log _{10}[$ exchangable K] & -0.286 & -0.100 & 0.134 \\
\hline $\log _{10}$ [exchangable Na] & -0.140 & -0.135 & -0.022 \\
\hline $\log _{10}[$ exchangable Al] & 0.161 & -0.359 & -0.137 \\
\hline $\log _{10}$ (effective cation exchange capacity) & $-\mathbf{0 . 3 2 9}$ & -0.202 & 0.109 \\
\hline $\log _{10}$ (base saturation) & -0.204 & 0.410 & 0.237 \\
\hline fraction sand & 0.199 & 0.442 & -0.261 \\
\hline fraction clay & -0.077 & -0.491 & 0.187 \\
\hline Axis definition & (in)fertility & texture \&Al & $C \& N$ \\
\hline
\end{tabular}

a Sum of both inorganic and organic fractions extracted by resin, bicarbonate and $\mathrm{NaOH}$ according to a modified Hedley extraction procedure as detailed in Quesada et al. (2009c).

Table 4. Kendall's partial correlation $\tau$ for the environmental contribution (plot effect estimate) of each foliar property with the set of environmental predictors. Kendall's $\tau$ are estimated as described in Legendre and Legendre (1998, pp. 202). Their significance is computed based on Maghsoodloo and Laszlo Pallos $(1981)$. Bold values indicate a very strong correlation $(p<0.001)$ and italics indicate significant correlations at $p<0.01$; see text for details. $M_{A}$ denotes leaf mass per unit area, $\delta^{13} \mathrm{C}$ represents the ${ }^{13} \mathrm{C} /{ }^{12} \mathrm{C}$ composition (per mil) with all other symbols representing the elemental composition of the leaves (dry weight basis).

\begin{tabular}{lrrrrrrrrr}
\hline & $M_{A}$ & {$[\mathrm{C}]$} & {$[\mathrm{N}]$} & {$[\mathrm{P}]$} & {$[\mathrm{Ca}]$} & {$[\mathrm{K}]$} & {$[\mathrm{Mg}]$} & {$[\mathrm{Al}]$} & $\delta^{13} \mathrm{C}$ \\
\hline Fertility $\varphi_{F}$ & -0.201 & -0.233 & 0.204 & $\mathbf{0 . 4 7 5}$ & $\mathbf{0 . 4 7 5}$ & $\mathbf{0 . 3 3 7}$ & 0.220 & 0.097 & 0.203 \\
Texture $\varphi_{T}$ & 0.048 & 0.103 & 0.115 & 0.043 & $-\mathbf{0 . 2 7 2}$ & -0.169 & -0.178 & -0.149 & 0.022 \\
Temperature $T_{a}$ & 0.107 & 0.051 & $\mathbf{- 0 . 3 8 2}$ & -0.256 & -0.081 & $\mathbf{- 0 . 4 0 8}$ & 0.031 & -0.176 & -0.133 \\
Precipitation $P_{a}$ & $\mathbf{0 . 3 2 9}$ & $\mathbf{0 . 3 0 0}$ & -0.178 & 0.171 & -0.010 & 0.113 & $-\mathbf{0 . 3 0 6}$ & 0.016 & 0.244 \\
Radiation $Q_{a}$ & -0.058 & 0.152 & 0.018 & 0.117 & -0.140 & 0.075 & 0.003 & -0.139 & 0.119 \\
\hline
\end{tabular}

discussed above, we suggest that $\tau_{P}>0.23$ (approximately relating to the probability of a Type II error, $P$, being less than 0.01) should be taken as a minimum criterion for statistical significance with $\tau_{P}>0.31$ almost certainly indicating a meaningful correlative relationship $(P<0.001)$. Nevertheless, relationships with $0.17<\tau_{P}<0.23$ cannot be entirely discounted.

Table 4 shows that very strongly related to $\varphi_{F}$ were the plot effects for [P], [Ca] and [K], and, with the exception of [Al], the other parameters examined also had close to significant relationships with $M_{A}$, [C] declining somewhat with increased soil fertility and $\delta^{13} \mathrm{C}$ increasing. On the other hand, only the [Ca] plot effect was significantly associated with $\varphi_{T}$ although all other cations (including [Al]) did show trends in the same direction, viz a decline with increasing soil sandiness and/or higher soil $\mathrm{pH}$. Of the climatic parameters, $Q_{a}$, showed no meaningful associations, but $[\mathrm{N}],[\mathrm{P}]$ and $[\mathrm{K}]$ were all negatively associated with $T_{a}$. There were several strong relationships detected with $P_{a}$; in particular an increase in both $M_{A}$ and [C] with increasing precipitation, and with significant declines in $[\mathrm{Mg}]$ and less negative $\delta^{13} \mathrm{C}$ as $P_{a}$ increased.

\section{Discussion}

Suites of plant traits are often used to infer the functioning and performance of different species (Westoby et al., 2002) as well as to identify potential evolutionary pathways of trait variation (Reich et al., 2003; Ackerly, 2003). Among the 
range of functional characters some are regarded as highly conservative while others are considered more plastic. Identifying the variation of different functional traits among and within different evolutionary affinities and exploring the way these plant functional characteristics vary across environmental gradients should help us to understand the functioning of different ecosystems and their responses to global change.

\subsection{Genetic and environmental variation in leaf foliar properties of Amazon trees}

Analyses of global (Wright et al., 2004) and regional (Fonseca et al., 2000; Wright et al., 2001) datasets have highlighted that a large portion of the variation observed in $M_{A}$, $[\mathrm{N}]$ and $[\mathrm{P}]$ is found between species within a common environment. Data from north-west Amazonia presented a thirtyfold variation in leaf longevity and a three-fold variation in $M_{A}$ and [N] in adjacent communities (Reich et al., 1991) with Townsend et al. (2007) highlighting the importance of local-scale species diversity as an important component controlling the variation of foliar N:P ratio. Our results place a special emphasis on this variability, covering considerable tree species diversity across an ecosystem-wide climate and soil gradient. A ten-fold range of variation was identified for $M_{A}$, covering a similar range (30 to $300 \mathrm{~g} \mathrm{~m}^{-2}$ ) as a recent worldwide review (Poorter et al., 2009). At the same time $[\mathrm{N}]$ and $[\mathrm{P}]$ presented a six-fold and a seventeen-fold range respectively. Significant differences in average $M_{A}$, $[\mathrm{N}]$ and $[\mathrm{P}]$ exist between many families as well as varying with genera within several of the more widely abundant ones (Figs. B1 and B2).

In our dataset some properties like $M_{A}$, and leaf [C], [N], $[\mathrm{Mg}]$ and $[\mathrm{Al}]$ seem to be more strongly genetically than environmentally constrained, with much of their variation attributable to their phylogenetic grouping (Fig. 2). For example approximately $0.07,0.11$ and 0.19 of the total variation in $M_{A}$, is apportioned to the family, genus and species component respectively (i.e. 0.37 of the total variance is attributable to genotype) and only 0.15 is due to the location of an individual. At the other end, traits such as $[\mathrm{P}],[\mathrm{Ca}]$ and $[\mathrm{K}]$ had a much higher level of plasticity, with $0.47,0.41$ and 0.47 of the respective variation being attributed to the site at which the leaf was measured, and thus suggesting a strong environmental control.

For the cations, significant genetic variation has been observed before for both herbaceous (Thompson et al., 1997) and woody (Dauer et al., 2007) plant communities (see also Broadley et al., 2004). Much of the genetically controlled variation in $[\mathrm{Ca}]$ and $[\mathrm{Mg}]$ seems to be mediated through differences in cation exchange capacities of cell walls (Demarty et al., 1984; White and Broadley, 2003), which are themselves strongly influenced by genetic variations in pectin and galacturonic acid chemistry (Kirkby and Pilbeam, 1984; Sattelmacher, 2001). Nevertheless, even though the uptake of both cations is clearly genetically controlled and with some evidence of similar transport mechanisms (Broadley et al., 2008), $\mathrm{Mg}^{2+}$-specific transport genes also exist (Gardner, 2003). This is consistent with the much greater plot effect for calcium observed here (Fig. 2) with $\mathrm{Mg}^{2+}$-uptake likely subject to a much tighter physiological regulation via symplastic transport pathways and hence the relatively lower environmental effect.

It is also intuitive that should an element be limiting for ecosystem function then foliar concentrations should show a strong correlation with variations in its availability within the soil and with the associated environmental component of variation likely being high compared to any genetic component. In this respect the strong environmental components observed for [P], [Ca] and [K] in Fig. 2 and their strong correlation with the fertility axis, $\varphi_{F}$ (Fig. 6), are especially informative. It has, of course, long been argued that phosphorus may be the main element limiting tropical forest productivity (Vitousek, 1984) and analysing the relationship between above-ground growth rates and various soil fertility measures, Quesada et al. (2009b) have also found good evidence supporting this critical role for phosphorus in modulating tropical forest productivity. Nevertheless, from the data presented here it is clear that foliar potassium in particular seems to always correlate strongly with foliar phosphorus (Fig. 5), this also being observed for the genetically dependent relationship with a virtually identical slope (Fig. 4).

\subsection{Scaling relationships and species distributions across the Amazon}

Scaling relationships were identified between all $M_{A} \leftrightarrow$ [nutrient] raw data pairs with the only exception being the $M_{A} \leftrightarrow[\mathrm{Al}]$ pair (Table 1). Additionally for the genetic $M_{A} \leftrightarrow$ [nutrient] pairs common slope SMA axes were identified, indicating similar scaling mechanisms regardless of edaphic conditions (Table 2). Thus at this level, general axes of leaf traits variation expressing the economic spectrum of fast and slow resource turnover are indeed valid for Amazonian forests (Table 1, middle panel).

However there is a clear distinction in the inherent physiological ranges that low and high fertility oriented species operate (Paoli, 2006; Kraft et al., 2008) and this is illustrated by the significant shifts across the common axis of variation identified for the genetic component (Table 2). Thus species which are found on fertile soils tend to be at the fast return (right hand) side of the intrinsic $M_{A} \leftrightarrow$ [nutrient] continuum (Fig. 3). In the raw dataset this distinction was expressed both with significant difference in the intercept and/or shifts of the principal axis or even more in some cases with difference is the SMA slope (Table SI2). This was also shown for $[N]$ vs. [P] by Townsend et al. (2007). Shifts in the intercept of the raw data SMA seem to be controlled by the environmental contribution of trait variation, as no such difference was identified in the genetic scaling. Thus the environment 
within which a plant is growing clearly affects the nature of the $M_{A} \leftrightarrow$ [nutrient] relationship.

Across the Amazon Basin there are two well-recorded gradients of resource availability, namely a northeast to southwest gradient of soil fertility (Quesada et al., 2009b) and a northwest to southeast gradient in precipitation and dry season length (Sombroek, 2001; Malhi and Wright, 2004). Tree species distributions (ter Steege et al., 2006), diversity (ter Steege et al., 2006) and forest turnover (Phillips et al., 2004) all follow these gradients, with westerns forests being more dynamic and with faster growth rates (Malhi et al., 2004; Phillips et al., 2004; Quesada et al., 2009b). Results here suggest that these gradients are reflected in foliar characteristics as well as other functional properties (Patiño et al., in preparation; Baker et al., 2009). Specifically, species on richer soils tend to have intrinsically lower $M_{A}$, and intrinsically higher leaf nutrient concentrations compared with species on poor soils. Of special interest are the identified shifts across the principal axis of genetic variation, supporting the "habitat tracking" hypothesis (Ackerly, 2003). We suggest that specific trait dimensions systematically change along soil fertility gradients.

Our sampling strategy and subsequent analyses were not designed to specifically explore niche separation mechanisms occurring across the RAINFOR plots. Nevertheless, the clear shift in the genetic component of foliar traits associated with rich or poor soils implies that soil fertility exerts a fundamental role in modulating community composition across Amazonia. As is also discussed in Fyllas and Lloyd (2009), it seems potential resourced-based tree niche differentiation processes are accompanied by specific suites of functional foliar and other properties. The unbalanced nature of our data-sampling with more than half of the species (303) being measured only once, is unlikely to have given rise to biased species effect estimates driven by the environmental conditions of the site (Supplementary Information II: http://www.biogeosciences.net/6/2677/2009/ bg-6-2677-2009-supplement.zip). However, these correlations could have arisen through a small number of ancient events, and subsequent diversification from common ancestors that colonised rich and poor soils respectively. Alternatively, habitat specialisation may have repeatedly driven diversification in a large range of clades, such as in the Burseraceae (Fine et al., 2005). Distinguishing these hypotheses will require mapping the genetic component of species traits onto their phylogenetic relationships and assessing whether the genetic component of these trait values show overdispersed or clustered distributions (Cavendar-Bares et al., 2006).

\subsection{Environmental predictors of foliage properties variation}

Although there have been several previous studies investigating effects of climate and/or soil conditions on foliar trait combinations (e.g. Fonseca et al., 2000; Wright et al., 2004, 2005a; Townsend et al., 2007) all of these have treated the measured values of the traits examined as being genetically determined, often pooling several values into a single set of values for the one species. We have taken a different approach here, allowing for the traits observed for any given species to vary with location by utilising the REML methodology. A similar statistical approach has been independently undertaken by Watanabe et al. (2007) in an analysis of evolutionary controls of plant nutrient composition. They fitted a REML model of a similar form, also using random terms only (in their case "site + clade/family/species"), though in their study they were more interested in partialing out any site effects, rather than, as in our case, trying to quantify and understand them. Our approach of quantifying both the genetic and environmental components through REML is a valid one despite the strongly unbalanced nature of the data set employed (see Supplementary Information II) and occurs because about half of the species in the dataset occurred in more than one plot. This species/plot overlap allows for a direct estimate of plot-environmental effects as well as estimates of the genetic effects of these species occurring in more than one plot. These plot effect estimates, once subtracted from the raw observations, then allow for "genetic effects" to be estimated for those species occurring only once in the dataset. A nested genetic variance structure used within a REML context to analyse the genetic variations observed (in our case "family/genus/species") has previously been recognised by other workers and extensively applied in phylogenetic analyses (Broadley et al., 2004).

By combining the non-spatial and spatially explicit regression models of the plot-level effects and then using this information to help us interpret the partial Kendall's $\tau$, soil fertility emerges as a key axis of association between leaf level nutrient variation and environmental factors. Soil fertility was positively related with leaf nutrient concentrations and negatively associated with $M_{A}$ and with leaf [C] (Fig. 6). Based on studies with soil nutrients and/or investigations on the effects of variations in soil fertility on tropical tree leaf nutrient concentrations (Montagini, 2000; Webb et al., 2000; Specht and Turner, 2006), increased foliar nutrient concentrations for any given species on more fertile soils are not all that surprising. What is more interesting is the coordinated response of $M_{A}$ and [C]. Clearly for any given species considerable plasticity exists. Leaf structure and physiology can vary together with the wider ranging species investing fewer resources into structural carbon and $M_{A}$ under high nutrient conditions.

Plot level variation in $M_{A}$ and leaf [C] also showed a strong positive trend with increasing precipitation, with a significant decline in leaf $[\mathrm{Mg}]$ also observed (Fig. 7). This increase in $M_{A}$ with increased moisture availability contrasts with the generally accepted pattern for evergreen species where $M_{A}$ declines with increasing rainfall (Wright et al., 2005a). Nevertheless, it might be explicable on the basis 
of higher $M_{A}$ leaves being structurally more robust and thus more resistant to the increased intensities of pathogen and herbivore attack which would be expected in the less seasonal and higher rainfall environments. Consistent with this idea is the increase in [C] also observed with increasing precipitation, pointing to an increased investment of carbon in constitutive compounds, as has been reported, for example to occur for lignin and phenolics (though in this case across different life forms and with a reduction rather than an increase in $M_{A}$ ) in northern Patagonia (Bertiller et al., 2006).

More difficult to explain is the observed decrease in $[\mathrm{Mg}]$ with increasing precipitation. Perhaps there are changes in cell wall carbohydrate chemistry associated with increased foliar defences (Vorwerk et al., 2004) at higher precipitation sites. This would likely be achieved through changes in cell wall structure as mediated, for example, by pectin methylesterase (Pelloux et al., 2007). If so, such differences would be expected to give rise to substantial changes in cell wall ionic properties and, in particular, associated changes in foliar magnesium contents (Pilling et al., 2004).

It is also interesting to note that the three foliar properties showing significant changes with precipitation, viz $M_{A}$, [C] and $[\mathrm{Mg}]$, are also those for which the overall environmental contribution to the observed variance were all but the lowest, but with a substantial genetic contribution to the variation observed (Fig. 2). This suggests that rather than being directly caused by precipitation per se, the "precipitation effect" as calculated might actually reflect phenotypically distinct populations. Such intraspecific variation has been observed before for woody species. For example, in a "common garden" experiment using fifteen distinct populations of red ironbark (Eucalyptus sideroxylon subsp. tricarpa) in Australia, Warren et al. (2005) found considerable between inter-population variability (i.e. phenotypic plasticity) for both $M_{A}$ and [N] and with some of this variation attributable to seed-source precipitation regime. Despite the notoriously high biodiversity of Amazon forest (Hubbell et al., 2008) there is no reason why such intra-specific variation should not occur for at least some of the species growing there, as has been shown for different populations of Costa Rican Cedrela odorata for example (Gillies et al., 1997; Navarrro et al., 2002).

Environmental effects on leaf $\mathrm{N}$ concentration were negatively related with annual mean temperature (Fig. 7). This result is in agreement with the global scale prediction of leaf nitrogen decreasing with temperature (Reich and Oleskyn, 2004), supporting the "Temperature-Plant Physiology Hypothesis" (Woods et al., 2003) which argues that plants at lower temperatures should show higher concentrations of physiologically relevant compounds in order to compensate for repressed rates of fundamental biochemical processes. Even after removing the genetic $\mathrm{N}$ component of species adapted and established to more fertile environments and accounting for the potential existence of spatial autocorrelation phenomena, the negative effect of temperature on foliar [N] remained highly significant (Table A1) as was also the case for [P] from the partial Kendall's $\tau$ analysis (Table 4).

\subsection{Amazonian axes of trait coordination in a global context}

Concentrating on the genetic component, it is interesting to compare the slopes of the bivariate relationships we have observed with those proposed to operate globally (Wright et al., 2004). Here we note that for the (aggregated) genetic component of trait variation we observed $[\mathrm{N}] \leftrightarrow M_{A}$ slopes (with confidence intervals in brackets) of $-0.99(-0.91$ to -1.07$)$ slightly steeper than that of Wright et al. (2004), who (taking reciprocal values from the $M_{A} \leftrightarrow[\mathrm{N}]$ slopes, their Table 1) reported a value of $-0.78(-0.76$ to -0.81$)$. If we accept that the negative $[\mathrm{N}] \leftrightarrow M_{A}$ scaling relationship occurs because higher $M_{A}$ leaves invest a greater proportion of their biomass in structural rather than metabolic compartments (Reich et al., 1999), then this suggests that higher $M_{A}$ tropical tree species may retain a lesser amount of nitrogen in structural compartments such as cell walls. It is well known that cell wall $\mathrm{N}$ contents can vary substantially (Lamport, 1965; Takashima et al., 2004) with several classes of cell wall protein with an important role in disease resistance (Showalter, 1993; de Bruxelles and Roberts, 2001). It is, however less likely that this nitrogen-based defensive strategy, would be employed for species characteristic of the more infertile soils (including white sands) as some evidence for N-deficiency exists (Quesada et al., 2009c). According to the Carbon: Nutrient Balance Hypothesis (CNB: Bryant et al., 1993), C-based constitutive defences would be expected to be more prevalent as has shown to be the case by Fine et al. (2006). Consistent with this idea is the significant positive [C] $\leftrightarrow M_{A}$ relationship observed for species found on low fertility soils. This may be accountable for in terms of high $M_{A}$ leaves having a greater investment in carbon based defensive compounds such as phenols, lignin and tannin, all of which have a relatively high carbon content (Poorter and Villar, 1997). A critical discussion of the CNB and other relevant plant defence hypotheses as related to plant genotypic characteristics and edaphic limitations may be found in Stamp (2003).

In contrast to $[\mathrm{N}] \leftrightarrow M_{A}$ our genetic scaling slopes for $[\mathrm{P}] \leftrightarrow M_{A}$, of $-1.17(-1.08$ to -1.27$)$ are all but identical to the Wright et al. (2004) global estimate of $-1.22(-1.16$ to -1.28 ) suggesting stronger similarities between Amazon forest trees and other terrestrial plants. The steeper negative slope for the $[\mathrm{P}] \leftrightarrow M_{A}$ relationship as compared to that for $[\mathrm{N}] \leftrightarrow M_{A}$ may be explained by the presence of still appreciable amounts of $\mathrm{N}$, but not $\mathrm{P}$, in structural tissues such as cell walls (Showalter, 1993; Gabriel and Kesselmeir, 1999; White and Hammond, 2008), the proportion of which should generally increase as $M_{A}$ increases. Also important may be the ability for low $\mathrm{P}$ requiring species to exhibit a more conservative use of phosphorus in their metabolically active tissues, for example, through employing organic acids rather than 
inorganic phosphate to maintain ionic balance in the vacuole, and through substitution of phospholipids with galactolipids and sulpholipids in thylakoid and extraplastidic membranes (Amtmann et al., 2006; White and Hammond, 2008).

Research quantifying relationships between metabolically active tissue properties, for example $[\mathrm{N}]$ and $[\mathrm{P}]$, and linking these with the way annual growth rate scales with plant mass, has received some attention in recent years, with modellers in this area attempting to provide a modelling framework to predict the way trees accumulate resources (Niklas et al., 2005; Niklas, 2006, 2008). Recent modelling exercises (Kerkhoff et al., 2005, 2006; Kerkhoff and Enquist, 2006) are based on a perceived strong association between leaf $[\mathrm{N}]$ and $[\mathrm{P}]$, according to a $2 / 3$ (Wright et al., 2004) or $3 / 4$ power law (Niklas et al., 2005). Whilst not necessarily endorsing the generality of such exercises, it is of some interest to see how our observations fit with the conceptual constructs. Our results verify the strong $[\mathrm{N}] \leftrightarrow[\mathrm{P}]$ relationship, on both fertile and infertile Amazonian soils. This scaling relationship was significant both in the raw data analyses (Tables 1 and SI2) and in the analyses of the multilevel effect estimates (Tables 1 and 2). The aggregated raw data estimate for the $[\mathrm{N}] \leftrightarrow[\mathrm{P}]$ scaling exponent is $(0.58-0.64)$, whereas, as was similarly found by Townsend et al. (2007), for low fertility sites the estimated N:P slope (in our case $0.77-0.93)$ is clearly higher than for high fertility sites $(0.63-$ $0.73)$. Scaling of the genetic component of leaf $[\mathrm{N}] \leftrightarrow[\mathrm{P}]$ is calculated at (0.78-0.97) and (0.76-0.89) for species found on low and high fertility sites respectively with Table 1 suggesting a value of $0.85(0.80,0.91)$ for the population as a whole. Thus although the raw data analyses, with environmental effects contribution included, seem reasonably close to the $2 / 3$ power law, the analyses of the genetic component clearly show that the $2 / 3$ power law is not adequate for expressing the $\mathrm{N}: \mathrm{P}$ scaling of Amazonian trees. Indeed, the exponent seems to even be a bit larger than $3 / 4$. The above estimates, in conjunction with the large portion of $[\mathrm{P}]$ variance attributed to the plot level (Fig. 2), underline the importance of soil conditions in influencing N:P ratios as is discussed further below.

In addition to $[\mathrm{N}]$ and $[\mathrm{P}]$ we also examined the relationships of [Ca], $[\mathrm{K}],[\mathrm{Mg}]$ and [Al] with $M_{A}$ as well as relationships between the various foliar nutrient concentrations, again separating genetic versus environmental effects. Considering genetic effects first: As was reported by Wright et al. (2005b) we found a reasonably strong relationship $(r=0.45)$ between $[\mathrm{K}]$ and $[\mathrm{P}]$ but our slope of 1.40 was nearly twice as high as their slope of 0.78 . This is probably due to the relatively low [P] in Amazon forest leaves (Lloyd et al., 2009b), meaning that phosphate ions are less often employed as reserve anions in the vacuole (where they would be normally balanced by $\mathrm{K}^{+}$and other cations) and with a greater proportion of foliar $\mathrm{P}$ assigned to the photosynthetic apparatus than is usually the case (White and Hammond, 2008). This would also mean that $[\mathrm{K}]$ should also scale with
$[\mathrm{P}]$ with a higher exponent than is generally observed. Notably the $[\mathrm{K}] \leftrightarrow[\mathrm{N}]$ genetic relationship was markedly less strong $(\mathrm{r}=0.178)$, although our slope of 1.65 was closer to the 1.19 reported in Wright et al. (2005b) than was the case for phosphorus.

The very strong genetic $[\mathrm{Ca}] \leftrightarrow[\mathrm{Mg}]$ association observed here has also been observed on other studies (Thompson et al., 1997; Broadley et al., 2004) and may be attributable to the chemical similarities between these two divalent cations and a general lack of selectivity during cation uptake by plants (White, 2001; Broadley et al., 2004). It is also likely that these two cations share, to a large extent, the same membrane transporters (Broadley et al., 2008). There were also very strong negative relationships between the concentration of $[\mathrm{Ca}],[\mathrm{Mg}]$ and $[\mathrm{K}]$ with $[\mathrm{C}]$, with significant shifts existing between low and high fertility plants. This has been observed before for a range of species (Poorter and de Jong, 1999) and may reflect an underappreciated dimension of the leaf economic spectrum, which reflects a continuum of strategies for leaf construction, ranging from the use of relatively cheap components (minerals) to more expensive carbon based constituents such as lignin. The latter strategy would also likely be associated with increased carbon based defences and other factors associated with long leaf durability such as a high $M_{A}$.

Strong genetic based relationships were also seen between $\delta^{13} \mathrm{C}$ and $[\mathrm{N}]$ and, to a stronger extent with foliar [P] (Table 1). It now seems clear that either $\mathrm{N}$ or $\mathrm{P}$ can limit photosynthetic metabolism in tropical tree species (Domingues et al., 2009) and this lower carbon isotope discrimination for the higher nutrient species suggesting, on average, a lower partial pressure of $\mathrm{CO}_{2}$ in their chloroplasts (Farquhar et al., 1989). This indicates that higher photosynthetic capacities of species characterised by intrinsically high nutrient concentrations are not totally balanced by higher stomatal conductances (Farquhar and Sharkey, 1982), perhaps suggesting form of hydraulic constraint on maximum photosynthetic rates of tropical tree species, even in the absence of soil moisture deficits (Santiago et al., 2004b; Patiño et al., 2009)

\section{Conclusions}

Taken together our results highlight three important points regarding the biogeochemistry of the Amazon basin, as expressed through a set of key tree foliar properties. First, there exists a substantial variability at most levels of the evolutionary grouping of species. This variability depends on the studied foliar property: Some leaf traits are more phylogenetically constrained than others; traits such as foliar [P] showing strong associations with growing conditions and are possibly linked to variations in stand-level productivity. Second, these environmental effects on leaf level nutrient concentrations make the use of general scaling relationships difficult within the Amazon basin, especially if the soil fertility 
variations are not implicitly taken into account. Nevertheless a third point is that the strong genetic correlations between $M_{A}$ and leaf nutrient concentrations underlines the general existence of the "leaf economic spectrum" across the diverse group of Amazonian tree species studied. Although varying along the same trait coordination axes, Amazonian trees also clearly associate with the soil conditions most appropriate for their growth. Species are not randomly distributed across the basin. But, rather, they follow distribution patterns based on an association between genetic trait potential and the availability of environmental resources.

\section{Appendix A}

\section{Multiple linear regressions and autoregressive models analysis of relationships between plot-environmental effect terms and environmental variables}

To deal with spatial autocorrelation issues in the dataset, we explored the results of the multiple linear regressions through the inspection of correlograms and estimation of the global Moran's I (Legendre and Legendre, 1998). Here the presence of spatial autocorrelation could simply reflect a patterned functioning of the plot level effects, i.e. nearby plots contributing similarly to the variation observed. Such a spatially structured environmental effect could arise as a consequence of basin-wide gradients in soil age and fertility (Quesada et al., 2009a, c) and/or precipitation (Malhi and Wright, 2004). Alternatively, it could be driven by species distribution patterns, with a species specific (or at least a functional group specific) effect modulating plot effect response. These two effects point at exogenous or endogenous forces respectively (Legendre and Legendre, 1993), either of which has the potential to give rise to a violation of the assumption of independently distributed errors. This leads to an overestimation of the relevant degrees of freedom as well as to an overestimation of the importance of the environmental variables included in any such analyses (Lennon, 2000). Interpretation of the macroecological patterns through statistical analyses where spatial autocorrelation is present is an issue of active debate (Lennon, 2000; Diniz-Filho et al., 2003), with recent simulations showing that the existence of autocorrelated residuals may not seriously affect parameter estimates (Hawkins et al., 2007).

To address the above issues, in addition to the nonspatially explicit linear models (OLS), we also fitted two simultaneous autoregressive models (SAR) including a spatial error term at a "fine scale" and at a "medium scale" (Lichstein et al., 2002; Kissling and Carl, 2008). Previous spatial analyses of ecological datasets have revealed that in some cases small neighbourhood distances (first-order) SAR models are able to remove the spatial autocorrelation signal (Jetz and Rahbek, 2002), while other studies suggest that larger neighbourhood (higher-order) SARs should be used
(Tognelli and Kelt, 2004). The usual practice for selecting the neighbourhood size in SAR models is to identify, through the inspection of the OLS residuals, the maximum distance of a significant autocorrelation signal and use this distance as a neighbourhood size (Lichstein et al., 2002; Hawkins et al., 2007). Our data revealed discrete maximum distances of spatial signal for each plot effect (determined from the correlograms of the OLS residuals off each parameter of interest) and we thus used a variant neighbourhood size for the medium scale SARs and a common $(50 \mathrm{~km})$ scale for fine scale SARs. We checked the value of the autoregression coefficient $(\lambda)$ in the SAR models; Specifically, if $\lambda$ was found to be significantly different from zero after controlling for the environmental effect, then the autoregressive component (i.e. the neighborhood effect) was deemed important. Furthermore, by inspecting the SAR residual correlograms we identified their ability to remove spatial autocorrelation. At the same time we used a Monte Carlo (999) permutation test for the significance of Moran's I for the initial plot effect estimates and the residuals from the OLS and SAR models. In all cases coefficients for ten distance classes of equal widths $(200 \mathrm{~km})$ are reported - at this distance all classes have an approximately balanced (more than 100) number of pairs (Legendre and Legendre, 1998). For correlograms the local significance of Moran's $I$ at the $j$-th class were corrected with a progressive Bonferroni procedure $\left(a^{*}=a / j\right.$, with $\alpha$ the original significance level set at $\alpha=0.05$ ), while the adjusted significance level for the global Moran's $I$ was $0.005(0.05 / 10$ reflecting the ten distance classes used) for which more information is available in Legendre and Legendre (1998) and Lichstein et al. (2002). The above were implemented with the R libraries $n c f$ (Bjornstad and Falck, 2001) and spdep (Bivand, 2006).

All foliar plot effect estimates had an important spatial pattern as illustrated in the respective maps and tested with the Monte Carlo permutation method at equally distant classes of $200 \mathrm{~km}$, and a global Bonferroni significance level $a *$ of 0.005 (Fig. SIII1: http://www.biogeosciences.net/ 6/2677/2009/bg-6-2677-2009-supplement.zip). This means that spatial autocorrelation needs to be taken into account in any analysis. The results of the non-spatial multiple OLS regression analyses are summarized in the top panel of Table A1, and in the second and third panel we present the results of the SAR models. Correlograms of residuals of all three models are shown in Fig. SIII 2 and the comparative consideration of these models gives some insights to the potential patterns of spatial autocorrelation of each foliar property of interest.

Both the OLS model residuals correlogram (Fig. SIII 2a) and the permutation method (Table A1 - OLS panel "Moran's I") did not identify an important autocorrelation signal in the non-spatial regression of $M_{A}$, with the OLS accounting for 0.42 of the variation in the plot effect $M_{A}$ contribution. The fertility PCA axis, $\varphi_{F}$, and total annual precipitation were the most important environmental predictors. 
Table A1. Coefficient estimates from non-spatially multiple linear regressions (OLS), simultaneous autoregressive models at a common fine scale (SAR FS, FS=50 km) and at variant medium scale (SAR MS), for each foliar property on the set of the environmental predictors. FS SARs had a common neighbourhood size of $50 \mathrm{~km}$, while the MS SARs were at $750 \mathrm{~km}$ for [C], $1000 \mathrm{~km} \mathrm{for} \mathrm{[P]} \mathrm{and} \delta^{13} \mathrm{C}, 1750 \mathrm{~km}$ for [Ca] and [K] and $1900 \mathrm{~km}$ for [Al]. See text and Fig. SIII 2 (http://www.biogeosciences.net/6/2677/2009/bg-6-2677-2009-supplement.zip) for selection of appropriate neighbourhood size. $\lambda$ gives the autoregression coefficient for each SAR (boldface indicate its significant difference from 0, at $p=0.05)$. Moran's I for each model's residuals tested at a global Bonferroni adjusted level (0.005), with 999 Monte Carlo permutations (bold values indicate the existence of spatial autocorrelation in the residuals). Significance levels for environmental predictors estimates: $* * *<0.001, * *<0.01, *<0.05,-<0.1$ and (-) non significant. $M_{A}$ denotes leaf mass per unit area, $\delta^{13} \mathrm{C}$ represents the ${ }^{13} \mathrm{C} /{ }^{12} \mathrm{C}$ composition (per mil) with all other symbols representing the elemental composition of the leaves (dry weight basis). All values had been $\log _{10}$ transformed prior to analysis.

\begin{tabular}{|c|c|c|c|c|c|c|c|c|c|}
\hline OLS & $M_{A}$ & {$[\mathrm{C}]$} & {$[\mathrm{N}]$} & {$[\mathrm{P}]$} & [Ca] & {$[\mathrm{K}]$} & {$[\mathrm{Mg}]$} & [Al] & $\delta^{13} \mathrm{C}$ \\
\hline Intercept & $\begin{array}{c}-9.54 \mathrm{E}-02 \\
* * *\end{array}$ & $\begin{array}{c}-5.78 \mathrm{E}-02 \\
* *\end{array}$ & $\begin{array}{c}\text { 4.39E-01 } \\
* * *\end{array}$ & $\begin{array}{c}-3.09 \mathrm{E}-01 \\
*\end{array}$ & $\begin{array}{c}1.63 \mathrm{E}+00 \\
*\end{array}$ & $\begin{array}{c}\text { 7.34E-01 } \\
(-)\end{array}$ & $\begin{array}{c}1.16 \mathrm{E}-01 \\
* * *\end{array}$ & $\begin{array}{c}3.09 \mathrm{E}+00 \\
*\end{array}$ & $\begin{array}{c}3.78 \mathrm{E}-02 \\
(-)\end{array}$ \\
\hline Fertility, $\varphi_{F}$ & $\begin{array}{c}-1.53 \mathrm{E}-02 \\
* *\end{array}$ & $\begin{array}{c}-5.98 \mathrm{E}-03 \\
* * *\end{array}$ & $\begin{array}{c}1.02 \mathrm{E}-02 \\
-\end{array}$ & $\begin{array}{c}9.07 \mathrm{E}-02 \\
* * *\end{array}$ & $\begin{array}{c}1.26 \mathrm{E}-01 \\
* * *\end{array}$ & $\begin{array}{c}7.09 \mathrm{E}-02 \\
* * *\end{array}$ & $\begin{array}{c}1.79 \mathrm{E}-02 \\
*\end{array}$ & & $\begin{array}{c}3.11 \mathrm{E}-03 \\
-\end{array}$ \\
\hline Texture, $\varphi_{T}$ & & $\begin{array}{c}2.88 \mathrm{E}-03 \\
(-)\end{array}$ & $\begin{array}{c}1.31 \mathrm{E}-02 \\
* *\end{array}$ & & $\begin{array}{c}-4.76 \mathrm{E}-02 \\
*\end{array}$ & $\begin{array}{c}-2.50 \mathrm{E}-02 \\
(-)\end{array}$ & & & \\
\hline Soil Carbon, $\varphi_{C}$ & $\begin{array}{c}-7.19 \mathrm{E}-03 \\
(-)\end{array}$ & $\begin{array}{c}2.58 \mathrm{E}-03 \\
(-)\end{array}$ & & & $\begin{array}{c}-7.05 \mathrm{E}-02 \\
* *\end{array}$ & & $\begin{array}{c}-1.79 \mathrm{E}-02 \\
*\end{array}$ & & \\
\hline Temperature & & & $\begin{array}{c}-1.66 \mathrm{E}-02 \\
* * *\end{array}$ & & $\begin{array}{c}-4.41 \mathrm{E}-02 \\
*\end{array}$ & $\begin{array}{c}-4.15 \mathrm{E}-02 \\
* *\end{array}$ & & $\begin{array}{c}-1.47 \mathrm{E}-01 \\
* *\end{array}$ & $\begin{array}{c}-2.60 \mathrm{E}-03 \\
-\end{array}$ \\
\hline Precipitation & $\begin{array}{c}3.88 \mathrm{E}-05 \\
* * *\end{array}$ & & & $\begin{array}{c}5.23 \mathrm{E}-05 \\
*\end{array}$ & & & $\begin{array}{c}-4.75 \mathrm{E}-05 \\
* * *\end{array}$ & $\begin{array}{c}-7.59 \mathrm{E}-04 \\
* *\end{array}$ & $\begin{array}{c}1.59 \mathrm{E}-05 \\
*\end{array}$ \\
\hline Dry Season Precipitation & & $\begin{array}{c}1.26 \mathrm{E}-04 \\
* * *\end{array}$ & $\begin{array}{c}-1.24 \mathrm{E}-04 \\
-\end{array}$ & & & $\begin{array}{c}6.61 \mathrm{E}-04 \\
*\end{array}$ & & $\begin{array}{c}1.09 \mathrm{E}-02 \\
* * *\end{array}$ & $\begin{array}{c}-9.62 \mathrm{E}-05 \\
(-)\end{array}$ \\
\hline Radiation & & $\begin{array}{c}2.63 \mathrm{E}-04 \\
*\end{array}$ & & $\begin{array}{c}1.11 \mathrm{E}-03 \\
-\end{array}$ & $\begin{array}{c}-2.96 \mathrm{E}-03 \\
* *\end{array}$ & $\begin{array}{c}1.60 \mathrm{E}-03 \\
(-)\end{array}$ & & $\begin{array}{c}8.28 \mathrm{E}-03 \\
*\end{array}$ & \\
\hline$R^{2}$ & 0.418 & 0.362 & 0.498 & 0.568 & 0.601 & 0.488 & 0.376 & 0.346 & 0.305 \\
\hline Moran's I & 0.053 & 0.394 & -0.049 & 0.173 & 0.425 & 0.460 & 0.143 & 0.477 & 0.469 \\
\hline SAR FS & $M_{A}$ & {$[\mathrm{C}]$} & {$[\mathrm{N}]$} & {$[\mathrm{P}]$} & {$[\mathrm{Ca}]$} & {$[\mathrm{K}]$} & {$[\mathrm{Mg}]$} & {$[\mathrm{Al}]$} & $\delta^{13} \mathrm{C}$ \\
\hline Intercept & & $\begin{array}{c}-2.73 \mathrm{E}-02 \\
(-)\end{array}$ & & $\begin{array}{c}-1.69 \mathrm{E}-01 \\
(-)\end{array}$ & $\begin{array}{c}1.19 \mathrm{E}+00 \\
-\end{array}$ & $\begin{array}{c}-4.00 \mathrm{E}-01 \\
(-)\end{array}$ & & $\begin{array}{c}1.34 \mathrm{E}+00 \\
(-)\end{array}$ & $\begin{array}{c}6.77 \mathrm{E}-02 \\
-\end{array}$ \\
\hline Fertility, $\varphi_{F}$ & & $\begin{array}{c}-4.97 \mathrm{E}-03 \\
* * *\end{array}$ & & $\begin{array}{c}8.26 \mathrm{E}-02 \\
* * *\end{array}$ & $\begin{array}{c}1.29 \mathrm{E}-01 \\
* * *\end{array}$ & $\begin{array}{c}6.10 \mathrm{E}-02 \\
* * *\end{array}$ & & & $\begin{array}{c}3.40 \mathrm{E}-03 \\
* *\end{array}$ \\
\hline Texture, $\varphi_{T}$ & & $\begin{array}{c}3.23 \mathrm{E}-03 \\
*\end{array}$ & & & $\begin{array}{c}-4.45 \mathrm{E}-02 \\
*\end{array}$ & $\begin{array}{c}-4.38 \mathrm{E}-02 \\
* * *\end{array}$ & & & \\
\hline Soil Carbon, $\varphi_{C}$ & & $\begin{array}{c}2.66 \mathrm{E}-03 \\
(-)\end{array}$ & & & $-6.26 \mathrm{E}-02$ & $* *$ & & & \\
\hline Temperature & & & & & $\begin{array}{c}-3.48 \mathrm{E}-02 \\
(-)\end{array}$ & $\begin{array}{c}5.68 \mathrm{E}-03 \\
(-)\end{array}$ & & $\begin{array}{c}-8.91 \mathrm{E}-02 \\
-\end{array}$ & $\begin{array}{c}-3.87 \mathrm{E}-03 \\
* *\end{array}$ \\
\hline Precipitation & & & & $\begin{array}{c}5.41 \mathrm{E}-05 \\
*\end{array}$ & & & & $\begin{array}{c}-8.40 \mathrm{E}-04 \\
* *\end{array}$ & $\begin{array}{c}1.68 \mathrm{E}-05 \\
*\end{array}$ \\
\hline Dry Season Precipitation & & $\begin{array}{c}8.47 \mathrm{E}-05 \\
*\end{array}$ & & & & $\begin{array}{c}1.38 \mathrm{E}-03 \\
* * *\end{array}$ & & $\begin{array}{c}1.21 \mathrm{E}-02 \\
* * *\end{array}$ & $\begin{array}{c}-9.29 \mathrm{E}-05 \\
(-)\end{array}$ \\
\hline Radiation & & $\begin{array}{c}9.83 \mathrm{E}-05 \\
(-)\end{array}$ & & $\begin{array}{c}1.63 \mathrm{E}-04 \\
(-)\end{array}$ & $\begin{array}{c}-1.73 \mathrm{E}-03 \\
(-)\end{array}$ & $\begin{array}{c}4.02 \mathrm{E}-04 \\
(-)\end{array}$ & & $\begin{array}{c}1.01 \mathrm{E}-02 \\
* *\end{array}$ & \\
\hline$\Lambda$ & & 0.483 & & 0.421 & 0.460 & 0.761 & & 0.461 & 0.566 \\
\hline Moran's I & & 0.033 & & 0.018 & 0.030 & 0.023 & & 0.154 & -0.010 \\
\hline SAR MS & $M_{A}$ & {$[\mathrm{C}]$} & {$[\mathrm{N}]$} & {$[\mathrm{P}]$} & {$[\mathrm{Ca}]$} & {$[\mathrm{K}]$} & {$[\mathrm{Mg}]$} & [Al] & $\delta^{13} \mathrm{C}$ \\
\hline Intercept & & $\begin{array}{c}-5.83 \mathrm{E}-02 \\
* *\end{array}$ & & $\begin{array}{c}-2.42 \mathrm{E}-01 \\
-\end{array}$ & $\begin{array}{c}1.71 \mathrm{E}+00 \\
* *\end{array}$ & $\begin{array}{c}\text { 4.14E-01 } \\
(-)\end{array}$ & & $\begin{array}{c}3.54 \mathrm{E}+00 \\
* *\end{array}$ & $\begin{array}{c}\text { 4.45E-02 } \\
(-)\end{array}$ \\
\hline Fertility, $\varphi_{F}$ & & $\begin{array}{c}-6.01 \mathrm{E}-03 \\
* * *\end{array}$ & & $\begin{array}{c}5.97 \mathrm{E}-02 \\
* * *\end{array}$ & $\begin{array}{c}1.13 \mathrm{E}-01 \\
* * *\end{array}$ & $\begin{array}{c}5.87 \mathrm{E}-02 \\
* * *\end{array}$ & & & $\begin{array}{c}3.58 \mathrm{E}-03 \\
*\end{array}$ \\
\hline Texture, $\varphi_{T}$ & & $\begin{array}{c}2.86 \mathrm{E}-03 \\
*\end{array}$ & & & $\begin{array}{c}-3.87 \mathrm{E}-02 \\
-\end{array}$ & $\begin{array}{c}-2.53 \mathrm{E}-02 \\
-\end{array}$ & & & \\
\hline Soil Carbon, $\varphi_{C}$ & & $\begin{array}{c}2.60 \mathrm{E}-03 \\
(-)\end{array}$ & & & $\begin{array}{c}-6.81 \mathrm{E}-02 \\
* *\end{array}$ & & & & \\
\hline Temperature & & & & & $\begin{array}{c}-4.50 \mathrm{E}-02 \\
* *\end{array}$ & $\begin{array}{c}-2.99 \mathrm{E}-02 \\
*\end{array}$ & & $\begin{array}{c}-2.03 \mathrm{E}-01 \\
* * *\end{array}$ & $\begin{array}{c}-2.98 \mathrm{E}-03 \\
*\end{array}$ \\
\hline Precipitation & & & & $\begin{array}{c}5.55 \mathrm{E}-05 \\
* * *\end{array}$ & & & & $\begin{array}{c}-7.94 \mathrm{E}-04 \\
* * *\end{array}$ & $\begin{array}{c}1.82 \mathrm{E}-05 \\
* *\end{array}$ \\
\hline Dry Season Precipitation & & $\begin{array}{c}1.26 \mathrm{E}-04 \\
* * *\end{array}$ & & & & $\begin{array}{c}5.20 \mathrm{E}-04 \\
(-)\end{array}$ & & $\begin{array}{c}1.25 \mathrm{E}-02 \\
* * *\end{array}$ & $\begin{array}{c}-1.21 \mathrm{E}-04 \\
*\end{array}$ \\
\hline Radiation & & $\begin{array}{c}2.66 \mathrm{E}-04 \\
* *\end{array}$ & & $\begin{array}{c}6.51 \mathrm{E}-04 \\
(-)\end{array}$ & $\begin{array}{c}-3.33 \mathrm{E}-03 \\
* * *\end{array}$ & $\begin{array}{c}1.56 \mathrm{E}-03 \\
-\end{array}$ & & $\begin{array}{c}1.35 \mathrm{E}-02 \\
* * *\end{array}$ & \\
\hline$\Lambda$ & & 0.012 & & 0.832 & -2.311 & 0.849 & & -0.856 & -0.622 \\
\hline Moran's $I$ & & 0.392 & & -0.060 & 0.377 & 0.381 & & 0.390 & 0.485 \\
\hline
\end{tabular}


a)

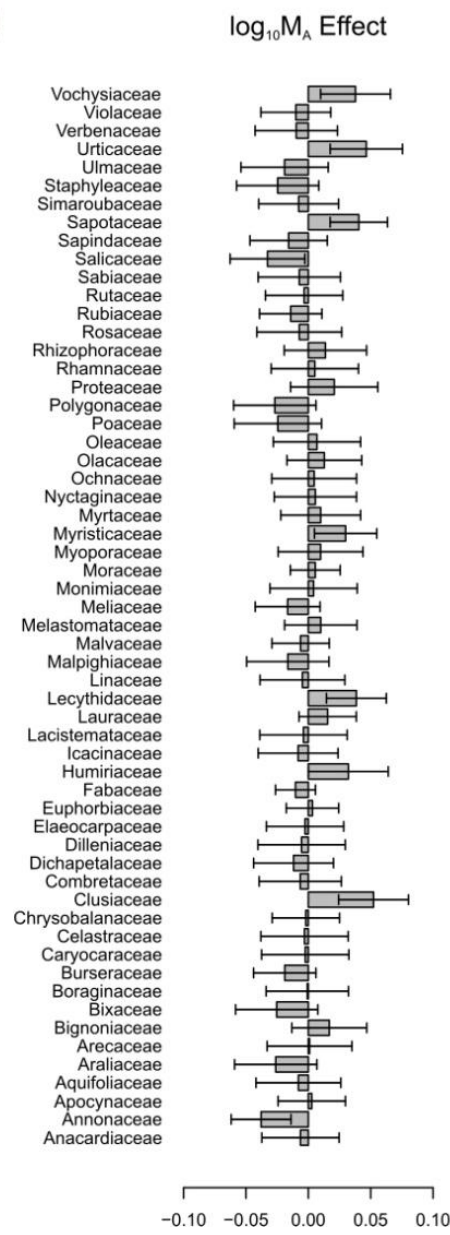

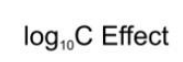
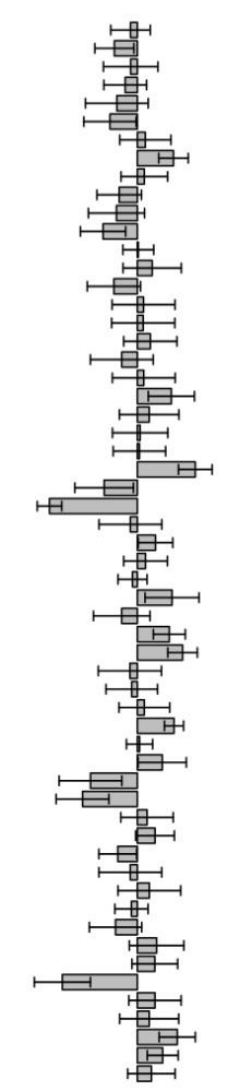

$\log _{10}$ N Effect

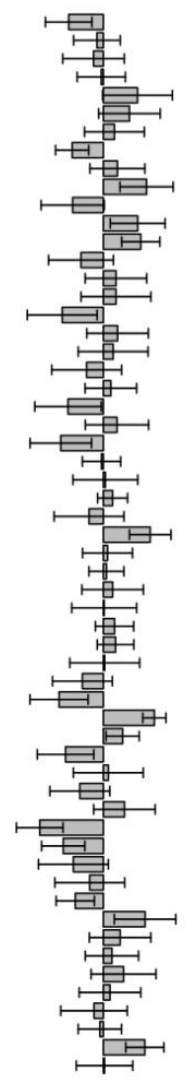

$\log _{10} P$ Effect

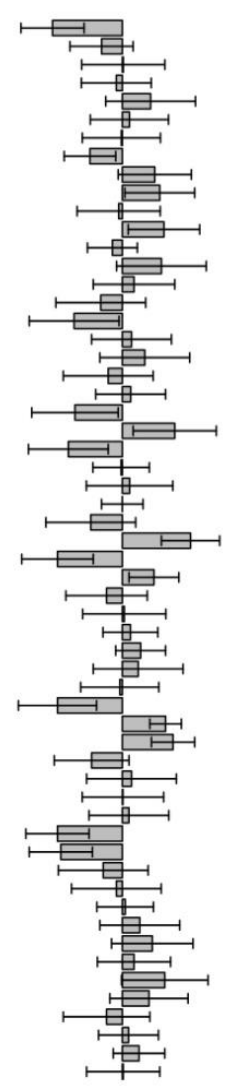

$\log _{10} \delta^{13} \mathrm{C}$ Effect

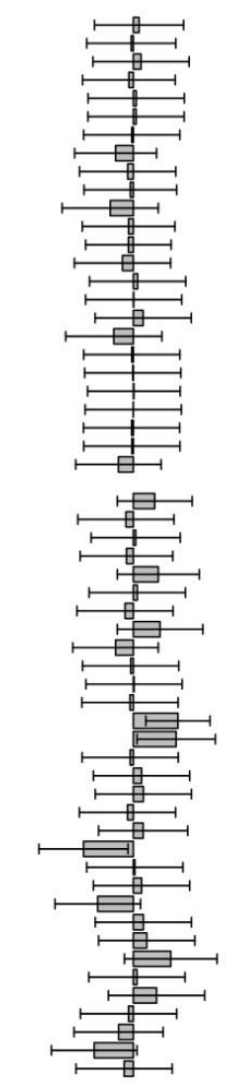

Fig. B1. Family effect \pm standard error estimates of the fitted multilevel model for leaf mass per unit area $\left(M_{A}\right)$ expressed in $\mathrm{g} \mathrm{m}^{-2}$, elemental concentrations (all in $\mathrm{mg} \mathrm{g}^{-1}$ ) and $\delta^{13} \mathrm{C}$ expressed in $\left[\%{ }^{0}\right]$. Note the $\log _{10}$ scale used for all parameters.

As another example we discuss the results for $[\mathrm{Ca}]$ plot effect regressions. The OLS indicated the $\varphi_{F}$ axis, the $\varphi_{T}$ axis, the $\varphi_{C}$ axis, annual temperature and solar radiation as important predictors The residuals of the non-spatial model (Fig. SIII 2b-OLS) and the permutation method for the global Moran's I (Table A1) identified a significant spatial signal in the simple OLS. Thus we proceeded by fitting the fine and medium scale SAR models. The fine scale $(50 \mathrm{~km})$ SAR model removed the spatial autocorrelation from the residuals as indicated by both the respective correlogram (Fig. SIII 2b-SAR50) and the global Moran's I (Table A1 - SAR50 panel). However in this model annual temperature and solar radiation lost their significance, while the rest of the predictors retained their significance with a small difference in their coefficient estimates. Finally the medium scale SAR model seemed not to perform better as it did not manage to remove spatial autocorrelation from the residuals. We thus accepted as the better predictors for [Ca] plot effect the three soil axis.

A similar comparative consideration was undertaken for the OLS and SAR results for other foliar properties, includ- ing $\delta^{13} \mathrm{C}$. In summary, plot level nitrogen and magnesium effects showed no spatial signal in the residuals, and thus the OLS model was considered adequate to describe the main environmental predictors. Plot level $[\mathrm{N}]$ effects were mainly associated with the mean annual temperature and the soil texture axis with a less important contribution of fertility and dry season precipitation. The plot level $[\mathrm{Mg}]$ effect was mainly related with $\varphi_{F}$ and the third $\varphi_{C}$ axis, as well as with annual precipitation. These environmental predictors accounted for a high 0.50 and 0.38 of the total plot effect $[\mathrm{N}]$ and $[\mathrm{Mg}]$ variability respectively.

On the other hand, leaf [C] variation had a strong spatial pattern which affected the residuals of the OLS (Moran's $I=0.39)$. Nevertheless, the fine scale $(50 \mathrm{~km})$ SAR model removed most of this strong spatial signal (Moran's $I=0.03$ ) although this was not the case for the medium scale $(750 \mathrm{~km})$ SAR model (0.39). Nevertheless, the main environmental predictors of the OLS model, namely soil fertility and dry season precipitation remained important in both SAR models, suggesting their valid influence. 
b)

$\log _{10}$ Ca Effect
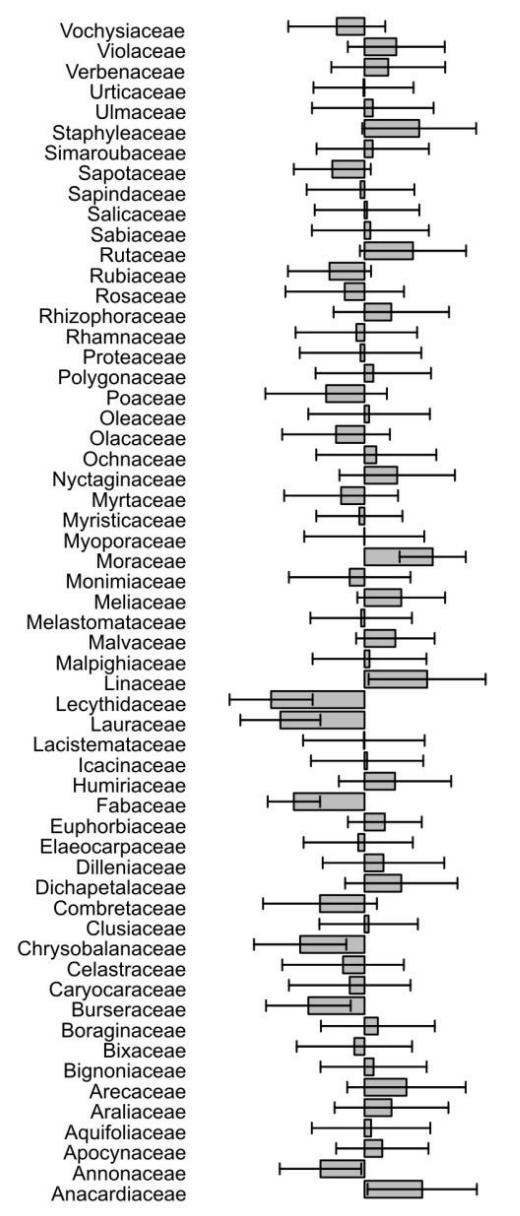

ae

aceae

eae

eae

ae ale

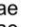

aee

ae

aee

aeae

ae

aeae

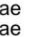
eae ae

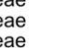
cae ae 西 西

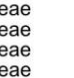
ceae
ceae
ceae eae
eae 作 eae
eae
eae

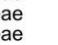
eae

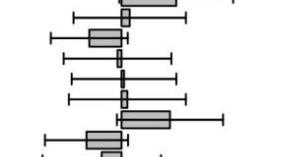

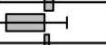
田 (1)
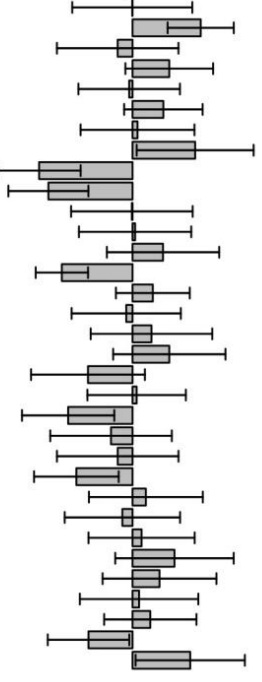

$\log _{10} K$ Effect
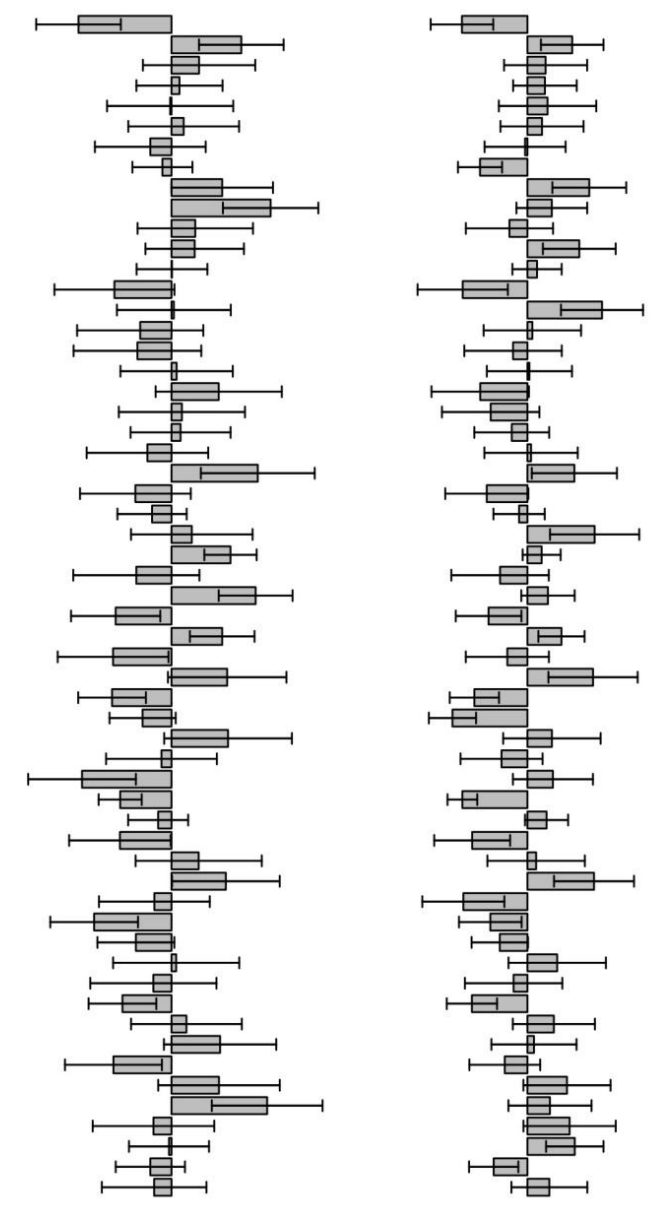

$\log _{10} M g$ Effect

$\log _{10} \mathrm{Al}$ Effect
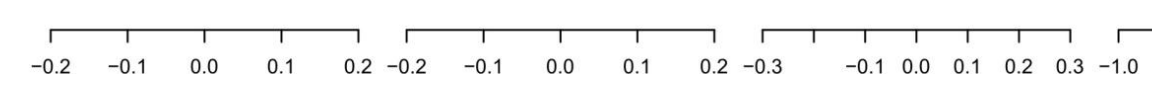

$\begin{array}{lllll}0.0 & 0.5 & 1.0 & 1.5 & 2.0\end{array}$

Fig. B1. Continued.

The residuals of the plot effect $[\mathrm{P}]$ non-spatial regression presented a spatial signal which was effectively removed by both the fine scale $(50 \mathrm{~km})$ and the medium scale $(1000 \mathrm{~km})$ SAR models (Fig. SIII2), and in both cases the autoregression coefficient $\lambda$ was significantly different from zero (Table A1). Following our comparative approach we thus suggest a significant plot level [P] contribution with the soil fertility axis and a weaker one with total annual precipitation.

Plot level $[\mathrm{K}]$ and $[\mathrm{Al}]$ effects had autocorrelated residuals when space was not explicitly taken into account. However no spatial signal in the residuals of the fine scale SARs was identified, and the spatial component as expressed through $\lambda$ was significant in all cases. Following again the comparative consideration of OLS and SAR results we retained as significant the possible associations between $\varphi_{F}, \varphi_{T}$ and dry season precipitation with plot $[\mathrm{K}]$ effect and annual and dry season precipitation as well as solar radiation with plot [Al] effect. Finally the spatial pattern in the OLS residuals for $\delta^{13} \mathrm{C}$ was greatly removed by the fine scale SAR model but not from the medium scale model. The plot $\delta^{13} \mathrm{C}$ effect was mainly related with $\varphi_{F}$, mean annual temperature and total annual precipitation. Summarizing the above we could suggest that the fine scale SAR models seemed more appropriate to account for the spatial patterns of our dataset, and that soil fertility, precipitation and to a lesser extent annual temperature were the main environmental predictors related with most plot effect contributions.

The simple spatial analysis applied, gave us some insights as to the effects of documented soil and climate gradients on the variation of the studied traits. The residuals of the OLS regression for the $M_{A},[\mathrm{~N}]$ and $[\mathrm{Mg}]$ plot level effects did not show any spatial autocorrelation (Fig. SIII 2, Table A1), suggesting that at these scales there was no specific fertility oriented pattern in the environmental contribution to the 

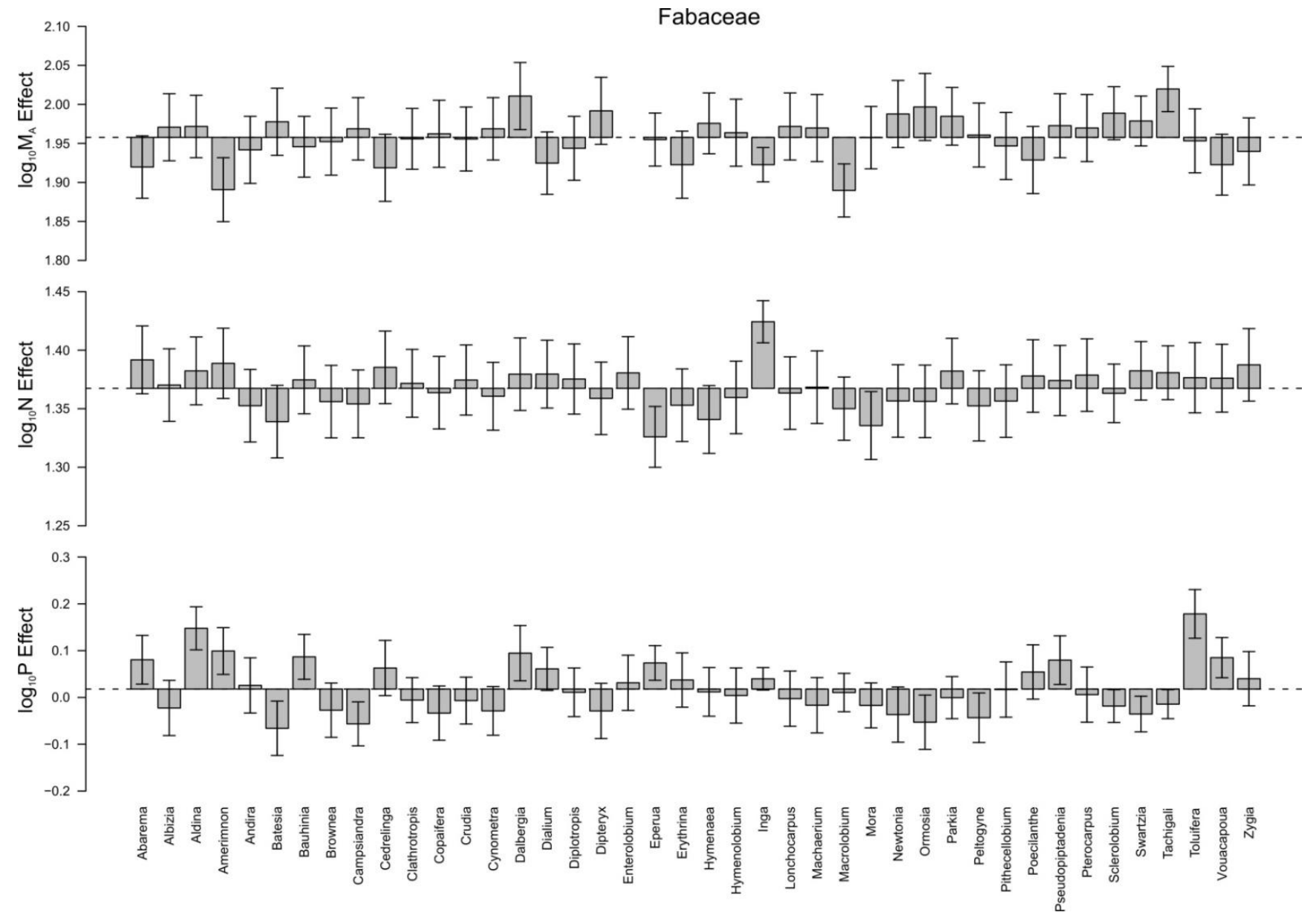

Fig. B2. Genus effect \pm standard error estimates from the multilevel model for sampled genera within Fabaceae. The dotted line illustrates the (mean) family effect for leaf mass per area $\left(M_{A}\right)$ in $\mathrm{g} \mathrm{m}^{-2}$ and leaf $\mathrm{N}$ and leaf $\mathrm{P}$ concentrations $\left(\mathrm{mg} \mathrm{g}^{-1}\right)$. Note the $\log _{10}$ used scale in all cases.

above variables. On the other hand, the residuals of the nonspatial regressions of $[\mathrm{P}],[\mathrm{Ca}]$ and $[\mathrm{K}]$ plot effects on environmental predictors illustrated a significant spatial signal, which was effectively removed by the fine scale $(50 \mathrm{~km})$ SAR models. For these three nutrients, the spatial component was important $(\lambda \neq 0$, Table A1) highlighting once more the substantial influence of environmental conditions on trait variation. We note, however, that for the plot level [P] contribution, the medium scale $(1000 \mathrm{~km})$ SAR model was equally capable of removing the spatial signal with the spatial component being similarly important. Thus the spatial patterning of environmental contribution to leaf $[\mathrm{P}]$ variation may be realized at broader scales. The results of the spatial analysis for $[\mathrm{C}], \delta^{13} \mathrm{C}$ and [Al], presented a similar behaviour, with fine scale SAR models removing most of the autocorrelation in the residuals. Although correlograms showed a significant Moran's $I$ for both plot $[\mathrm{C}]$ and $\delta^{13} \mathrm{C}$ effects at the second distance class (Fig. SIII 2), the Monte Carlo permutation did not identify a globally significant spatial signal (Table A1).
Thus the comparative consideration of both the spatial and non-spatial regressions identified the most significant environmental factors contributing to trait variation.

\section{Appendix B}

\section{Family, genera and species effects}

In our dataset there were significant differences between families for all sampled traits (ANOVA results not shown) with Fig. B1 illustrating mean family effects and their standard error estimates from the multilevel model. This shows that some families like Vochysiaceae, Urticaceae, Sapotaceae, Myristicaceae, Lecythidaceae, Humiriaceae and Clusiaceae are characterised by higher than average $M_{A}$, while others like Salicaceae and Annonaceae have unusually low $M_{A}$. Although $[\mathrm{N}]$ and $[\mathrm{P}]$ also tend to be lower in families with high $M_{A}$ such as Vochysiaceae, Sapotaceae, Humiriaceae and Clusiaceae, these concentrations were also 

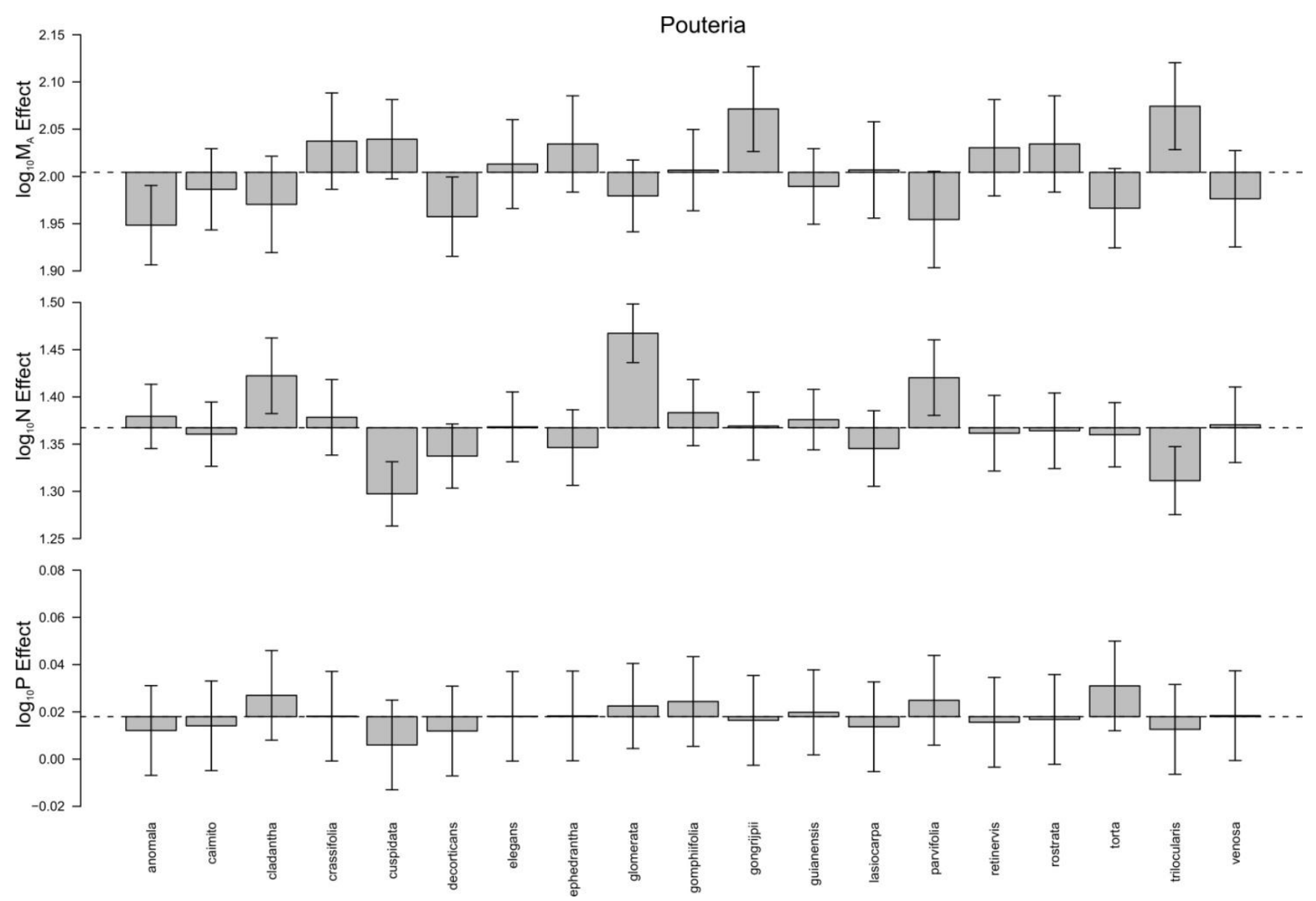

Fig. B3. Species effect \pm standard error estimates from the multilevel model for species within Pouteria. The dotted line illustrates the mean (family + genus) effect for leaf mass per area $\left(M_{A}\right)$ in $\mathrm{g} \mathrm{m}^{-2}$ and leaf $\mathrm{P}$ and leaf $\mathrm{N}$ concentrations $\left(\mathrm{mg} \mathrm{g}^{-1}\right)$. Note the $\log _{10}$ used scale in all cases.

Table B1. Mean genetic values (intercept + genetic effect) \pm standard deviation for taxa not belonging to Fabaceae, non-N-fixing Fabaceae and N-fixing Fabaceae. Values followed by different letters within a trait-column indicate significant differences at $p<0.001$ for the three groups.

\begin{tabular}{|c|c|c|c|c|c|c|c|c|c|}
\hline & $M_{A}\left(\mathrm{~g} \mathrm{~m}^{-2}\right)$ & {$[\mathrm{C}]\left(\mathrm{mg} \mathrm{g}^{-1}\right)$} & {$[\mathrm{N}]\left(\mathrm{mg} \mathrm{g}^{-1}\right)$} & {$[\mathrm{P}]\left(\mathrm{mg} \mathrm{g}^{-1}\right)$} & [Ca] $\left(\mathrm{mg} \mathrm{g}^{-1}\right)$ & {$[\mathrm{K}]\left(\mathrm{mg} \mathrm{g}^{-1}\right)$} & {$[\mathrm{Mg}]\left(\mathrm{mg} \mathrm{g}^{-1}\right)$} & {$[\mathrm{Al}]\left(\mathrm{mg} \mathrm{g}^{-1}\right)$} & $\delta^{13} \mathrm{C}(\% / 00)$ \\
\hline non-Fabaceae & $99.3 \pm 14.2^{\mathrm{a}}$ & $516.7 \pm 9.6^{\mathrm{a}}$ & $21.07 \pm 1.43^{\mathrm{c}}$ & $0.91 \pm 0.12^{\mathrm{c}}$ & $4.59 \pm 0.88^{\mathrm{a}, \mathrm{b}}$ & $5.78 \pm 1.16^{\mathrm{a}}$ & $1.95 \pm 0.35^{\mathrm{a}}$ & $0.042 \pm 0.012^{\mathrm{a}}$ & $-31.21 \pm 0.33$ \\
\hline $\begin{array}{l}\text { Fabaceae } \\
\text { non- } \mathrm{N}_{2} \text {-Fixers }\end{array}$ & $87.9 \pm 11.4^{\mathrm{b}}$ & $506.7 \pm 8.5^{\mathrm{b}}$ & $22.53 \pm 2.17^{\mathrm{b}}$ & $1.01 \pm 0.09^{\mathrm{b}}$ & $5.40 \pm 2.01^{\mathrm{a}}$ & $4.95 \pm 0.75^{\mathrm{b}}$ & $1.89 \pm 0.46^{\mathrm{a}, \mathrm{b}}$ & $0.033 \pm 0.006^{\mathrm{b}}$ & $-31.16 \pm 0.46$ \\
\hline $\mathrm{N}_{2}$-Fixers & $84.9 \pm 11.0^{\mathrm{b}}$ & $508.4 \pm 9.1^{\mathrm{b}}$ & $25.42 \pm 1.81^{\mathrm{a}}$ & $1.11 \pm 0.09^{\mathrm{a}}$ & $4.24 \pm 1.01^{b}$ & $5.17 \pm 0.63^{\mathrm{b}}$ & $1.69 \pm 0.26^{\mathrm{b}}$ & $0.033 \pm 0.008^{\mathrm{b}}$ & $-31.2 \pm 0.32$ \\
\hline
\end{tabular}

lower for families like Proteaceae, Ochnaceae, Myrtaceae and Chrysobalanaceae which were not distinctive in terms of $M_{A}$. Likewise, some families that do not display a markedly lower genetic $M_{A}$ component (Rutaceae, Meliaceae, Fabaceae and Euphorbiaceae) do have relatively high $[\mathrm{N}]$ and $[\mathrm{P}]$.

Looking at within family variation and using the Fabaceae as an example, genus level effects are shown for $M_{A},[\mathrm{P}]$ and
$[\mathrm{N}]$ in Fig. B2. For this family, the most abundant within the dataset (160 observations), there were significant genus effects for $M_{A}\left(F_{40,111}=3.832, p<0.001\right), \mathrm{N}\left(F_{41,109}=4.788\right.$, $p<0.001)$ and $\mathrm{P}\left(F_{41,108}=4.095, p<0.001\right)$ but with $M_{A}$ and $[\mathrm{N}]$ showing relatively less variability. Nevertheless, genera like Amerimnon, Dalbergia, Inga and Tachigalia all tended to differentiate in both $M_{A}$ and [P] with Inga also being notable for unusually high $[\mathrm{N}]$. 
For the other widely distributed families, genera within the Malvaceae differed in $M_{A}$, [N] and [P], with the Euphorbiaceae and Urticaceae showing differences in $M_{A}$ and [N] only; Moraceae and Myristicaceae in $[\mathrm{N}]$ and $[\mathrm{P}]$ only; and the Burseraceae and Lecythidaceae giving between-genera variability only for $[\mathrm{P}]$. Moreover, there were no differences in these foliar traits across genera in some families; for example the Chrysobalanaceae and Sapotaceae (results not shown). Generally speaking the highest within family variation was also observed for the more widespread families with the genus level analysis pointing to $M_{A},[\mathrm{P}]$ and $[\mathrm{N}]$ not necessarily always varying in concert with genotype as the sole course of variation. For example, genera within the Moraceae were statistically indistinguishable in terms of $M_{A}$, but showed large variations for [P] with Olmedia species tending to have significantly higher $[\mathrm{P}]$ and Pseudolmedia and Sahaqunia significantly lower [P] than the family mean estimate.

Within Eschweilera, the most extensively sampled genus in our dataset $(\mathrm{n}=60)$, significant species-to-species variation were identified in $M_{A}\left(F_{14,44}=2.009, p=0.040\right)$, and [P] $\left(F_{14,43}=2.591, p=0.008\right)$. Species within Pouteria $(n=44)$ showed differences in $M_{A}\left(F_{18,23}=2.728, p=0.012\right)$, $[\mathrm{N}]\left(F_{18,23}=4.157, p<0.001\right)$ and $[\mathrm{P}]\left(F_{18,23}=4.217, p<\right.$ $0.001)$, but within Inga $(n=38)$ no species specific differences were identified for either $M_{A}\left(F_{21,15}=1.051, p=0.470\right)$, $[\mathrm{N}]\left(F_{19,15}=1.876, p=0.110\right)$ or $[\mathrm{P}]\left(F_{19,15}=0.796, p=0.685\right)$. Other well represented genera such as Licania showed significant variation in $M_{A}$ and [P] only, but other genera for [N] only (Pourouma, Protium), or in many cases, with no difference at all (e.g. Pseudolmedia, Virola).

To illustrate such species effects, we summarize the $M_{A}$ and $[\mathrm{P}]$ estimates from the multilevel model for all Pouteria species sampled in Fig. B3. It should be noted that in our analysis all random effect estimates are shrunk towards the overall mean with this shrinkage increasing with decreasing genetic variance and increasing environmental variance (Galwey, 2006). Thus random effect estimates show a greater variability for $M_{A}$ and [N] compared with [P], which is realistic considering that only 0.01 of the total variance can be attributed to the species affiliation for [P], compared with the 0.19 for $M_{A}$ and 0.14 for [N]. Most obvious here is the exceptionally high $M_{A}$ for $P$. gongripii and $P$. tricularis, the latter also being accompanied by an unusually low [N], as well as very high $[\mathrm{N}]$ for $P$. glomerata. Thus within-genera variability is not restricted to specific foliar properties or even to combinations of them.

We were also interested to see if there was a difference in the physiological traits examined between the nitrogen fixing and non-nitrogen fixing members of the Fabaceae. We therefore utilised a database summarising published records of the presence or absence of $\mathrm{N}_{2}$ fixation in the Fabaceae (Patiño et al., 2008) taking a species as a $\mathrm{N}_{2}$ fixer if the proportion of positive records was greater than 0.9 and as a non-fixer if the proportion of negative records was greater than 0.9. Species with intermediate (conflicting) records of their $\mathrm{N}_{2}$-fixing status were not included in this analysis (Table $\mathrm{B} 1$ ). This showed that $\mathrm{N}_{2}$-fixing Fabaceae have significantly higher $[\mathrm{N}]$ and $[\mathrm{P}]$ than their non- $\mathrm{N}_{2}$-fixing relatives but with significantly lower [Ca] and no significant differences in $M_{A}$. In turn, the non- $\mathrm{N}_{2}$ fixing Fabaceae have significantly higher $[\mathrm{N}]$ and $[\mathrm{P}]$ but lower $[\mathrm{K}]$ than is the average for the other non- $\mathrm{N}_{2}$ fixing trees sampled across the Amazon Basin.

This result suggests that although $[\mathrm{P}]$ and $[\mathrm{N}]$ are indeed higher for the $\mathrm{N}_{2}$-fixing capable members of the Fabaceae, in accordance with the notion that $\mathrm{N}_{2}$ fixers have a high $[\mathrm{P}]$ and a high [N] requiring "lifestyle" (Vitousek et al., 2002), members of the Fabaceae who cannot fix nitrogen also have elevated $[\mathrm{N}]$ and $[\mathrm{P}]$ compared to the Amazon tree population as a whole. But with $[\mathrm{N}]$ and $[\mathrm{P}\}$ concentrations elevated to a lesser extent than for Fabaceae capable of $\mathrm{N}_{2}$ fixation. It has recently been suggested that $\mathrm{N}_{2}$-fixing Fabaceae are abundant in tropical ecosystems through their high [N] status, giving them an ability to exude high level of phosphatase enzymes and hence acquire extra phosphorus (Houlton et al., 2008), But it also seems to be the case that most Fabaceae within Amazonia do not fix nitrogen, even when physiologically capable of doing so (Nardoto et al., 2008). The lower foliar [Ca] for the $\mathrm{N}_{2}$-fixing Fabaceae may be attributable to the high calcium requirement for Rhizobia growth in the nodulating rhizosphere (O’Hara, 2001).

Acknowledgements. Nikos Fyllas and much of the data analysis and production phase of this work were funded through the UK National Research Council QUEST (Querying the Earth System) initiative, subprogram QUERCC (Quantifying and Understanding Ecosystems Role in the Carbon Cycle). Shiela Wilson helped with the final manuscript presentation. Comments from J. Grace and an anonymous referee improved this paper.

Edited by: J. Grace

\section{References}

Ackerly, D. D.: Community assembly, niche conservatism and adaptive evolution in changing environments, Int. J. Plant Sci., 164, S165-S184, 2003.

Aerts, R. and Chapin, F. S.: The mineral nutrition of wild plants revisited: a re-evaluation of processes and patterns. Adv. Ecol. Res., 30, 1-67, 2000.

Amtmann, A., Hammond, J. P., Armengaud, P., and White, P. J.: Nutrient sensing and signalling in plants: Potassium and phosphorus, Adv. Bot. Res., 43, 210-257, 2006.

APG II: An update of the Angiosperm Phylogeny Group classification of the orders and families of flowering plants. APG II. Bot J. Linn. Soc., 141, 399-436, 2003.

Baker, T. R., Phillips, O. L., Malhi, Y., Almeida, S., Arroyo, L., Di Fiore, A., Erwin, T., Killeen, T. J., Laurance, S. G., Laurance, W. F., Lewis, S. L., Lloyd, J., Monteagudo, A., Neill, D. A., Patiño, S., Pitman, N. C. A., Silva, N. J. M., and Vásquez Martínez, R.: 
Variation in wood density determines spatial patterns in Amazonian forest biomass, Global Change Biol., 10, 545-562, 2004.

Baker, T. R., Phillips, O. L., Laurance, W. F., Pitman, N. C. A., Almeida, S., Arroyo, L., DiFiore, A., Erwin, T., Higuchi, N., Killeen, T. J., Laurance, S. G., Nascimento, H., Monteagudo, A., Neill, D. A., Silva, J. N. M., Malhi, Y., López Gonzalez, G., Peacock, J., Quesada, C. A., Lewis, S. L., and Lloyd, J.: Do species traits determine patterns of wood production in Amazonian forests?, Biogeosciences, 6, 297-307, 2009,

http://www.biogeosciences.net/6/297/2009/.

Barthold, F., Stallard, R. F., and Elsenbeer, H.: Soil nutrientlandscape relationships in a lowland tropical forest in Panama, For. Ecol. Manag., 255, 1135-1148, 2008.

Bates, D. and Sarkar, D.: lme4: Linear Mixed-Effects Models Using S4 Classes, R package version 0.999375-27, 2007.

Bertiller, M. B., Mazzarino, M. J., Carrera, A. L., Diehl, P., Satti, P., Gobbi, M., and Sain, C. L.: Leaf strategies and soil N across a regional humidity gradient in Patagonia, Oecologia, 148, 612624, 2006.

Bivand, R.: Implementing Spatial Data Analysis Software Tools in R, Geogr. Anal., 38, 23-40, 2006.

Bjornstad, O. N. and Falck, W.: Nonparametric spatial covariance functions: estimation and testing, Environ. Ecol. Stat., 8, 53-70, 2001.

Broadley, M. R., Bowen, H. C., Cotterill, H. L., Hammond, J. P., Meacham, M. C., Mead, A., and White, P. J.: Phylogenetic variation in the shoot mineral concentration of angiosperms, J. Exp. Bot., 55, 321-336, 2004.

Broadley, M. R., Hammond, J. P., King, G. J., Astley, D., Bowen, H. C., Meacham, M. C., Mead, A., Pink, D. A. C., Teakle, G. R., Hayden, R. M., Spracklen, W. P., and White, P. J.: Shoot calcium and magnesium concentrations differ between subtaxa, are highly heritable, and associate with potentially pleiotropic loci in Brassica oleracea, Plant Physiol., 146, 1707-1720, 2008.

Bryant, J. P., Chapin, F. S., and Klein, D. R.: Carbon/nutrient balance of boreal plants in relation to vertebrate herbivory, Oikos, 40, 357-368, 1983.

Cavendar-Bares, J., Keen, A., and Miles, B.: Phylogenetic structure of Floridian plant communities depends on taxonomic and spatial scale, Ecology, 87, 107-122, 2006.

Chessel, D., Dufour, A. B., and Thioulouse, J.: The Ade4 package - I: One-table methods, R News, 4, 5-10, 2004.

Conover, W. J.: Practical Non-Parametric Statistics, 2nd edn, John Wiley and Sons, New York, 492 pp, 1980.

Cox, P. M., Betts, R. A., Jones, C. D., Spall, S. A., and Totterdell, I. J.: Acceleration of global warming due to carbon-cycle feedbacks in a coupled climate model, Nature, 408, 184-187, 2000.

Crawley, M. J.: The R Book, Jon Wiley and Sons, 942 pp, 2007.

Dauer, J. M., Chorover, J., Chadwick, O. A., Oleksyn, J., Tjoelker, M. G., Hobbie, S. E., Reich, P. B., and Eissenstat, D. M.: Controls over leaf and litter calcium concentrations among temperate trees, Biogeochemistry, 86, 175-187, 2007.

de Bruxelles, G. L. and Roberts, M. R.: Signals regulating multiple responses to wounding and herbivores, Crit. Rev. Plant Sci., 20, 487-521, 2001.

Demarty, M., Morvan, C., and Thellier, M.: Calcium and the cell wall. Plant, Cell Environ., 7, 441-448, 1984.

Diniz-Filho, J. A. F., Bini, L. M., and Hawkins, B. A.: Spatial autocorrelation and red herrings in geographical ecology, Global
Ecol. Biogeogr., 12, 53-64, 2003.

Domingues, T. F., Meir, P., Saiz, G., Feldpausch, T. R., Veenendaal, E. M., Schrodt, F., Bird, M., Djagbletey, G., Hien, F., Compaore, H., Diallo, A., Grace, J., and Lloyd, J.: Co-limitation of photosynthetic capacity by nitrogen and phosphorus along a precipitation gradient in West Africa, Plant Cell. Environ., submitted, 2009.

Drechsel, P. and Zech, W.: Foliar nutrient levels of broad leaved tropical trees. A tabular review, Plant Soil, 131, 29-46, 1991.

Elser, J. J., Sterner, R. W., Gorokhova, E., Fagan, W. F., Markow, T. A., Cotner, J. B., Harrison, J. F., Hobbie, S. E., Odell, G. M., and Weider, L. J.: Biological stoichiometry from genes to ecosystems, Ecol. Lett., 3, 540-550, 2000.

Farquhar, G. D. and Sharkey, T. D.: Stomatal conductance and photosynthesis, Ann. Rev. Plant Physiol., 33, 317-345, 1982.

Farquhar, G. D., Ehleringer, J. R., and Hubick, A. T.: Carbon isotope discrimination and photosynthesis, Ann. Rev. Plant Physiol. Plant Mol. Biol., 40, 503-537, 1989.

Federer, C. A., Hornbeck, J. W., Tritton, L. M., Martin, C. W., and Pierce, R. S.: Long-term depletion of calcium and other nutrients in eastern U.S. forests, Environ. Manag., 13, 593-601, 1998.

Fine, P. V. A., Daly, D. C., Munoz, G. V., Mesones, I., and Cameron, K. M.: The contribution of edaphic heterogeneity to the evolution and diversity of Burseraceae trees in the western Amazon, Evolution, 59, 1464-1478, 2005.

Fine, P. V. A., Miller, Z. J., Mesones, I., Irazuzta, S., Appel, H. M., Stgevens, M. H. H., Sääksjärvi, I., Schultz, J. C., and Coley, P. D.: The growth-defence trade-off and habitat specialization by plants in Amazonian forests, Ecology, 87, S150-S162, 2006.

Fonseca, C. R., Overton, J. M. C., Collins B., and Westoby, M.: Shifts in trait-combinations along rainfall and phosphorus gradients, J. Ecol., 88, 964-977, 2000.

Fyllas, N. M. and Lloyd, J.: Deriving Plant Functional Types for Amazonian trees using numerical techniques, in preparation, 2009.

Gabriel, R. and Kesselmeier, J.: Apoplastic solute concentrations of organic acids and mineral nutrients in the leaves of several Fagaceae, Plant Cell Physiol., 40, 604-612, 1999.

Galwey, N. W.: Introduction to Mixed Modelling: Beyond Regression and Analysis of Variance. Wiley, Chichester, England, Hoboken, NJ, 376 pp, 2006.

Gardner, R. C.: Genes for magnesium transport, Curr. Opinion Plant Biol., 6, 263-267, 2003.

Garnier, E., Cortez, J., Billes, G., Navas, M.-L., Roumet, C., Debussche, M., Laurent, G., Blanchard, A., Aubry, D., Bellmann, A., Neill, C., and Toussaint, J.-P.: Plant functional markers capture ecosystem properties during secondary succession, Ecology, 85, 2630-2637, 2004.

Gelman, A. and Hill, J.: Data Analysis Using Regression and Multilevel/Hierarchical Models, Cambridge University Press, 648 pp, 2006.

Gillies, A. C. M,, Cornelius, J. P., Newton, A. C., Navarro, C., Hernández, M., and Wilson, J.: Genetic variation in Costa Rican populations of the tropical timber species Cedrela odorata L., assessed using RAPDs, Mol. Ecol., 6, 11333-1146, 1997.

Hättenschwiler, S., Aeschlimann, B., Coûteaux, M.-M., Roy, J., and Bonal, D.: High variation in foliage and leaf litter chemistry among 45 tree species of a neotropical rainforest community, New Phytol., 179(1), 165-175, doi:10.1111/j.1469- 
8137.2008.02438.x, 2008.

Hawkins, B. A., Diniz-Filho, J. A. F., Mauricio Bini, L., De Marco, P., and Blackburn, T. M.: Red herrings revisited: spatial autocorrelation and parameter estimation in geographical ecology, Ecography, 30, 375-384, 2007.

Hijmans, R. J., Cameron, S. E., Parra, J. L., Jones, P. G., and Jarvis, A.: Very high resolution interpolated climate surfaces for global land areas, Int. J. Climatol., 25, 1965-1978, 2005.

Hobbie, E. A. and Werner, R. A.: Intramolecular, compoundspecific, and bulk carbon isotope patterns in $\mathrm{C}_{3}$ and $\mathrm{C}_{4}$ plants: a review and synthesis, New Phytol., 161, 371-385, 2004.

Houlton, B. Z., Wang, Y-P., Vitousek, P. M., and Field, C. B.: A unifying framework for dinitrogen fixation in the terrestrial biosphere, Nature, 454, 327-330, 2008.

Hubbell, S. P., He, F., Condit, R., Borda-de-Água, L., Kellner, J., and ter Steege, H.: How many tree species are there in the Amazon and how many of them will go extinct?, P. Natl. Acad. Sci. USA, 105, 11498-11504, 2008.

Hungate, B. A., Stiling, P. D., Dijkstra, P., Johnson, D. W., Ketterer, M. E., Hymus, G. J., Hinkle, C. R., and Drake, B. G.: $\mathrm{CO}_{2}$ Elicits Long-Term Decline in Nitrogen Fixation, Science, 304, 1291, 2004.

IUSS (International Union of Soil Science) Working Group WRB: World Reference Base for Soil Resources 2006. World Soil Resources Report No. 103., FAO, Rome, 132 pp, 2006.

Jansens, S., Broadley, M. R., Robbrecht, E., and Smets, E.: Aluminum Hyperaccumulation in Angiosperms: A Review of Its Phylogenetic Significance, The Botanical Review, 68, 235-269, 2002

Jetz, W. and Rahbek, C.: Geographic Range Size and Determinants of Avian Species Richness, Science, 297, 1548-1551, 2002.

Jobbagy, E. G. and Jackson, R. B.: The Uplift of Soil Nutrients by Plants: Biogeochemical Consequences Across Scales, Ecology, 85, 2380-2389, 2004.

John, R., Dalling, J. W., Harms, K., Yavitt, J. B., Stallard, R. F., Mirabello, M., Hubbell, S. P., Valencia, R., Navarette, H., Vallejo, M., and Foster, R.: Soil nutrients influence spatial distributions of tropical tree species, P. Natl. Acad. Sci. USA, 104, 864-869, 2007.

Kanowski, J.: Effect of elevated $\mathrm{CO}_{2}$ on the foliar chemistry of seedlings of two rainforest trees from north-east Australia: Implications for foliar marsupials, Aust. Ecol., 26, 165-172, 2001.

Kaspari, M., Garcia, M. N., Harms, K. E., Santana, M., Wright, S. J., and Yavitt, J. B.: Multiple nutrients limit litterfall and decomposition in a tropical forest, Ecol. Lett., 11, 35-43, 2008.

Kattge, J., Knorr, W., Raddatz, T., and Wirth, C.: Quantifying photosynthetic capacity and its relationship to leaf nitrogen content for global-scale terrestrial biosphere models, Global Change Biol., 15, 976-991, 2009.

Kerkhoff, A. J. and Enquist, B. J.: Ecosystem allometry: the scaling of nutrient stocks and primary productivity across plant communities, Ecol. Lett., 9, 419-427, 2006.

Kerkhoff, A. J., Enquist, B. J., Elser, J. J., and Fagan, W. F.: Plant allometry, stoichiometry and the temperature-dependence of primary productivity, Global Ecol. Biogeogr., 14, 585-598, 2005.

Kerkhoff, A. J., Fagan, W. F., Elser, J. J., and Enquist, B. J.: Phylogenetic and Growth Form Variation in the Scaling of Nitrogen and Phosphorus in the Seed Plants, Am. Nat., 168, 103-122, 2006.
Kirkby, E. A. and Pilbeam, D. J.: Calcium as a plant nutrient. Plant, Cell Environ., 7, 397-405, 1984.

Kissling, W. D. and Carl, G.: Spatial autocorrelation and the selection of simultaneous autoregressive models, Global Ecol. Biogeogr., 17, 59-71, 2008.

Koerselman, W. and Meuleman, A. F. M.: The vegetation N:P ratio: A new tool to detect the nature of nutrient limitation, J. Appl. Ecol., 33, 1441-1450, 1996.

Kraft, N. J. B., Valencia, R., and Ackerly, D. A.: Tree community assembly in an Amazonian forest, Science, 322, 580-582, 2008.

Lambers, H. and Poorter, H.: Inherent variation in growth rate between higher plants: A search for physiological causes and ecological consequences, Adv. Ecol. Res., 23, 187-261, 1992.

Lamont, B. B., Groom, P. K., and Cowling, R. M.: High leaf mass per area of related species assemblages may reflect low rainfall and carbon isotope discrimination rather than low phosphorus and nitrogen concentrations, Funct. Ecol., 16, 403-412, 2002.

Lamport, D. T. A.: The protein component of primary cell walls, Adv. Bot. Res., 2, 151-218, 1965.

Legendre, P. and Legendre, L.: Numerical Ecology, 2nd English edn, Elsevier, Amsterdam, 853 pp, 1998.

Lennon, J. J.: Red-shifts and red herrings in geographical ecology, Ecography, 23, 101-113, 2000.

Lichstein, J. W., Simons, T. R., Shriner, S. A., and Franzreb, K. E.: Spatial autocorrelation and autoregressive models in ecology, Ecol. Monogr., 72, 445-463, 2002.

Lloyd, J., Kruijt, B., Hollinger, D. Y., Grace, J., Francey, R. J., Wong, S.-C., Kelliher, F. M., Miranda, A. C., Farquhar, G. D., Gash, J. H. C., Vygodskaya, N. N., Wright, I. R., Miranda, H. S., and Schulze, E.-D.: Vegetation effects on the isotopic composition of atmospheric $\mathrm{CO}_{2}$ as local and regional scales: Theoretical aspects and a comparison between rainforest in Amazonia and a boreal forest in Siberia, Australian J. Plant Physiol., 23, 371-399, 1996.

Lloyd, J., Patiño, S., Paiva, R. Q., Nardoto, G. B., Quesada, C. A., Santos, A. J. B., Baker, T. R., Brand, W. A., Hilke, I., Gielmann, H., Raessler, M., Luizão, F. J., Martinelli, L. A., and Mercado, L. M.: Variations in leaf physiological properties within Amazon forest canopies, Biogeosciences Discuss., 6, 4639-4692, 2009, http://www.biogeosciences-discuss.net/6/4639/2009/.

Maghsoodloo, S. and Laszlo Pallos, L.: Asymtotic behaviour of Kendall's partial rank correlation coefficient and additional quantile estimates, J. Stat. Comput. Simul., 13, 41-48, 1981.

Malhi, Y. and Wright, J.: Spatial patterns and recent trends in the climate of tropical rainforest regions, Philos. T. Roy. Soc B., 359, 311-329, 2004.

Malhi, Y., Baker, T. R., Phillips, O. L., Almeida, S., Alvares, E., Arroyo, L., Chave, J., Czimczik, C., Di Fiore, A., Higuchi, N., Killeen, T., Laurance, S. G., Laurance, W. F., Lewis, S., Montoya, L. M. M., Monteagudo, A., Neill, D., Nunes Vargas, P., Panfil, S. N., Patino, S., Pitman, N., Quesada, C. A., Salomao, R., Silva, N., Lezama, A. T., Vasquez Martinez, R., Terborgh, J., Vinceti, B., and Lloyd, J. The above-ground coarse wood productivity of 104 Neotropical forest plots, Global Change Biol., 10, 563-591, 2004.

McCulloch, C. E. and Searle, S. R.: Generalized, Linear and Mixed Models, J. Wiley, New York, 2001.

McMahon, S. M. and Diez, J. M.: Scales of Association: Hierarchical Linear Models and the Measurement of Ecological Systems, 
Ecol. Lett., 10, 437-452, 2007.

Montagnini, F.: Accumulation in above-ground biomass and soil storage of mineral nutrients in pure and mixed plantations in a humid tropical lowland, For. Ecol. Man., 134, 257-270, 2000.

Muggeo, V.: Segmented: an R package to fit regression models with broken-line relationships, Rnews, 8(1), 20-25, 2008.

Nardoto, G. B., Ometto, J. P. H. B., Ehleringer, J. R., Higuchi, N., Bustamante, M. M., Da, C., and Martinelli, L. A.: Understanding the influences of spatial patterns on $\mathrm{N}$ availability within the Brazilian Amazon forest, Ecosystems, 11(8), 1234-1246, doi:10.1007/s10021-008-9189-1, 2008.

Navarro, C., Ward, S., and Hernández, M.: The tree Cedrela odorata (Meliaceae): A morphologically subdivided species in Costa Rica, Rev. Biol. Trop., 50, 21-29, 2002.

New, M., Lister, D., Hulme, M., and Makin, I.: A high-resolution data set of surface climate over global land areas, Climate Res., $21,1-25,2002$.

Niinemets, U. and Kull, K.: Leaf structure vs. nutrient relationships vary with soil conditions in temperate shrubs and trees, Acta Oecol., 24, 209-219, 2003.

Niinemets, U.: Distribution patterns of foliar carbon and nitrogen as affected by tree dimensions and relative light conditions in the canopy of Picea abies, Trees, 11, 144-154, 1997.

Niklas, K. J., Owens, T., Reich, P. B., and Cobb, E. D.: Nitrogen/phosphorus leaf stoichiometry and the scaling of plant growth, Ecol. Lett., 8, 636-642, 2005.

Niklas, K. J.: Carbon/nitrogen/phosphorus allometric relations across species, in: The Ecophysiology of Plant-Phosphorus Interactions, edited by: White, P. J. and Hammond, J. P., Springer Science, p. 9-30, 2008.

Niklas, K. J.: Plant Allometry, Leaf Nitrogen and Phosphorus Stoichiometry, and Interspecific Trends in Annual Growth Rates, Ann. Bot, 97, 155-163, 2006.

O'Hara, G. W.: Nutritional constraints on root nodule bacteria affecting symbiotic nitrogen fixation: a review, Aust. J. Exp. Agr., 41, 417-433, 2001.

Paoli, G. D.: Divergent leaf traits among congeneric tropical trees with contrasting habitat associations on Borneo, J. Trop. Ecol., 22, 397-408, 2006.

Patiño, S., Lloyd, J., Paiva, R., Baker, T. R., Quesada, C. A., Mercado, L. M., Schmerler, J., Schwarz, M., Santos, A. J. B., Aguilar, A., Czimczik, C. I., Gallo, J., Horna, V., Hoyos, E. J., Jimenez, E. M., Palomino, W., Peacock, J., Peña-Cruz, A., Sarmiento, C., Sota, A., Turriago, J. D., Villanueva, B., Vitzthum, P., Alvarez, E., Arroyo, L., Baraloto, C., Bonal, D., Chave, J., Costa, A. C. L., Herrera, R., Higuchi, N., Killeen, T., Leal, E., Luizão, F., Meir, P., Monteagudo, A., Neil, D., NñezVargas, P., Peñuela, M. C., Pitman, N., Priante Filho, N., Prieto, A., Panfil, S. N., Rudas, A., Salomo, R., Silva, N., Silveira, M., Soares deAlmeida, S., Torres-Lezama, A., Vásquez-Martnez, R., Vieira, I., Malhi, Y., and Phillips, O. L.: Branch xylem density variations across the Amazon Basin, Biogeosciences, 6, 545568, 2009,

http://www.biogeosciences.net/6/545/2009/.

Patiño, S., Fyllas, N. M., Baker, T. R., Paiva, R., Quesada, C. A., Santos, A. J. B., Mercado, L. M. M., Schwarz, M., ter Steege, H., and Lloyd, J.: Relationships among ecologically important dimensions of trait variation in Amazon forest trees as affected by species, Soils and Climate, in preparation, 2009.
Patiño, S., Lloyd, J., and Lopez-Gonzalez, G.: Nodulation, in: Functional Traits Database, edited by: Lopez-Gonzalez, G., Baker, T. R., Lewis, S. L., Phillips, O. L., et al., Functional Traits Database, RAINFOR project, University of Leeds 2008, date of extraction: 1 October 2008.

Pelloux, J., Rustérucci, C., and Mellerowicz, E. J.: New insights into pectin methylesterase structure and function, Trends Plant Sci., 12, 267-277, 2007.

Phillips, O. L., Vargas, P. N., Monteagudo, A. L., Cruz, A. P., Chuspe Zans, M.-E., Sanchez, A. P., Yli-Halla, M., and Rose, S.: Habital association among Amazonian tree species: a landscapescale approach, J. Ecol., 91, 757-775, 2003.

Phillips, O. L., Baker, T., Arroyo, L., Higuchi, N., Killeen, T., Laurance, W. F., Lewis, S. L., Lloyd, J., Malhi, Y., Monteagudo, A., Neill, D., Núñez Vargas, P., Silva, N., Terborgh, J., Vásquez Martínez, R., Alexiades, M., Almeida, S., Brown, S., Chave, J., Comiskey, J. A., Czimczik, C. I., Di Fiore, A., Erwin, T., Kuebler, C., Laurance, S. G., Nascimento, H. E. M., Olivier, J., Palacios, W., Patiño, S., Pitman, N., Quesada, C. A., Saldias, M., Torres Lezama, A., and Vinceti, B.: Patterns and process in Amazon tree turnover, 1976-2001, Phil. Trans. Roy. Soc. B, 359, 437462, 2004.

Pilling, J., Willmitzer, L., Bücking, H., and Fisahn, J.: Inhibition of a ubiquitously expressed pectin methyl esterase in Solanum tuberosum L. affects plant growth, leaf growth polarity, and ion partitioning, Planta, 219, 32-40, 2004.

Poorter, H., Niinemets, U., Poorter, L., Wright, I. J., and Villar, R.: Causes and consequences of variation in leaf mass per area (LMA): a meta-analysis, The New Phytologist, 182, 565-588, 2009.

Poorter, H. and Villar, R.: The fate of acquired carbon in plants: chemical composition and construction costs, in: Plant Resource Allocation, edited by: Bazzaz, F. A. and Grace, J., Academic Press, San Diego, CA, p. 39-72, 1997.

Poorter, L. and Bongers, F.: Leaf traits are good predictors of plant performance across 53 rain forest species, Ecology, 87, 17331743, 2006.

Poorter, L. and De Jong, R.: A comparison of specific leaf area, chemical composition and leaf construction costs of field plants from 15 habitats differing in productivity, New Phytol., 143, 163-176, 1999.

Quesada, C. A., Lloyd, J., Schwarz, M., Baker, T. R., Phillips, O. L., Patiño, S., Czimczik, C., Hodnett, M. G., Herrera, R., Arneth, A., Lloyd, G., Malhi, Y., Dezzeo, N., Luizão, F. J., Santos, A. J. B., Schmerler, J., Arroyo, L., Silveira, M., Priante Filho, N., Jimenez, E. M., Paiva, R., Vieira, I., Neill, D. A., Silva, N., Peñuela, M. C., Monteagudo, A., Vásquez, R., Prieto, A., Rudas, A., Almeida, S., Higuchi, N., Lezama, A. T., López-González, G., Peacock, J., Fyllas, N. M., Alvarez Dávila, E., Erwin, T., di Fiore, A., Chao, K. J., Honorio, E., Killeen, T., Peña Cruz, A., Pitman, N., Núñez Vargas, P., Salomo, R., Terborgh, J., and Ramrez, H.: Regional and large-scale patterns in Amazon forest structure and function are mediated by variations in soil physical and chemical properties, Biogeosciences Discuss., 6, 39934057, 2009a,

http://www.biogeosciences-discuss.net/6/3993/2009/.

Quesada, C. A., Lloyd, J., Anderson, L. O., Fyllas, N. M., Schwarz, M., and Czimczik, C. I.: Soils of amazonia with particular reference to the rainfor sites, Biogeosciences Discuss., 6, 3851-3921, 
$2009 b$,

http://www.biogeosciences-discuss.net/6/3851/2009/.

Quesada, C. A., Lloyd, J., Schwarz, M., Patiño, S., Baker, T. R., Czimczik, C., Fyllas, N. M., Martinelli, L., Nardoto, G. B., Schmerler, J., Santos, A. J. B., Hodnett, M. G., Herrera, R., Luizão, F. J., Arneth, A., Lloyd, G., Dezzeo, N., Hilke, I., Kuhlmann, I., Raessler, M., Brand, W. A., Geilmann, H., Moraes Filho, J. O., Carvalho, F. P., Araujo Filho, R. N., Chaves, J. E., Cruz Junior, O. F., Pimentel, T. P., and Paiva, R.: Chemical and physical properties of Amazon forest soils in relation to their genesis, Biogeosciences Discuss., 6, 3923-3992, 2009c,

http://www.biogeosciences-discuss.net/6/3923/2009/.

R Development Core Team: R: A language and environment for statistical computing. R Foundation for Statistical Computing, Vienna, Austria, ISBN 3-900051-07-0, http://www.R-project.org, 2008.

Reich, P. B.: Global biogeography of plant chemistry: filling in the blanks, New Phytologist, 168, 263-266, 2005.

Reich, P. B. and Oleksyn, J.: Global patterns of plant leaf N and P in relation to temperature and latitude, Pub. Nat. Acad. Sci. USA, 101, 11001-11006, 2004.

Reich, P. B., Ellsworth, D. S., Walters, M. B., Vose, J. M., Gresham, C., Volin, J. C., and Bowman, W. D.: Generality of leaf trait relationships: A test across six biomes, Ecol., 80, 1955-1969, 1999.

Reich, P. B., Uhl, C., Walters, M. B., and Ellsworth, D. S.: Leaf lifespan as a determinant of leaf structure and function among 23 Amazonian tree species, Oecologia, 86, 16-24, 1991.

Reich, P. B., Walters, M. B., and Ellsworth, D. S.: From tropics to tundra: Global convergence in plant functioning, P. Natl. Acad. Sci. USA, 94, 13730-13734, 1997.

Reich, P. B., Wright, I. J., Cavender-Bares, J., Craine, M., Oleksyn, J., Westoby, M., and Walters, M. B.: The Evolution of Plant Functional Variation: Traits, Spectra, and Strategies, Int. J. Plant Sci., 164(S3), 143-164, 2003.

Reich, P. B. and Walters, M. B.: Photosynthesis-nitrogen relations in Amazonian tree species. 2. Variation in nitrogen vis a vis specific leaf area influences mass- and area-based expressions, Oecologia, 97, 73-81, 1994.

Reich, P. B., Walters, M. B., Ellsworth, D., and Uhl, C.: Photosynthesis-nitrogen relations in Amazonian tree species. I: Patterns among species and communities, Oecologia, 97, 62-72, 1994.

Russo, S. E., Brown, P., Tan, S., and Davies, S. J.: Interspecific demographic trade-offs and soil-related habitat associations of tree species along resource gradients, J. Ecol., 96, 192-203, 2008.

Santiago, L. S., Kitajima, K., Wright, S. J., and Mulkey, S. S.: Coordinated changes in photosynthesis, water relations and leaf nutritional traits of canopy trees along a precipitation gradient in lowland tropical forest, Oecologia, 139, 495-502, 2004a.

Santiago, L. S., Goldstein, G., Meinzer, F. C., Fisher, J. B., Machado, K., Woodruff, D. R., and Jones, T.: Leaf photosynthetic traits scale with hydraulic conductivity and wood density in Panamanian forest canopy trees, Oecologia, 140, 543-550, 2004b.

Sattelmacher, B.: The apoplast and its significance for plant mineral nutrition, New Phytol., 149, 167-192, 2001.

Showalter, A. M.: Structure and function of plant cell wall proteins, The Plant Cell, 5, 9-23, 1993.
Snijders, T. A. B. and Bosker, R. J.: Multilevel Analysis: An Introduction to Basic and Advanced Multilevel Modeling, SAGE, 266 pp, 1999.

Sombroek, W. G.: Amazonian landforms and soils in relations to biological diversity, Acta Amazonica, 30, 81-100, 2000.

Sombroek, W. G.: Spatial and Temporal Patterns of Amazon Rainfall, Ambio, 30, 388-396, 2001.

Specht, A. and Turner, J.: Foliar nutrient concentrations in mixedspecies plantations of subtropical cabinet timber species and their potential as a management tool, For. Ecol. Man., 233, 324-337, 2006.

Stamp, N.: Out of the quagmire of plant defense hypotheses, Quart. Rev. Biol., 78, 23-55, 2003.

Sultan, S. E.: Phenotypic plasticity for plant development, function and life history, Trends Plant Sci., 5, 537-542, 2000.

Takashima, T., Hikosaka, K., and Hirose, T.: Photosynthesis or persistence: nitrogen allocation in leaves of evergreen and deciduous Quercus species, Plant, Cell \& Environ., 27, 1047-1054, 2004.

ter Steege, H., Pitman, N. C. A., Phillips, O. L., Chave, J., Sabatier, D., Duque, A., Molino, J.-F., Prévost, M. F., Spichiger, R., Castellanos, H., Hildebrand, P., and Vásquez, R.: Continentalscale patterns of canopy tree composition and function across Amazonia, Nature, 443, 444-447, 2006.

Tessier, J. T. and Raynal, D. J.: Use of nitrogen to phosphorus ratios in plant tissue as an indicator of nutrient limitation and nitrogen saturation, J. Appl. Ecol., 40(3), 523-534, 2003.

Thompson, K., Parkinson, J. A., Band, S. R., and Spencer, R. E.: A comparative study of leaf nutrient concentrations in a regional herbaceous flora, New Phytol., 136, 679-689, 1997.

Tognelli, M. F. and Kelt, D. A.: Analysis of determinants of mammalian species richness in South America using spatial autoregressive models, Ecography, 27, 427-436, 2004.

Townsend, A. R., Asner, G. P., and Cleveland, C. C.: The biogeochemical heterogeneity of tropical forests, Trends Ecol. Evol., 23, 424-431, 2008.

Townsend, A. R., Cleveland, C. C., Asner, G. P., and Bustamante, M. M. C.: Controls over foliar N:P ratios in tropical rain forests, Ecology, 88, 107-118, 2007.

Veenedaal, E. M., Swaine, M. D., Lecha, R. T., Walsh, M. F., Abrese, I. K., and Owusu-Afiyie, K.: Response of West African forest tree seedlings to irradiance and soil fertility, Funct. Ecol., 10, 501-511, 1996.

Vitousek, P. M.: Litterfall, nutrient cycling and nutrient limitation in tropical forest, Ecology, 65, 285-298, 1984.

Vitousek, P. M., Cassman, K., Cleveland, C., Crews, T., Field, C. B., Grimm, N. B., Robert, W. H., Marino, R., Martinelli, L., Rastetter, E. B., and Sprent, J. I.: Towards an ecological understanding of biological nitrogen fixation, Biogeochemistry, 57-58, 1-45, 2002.

Vorwerk, S., Somerville, S., and Somerville, C.: The role of plant cell well polysaccharide compstion in disease resistance, Trends in Plant Sci., 9, 203-209, 2004.

Warren, C. R., Tausz, M., and Adams, M.: Does rainfall explain variation in leaf morphology and physiology among populations of red ironbark (Eucalyptus sideroxylon subsp. tricarpa) grown in a common garden?, Tree Physiol., 25, 1369-1378, 2005.

Warton, D. I., Wright, I. J., Falster, D. S., and Westoby, M.: Bivariate line-fitting methods for allometry, Biol. Rev., 81, 259-291, 
2006.

Watanabe, T., Broadley, M. R., Jansen, S., White, P. J., Takada, J., Satake, K., Takamatsu, T., Tuah, S. J., and Osaki, M.: Evolutionary control of leaf element composition in plants, New Phytol., 174, 516-523, 2007.

Webb, M. J., Reddell, P., Hambleton, A., and Robson, K. E. N.: Growth response of four tropical plantation timber species to increasing phosphorus supply and assessment of phosphorus requirements using foliar analysis, New Forests, 20, 193-211, 2000.

Westoby, M., Falster, D. S., Moles, A. T., Vesk, P. A., and Wright, I. J.: Plant ecological strategies: Some leading dimensions of variation between species, Ann. Rev. Ecol. Syst., 33, 125-159, 2002.

White, P. J.: The pathways of calcium movement to the xylem, J. Exp. Bot., 52, 891-899, 2001.

White, P. J. and Hammond, J. P.: Phosphorus nutrition of terrestrial plants, in: The Ecophysiology of Plant-Phosphorus Interactions, edited by: White, P. J. and Hammond, J. P., Springer Science, p. 51-81, 2008.

White, P. J. and Broadley, M. R.: Calcium in plants, Ann.Bot., 92, 487-511, 2003.

Woods, H. A., Makino, W., Cotner, J. B., Hobbie, S. E., Harrison, J. F., Acharya, K., and Elser, J. J.: Temperature and chemical composition of poikothermic organisms, Funct. Ecol., 17, 237$245,2003$.
Wright, I. J., Reich, P. B., and Westoby, M.: Strategy shifts in leaf physiology, structure and nutrient content between species of high- and low-rainfall and high- and low-nutrient habitats, Funct. Ecol., 15, 423-434, 2001.

Wright, I. J., Reich, P. B., Westoby, M., Ackerly, D. D., Baruch, Z., Bongers, F., Cavender-Bares, J., Chapin, T., Cornelissen, J. H., Diemer, M., Flexas, J., Garnier, E., Groom, P. K., Gulias, J., Hikosaka, K., Lamont, B. B., Lee, T., Lee, W., Lusk, C., Midgley, J. J., Navas, M. L., Niinemets, U., Oleksyn, J., Osada, N., Poorter, H., Poot, P., Prior, L., Pyankov, V. I., Roumet, C., Thomas, S. C., Tjoelker, M. G., Veneklaas, E. J., and Villar, R.: The worldwide leaf economics spectrum, Nature, 428, 821-827, 2004.

Wright, I. J., Reich, P. B., Cornelissen, J. H. C., Falster, D. S., Garnier, E., Hikosaka, K., Lamont, B. B., Lee, W., Oleksyn, J., Osada, N., Poorter, H., Villar, R., Warton, D. I., and Westoby, M.: Assessing the generality of global leaf trait relationships, New Phytol., 166, 485-496, 2005a.

Wright, I. J., Reich, P. B., Cornelissen, J. H. C., Falster, D. S., Groom, P. K., Hikosaka, K., Lee, W., Lusk, C. H., Niinemets, U., Oleksyn, J., Osada, N., Poorter, H., Warton, D. I., and Westoby, M.: Modulation of leaf economic traits and trait relationships by climate, Global Ecol. Biogeogr., 14, 411-421, 2005 b. 